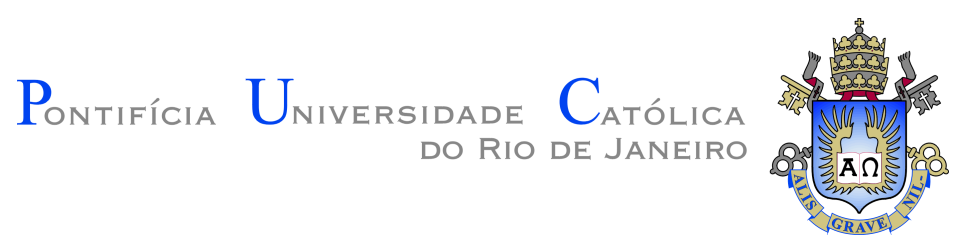

Abel González Mondéjar

BraPolar: uma aplicação para o monitoramento
remoto de pessoas com transtorno bipolar

Dissertação de Mestrado

Dissertação apresentada como requisito parcial para a obtenção do grau de Mestre pelo Programa de Pós-graduação em Informática da PUC-Rio.

Orientador : Prof. Alberto Barbosa Raposo Co-orientador: Prof. Daniel Corrêa Mograbi 


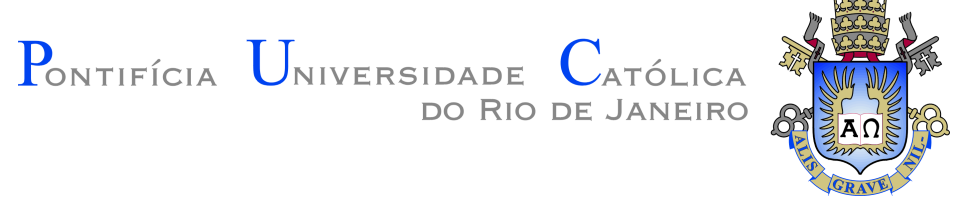

Abel González Mondéjar

\title{
BraPolar: uma aplicação para o monitoramento remoto de pessoas com transtorno bipolar
}

Dissertação apresentada como requisito parcial para a obtenção do grau de Mestre pelo Programa de Pós-graduação em Informática da PUC-Rio. Aprovada pela Comissão Examinadora abaixo.

\author{
Prof. Alberto Barbosa Raposo \\ Orientador \\ Departamento de Informática - PUC-Rio \\ Prof. Daniel Corrêa Mograbi \\ Co-orientador \\ Departamento de Psicología - PUC-Rio
}

Profa. Daniela Gorski Trevisan

Departamento de Informática - UFF

Greis Francy Mireya Silva Calpa

Departamento de Informática - PUC-Rio

Rio de Janeiro, 01 de Outubro de 2019 
Todos os direitos reservados. É proibida a reprodução total ou parcial do trabalho sem autorização da universidade, do autor e do orientador.

\section{Abel González Mondéjar}

Abel González Mondéjar é formado em Engenharia Informática na Universidade de Matanzas, Cuba (2015). Expôs parte do presente estudo na 7th International Conference on Serious Games and Applications for Health, IEEE SeGAH 2019 em Quioto, Japão. Abel González trabalha no Instituto Tecgraf de Desenvolvimento de Software Técnico-Científico da PUC-Rio (Tecgraf/PUC-Rio).

Ficha Catalográfica

González Mondéjar, Abel

BraPolar: uma aplicação para o monitoramento remoto de pessoas com transtorno bipolar / Abel González Mondéjar; orientador: Alberto Barbosa Raposo; co-orientador: Daniel Corrêa Mograbi. - Rio de janeiro: PUC-Rio, Departamento de Informática, 2019.

v., 122 f: il. color. ; $30 \mathrm{~cm}$

Dissertação (mestrado) - Pontifícia Universidade Católica do Rio de Janeiro, Departamento de Informática.

Inclui bibliografia

1. Informática - Teses. 2. m-health;. 3. fenotipagem digital;. 4. transtorno afetivo bipolar;. 5. monitoramento remoto.. I. Barbosa Raposo, Alberto. II. Mograbi Corrêa., Daniel. III. Pontifícia Universidade Católica do Rio de Janeiro. Departamento de Informática. IV. Título. 
A aquellos que confiaron y me motivaron a continuar. 


\section{Agradecimentos}

Esta se torna a página mais difícil de escrever, especialmente quando existem tantas pessoas que participaram dessa longa jornada. Quero agradecer a todos que, de uma forma ou de outra, contribuíram para tornar este objetivo realidade:

Primeiramente a Deus, por ter me dado saúde e força para superar as adversidades.

A minha família em Cuba, Estados Unidos e Chile por ser partícipes desta travessia na qual me aventurei há pouco mais de 2 anos.

A meu orientador, Prof. Alberto Raposo que me deu a oportunidade de trabalhar com ele. Agradeço a confiança depositada e seu suporte ao longo do mestrado todo. Sempre estarei em dívida com você.

A meu co-orientador, por manter a calma e a paciência diante desafios que foram aparecendo durante o mestrado. Preciso aprender muito de vocês.

À Greis, não tenho palavras para descrever toda sua ajuda na realização deste trabalho que hoje, concluímos. Muito obrigado por sua disponibilidade.

A minha esposa, por me suportar, apoiar e acompanhar diante cada novo projeto. Vamos a chegar bem longe, confia.

A meus sogros cubanos Mabel e Camilo, e brasileiros Vladimir e Luizelena. Seu suporte foi essencial para continuar. Os amo muito e respeito.

Aos amigos que deixei em Cuba e me acompanharam a $6500 \mathrm{~km}$ de distância mas, sempre estão no meu coração: Félix, Dayana, Randy y Yosmely.

Aos amigos que me ajudaram ao começo no Brasil: Alexander, Yuleika, Bénédicte, Yosveni, Reinier; e demais amigos cubanos e brasileiros que conheci neste maravilhoso país.

À banca desta dissertação de mestrado, por suas oportunas recomendações para obter um resultado satisfatório neste trabalho.

Ao corpo docente do Departamento de Informática da PUC-Rio e colaboradores. Orgulho de ser mais um filho da PUC.

O presente trabalho foi realizado com apoio da Coordenação de Aperfeiçoamento de Pessoal de Nível Superior - Brasil (CAPES) - Código de Financiamento 001 e ao Conselho Nacional de Desenvolvimento Científico e Tecnológico (CNPq). Agradeço cada oportunidade que tive, incluindo o suporte financeiro para realizar esta pesquisa.

A todos que direta ou indiretamente fizeram parte da minha formação, de coração, o meu muito obrigado. 


\section{Resumo}

González Mondéjar, Abel; Barbosa Raposo, Alberto; Mograbi Corrêa., Daniel. BraPolar: uma aplicação para o monitoramento remoto de pessoas com transtorno bipolar. Rio de Janeiro, 2019. 122p. Dissertação de Mestrado - Departamento de Informática, Pontifícia Universidade Católica do Rio de Janeiro.

O presente trabalho aborda o monitoramento remoto em tempo real de pessoas com Transtorno Afetivo Bipolar e sua interação com seus dispositivos móveis. Algumas abordagens na área da ciência da computação apresentam experiências para coletar informações subjetivas as quais podem ser usadas por especialistas em benefício de pessoas com necessidades específicas. Por outra parte, a fenotipagem digital é um campo de ciência multidisciplinar, usado para descrever uma nova abordagem para acompanhar a interação dos usuários com seu smartphone e poder mapear transtornos fazendo uso dos sensores do celular. Embora algumas pesquisas avaliem as vantagens dos aplicativos móveis para o tratamento das doenças mentais, na literatura não foi encontrada nenhuma solução que faça uso da análise do fenótipo digital e a visualização da informação em tempo real como marcadores de estado e traço de intervenção terapêutica não invasiva, ao detectar precocemente alterações nos padrões comportamentais dos pacientes. Neste trabalho, apresentamos o BraPolar, uma m-Health para monitoramento remoto de pacientes com Transtorno Afetivo Bipolar, apresentando em tempo real flutuações de humor e comportamentos nos participantes através da interação com seus dispositivos móveis. A fenotipagem digital coletada é apresentada aos especialistas em tempo real poderá ajudar a prever alterações no comportamento das pessoas antes que atinjam consequências funcionais extremas. Neste estudo, apresentamos avaliações de usabilidade piloto envolvendo seis usuários não portadores da doença e cinco especialistas para avaliar a percepção que tem do aplicativo. Apresentamos também um estudo longitudinal realizado durante um mês e avaliação em tempo real com especialistas das áreas de psicologia e psiquiatria. Finalmente, apresentamos o potencial de BraPolar no monitoramento remoto de pessoas com transtorno bipolar.

\section{Palavras-chave}

m-health; fenotipagem digital; transtorno afetivo bipolar; monitoramento remoto. 


\section{Abstract}

González Mondéjar, Abel; Barbosa Raposo, Alberto (Advisor); Mograbi Corrêa., Daniel (Co-Advisor). BraPolar: an application for the remote monitoring of people with bipolar disorder. Rio de Janeiro, 2019. 122p. Dissertação de Mestrado - Departamento de Informática, Pontifícia Universidade Católica do Rio de Janeiro.

This work addresses the real-time remote monitoring of people with Bipolar Affective Disorder and their interaction with their mobile devices. Some approaches in computer science present experiments for collecting subjective information that can be used by experts for the benefit of people with specific needs. On the other hand, digital phenotyping is a multidisciplinary field of science, used to describe a new approach to monitor user interaction with their smartphone and to map disturbances using cell phone sensors. Although, some research assesses the advantages of mobile applications for the treatment of mental illness but no solution has been found in the literature that makes use of digital phenotype analysis and real-time information visualization as state markers and non-invasive therapeutic intervention traits by early detection of changes in patients' behavioral patterns. In this dissertation we present BraPolar, an m-Health for remote monitoring of patients with Bipolar Affective Disorder, featuring real-time fluctuations in mood and behavior in participants through interaction with their mobile devices. Collected digital phenotyping presented to real-time specialists can help predict changes in people's behavior before they reach extreme functional consequences. In this study, we present pilot usability assessments involving six non-disease users and five experts to assess their perception of the application. We also present a longitudinal study conducted over a month and real-time evaluation with experts in the fields of psychology and psychiatry. Finally, we present the potential of BraPolar in remote monitoring of people with bipolar disorder.

\section{Keywords}

m-health; digital phenotyping; bipolar affective disorder; remote monitoring. 


\section{Sumário}

1 Introdução 14

$\begin{array}{lll}1.1 & \text { Motivação } & 15\end{array}$

$\begin{array}{lll}1.2 & \text { Objetivo } & 16\end{array}$

$\begin{array}{ll}1.3 \text { Questão de pesquisa } & 16\end{array}$

$\begin{array}{ll}1.4 \text { Metodologia } & 17\end{array}$

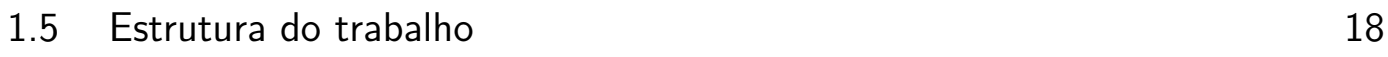

2 Contextualização e trabalhos relacionados $\quad 19$

$\begin{array}{lll}2.1 & \text { Transtorno Afetivo Bipolar e o IPUB } & 19\end{array}$

2.2 Avaliação convencional de pacientes com TAB 20

2.3 Pacientes com doenças mentais e tecnologias móveis 21

2.4 A fenotipagem digital como nova abordagem no TAB 22

2.5 Teste de dependência ao celular como complemento à FD 22

2.6 As m-Health no controle de doenças mentais 23

3 Metodologia $\quad 26$

3.1 Método de pesquisa 26

$\begin{array}{ll}3.2 & \text { Participantes } \\ 3.3 & 27\end{array}$

$\begin{array}{lll}3.3 & \text { Procedimento } & 27\end{array}$

3.4 Aspectos éticos e legais da pesquisa 28

$\begin{array}{lll}3.5 & \text { Riscos associados } & 29\end{array}$

$4 \quad$ O aplicativo BraPolar $\quad 30$

4.1 Caraterísticas de um m-health para o monitoramento remoto 30

4.2 Funcionalidades requeridas no BraPolar 31

4.3 Comparativo das soluções existentes com o BraPolar 34

4.4 Arquitetura e interfaces do BraPolar 35

4.5 Diferenças entre BraPolar modo paciente e especialista 42

5 Avaliação do modo paciente $\quad 44$

5.1 Participantes das avaliações 44

5.2 Teste de dependência ao celular $\quad 45$

5.3 Resultados do teste de dependência ao celular 47

$\begin{array}{lll}5.4 & \text { Teste de usabilidade } & 49\end{array}$

5.5 Resultados do teste de usabilidade $\quad 55$

5.6 Discussão 57

5.7 Publicações 58

$\begin{array}{lll}5.8 & \text { Preparação para o próximo estudo } & 59\end{array}$

$\begin{array}{ll}5.9 \text { Conclusões do capítulo } & 61\end{array}$

6 Avaliação do modo especialista $\quad 62$

6.1 Definição do objetivo do teste com especialistas 62

6.2 Instrumentação 63

6.3 Seleção dos especialistas participantes 66

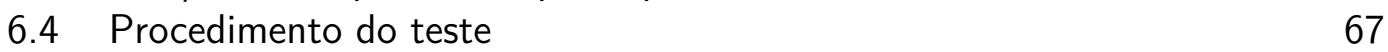


$\begin{array}{lll}6.5 & \text { Resultados da avaliação } & 69\end{array}$

6.6 Discussão 77

$\begin{array}{lll}6.7 & \text { Conclusões do capítulo } & 79\end{array}$

7 Conclusões e trabalhos futuros $\quad 81$

$\begin{array}{lll}7.1 & \text { Principais contribuições } & 81\end{array}$

7.2 Limitações 83

$\begin{array}{lll}7.3 & \text { Trabalhos futuros } & 84\end{array}$

8 Referências bibliográficas $\quad 86$

9 Anexos $\quad 92$

9.1 Anexo A Termo de consentimento livre e esclarecido - Paciente 92

9.2 Anexo B Teste de dependência ao celular 97

9.3 Anexo C Orientações gerais - participantes 102

9.4 Anexo D Lista de atividades - participantes 103

9.5 Anexo E Questionário de usabilidade - participante 105

9.6 Anexo F Resultados teste de dependência ao celular 107

9.7 Anexo G Termo de consentimento livre e esclarecido - Especialista 111

9.8 Anexo H Orientações gerais - especialistas 116

9.9 Anexo I Lista de atividades - especialistas $\quad 117$

9.10 Anexo J Questionário pós teste - Especialistas 118

9.11 Anexo K Questionário usabilidade - Especialistas 120

9.12 Anexo L Certificado de apresentação na conferência SeGAH 122 


\section{Lista de figuras}

Figura 2.1 Escala de dependência ao celular 23

Figura 4.1 Sintomas bipolares e possíveis medidas de smartphone (Matthews et al [47]) 31

Figura 4.2 Sintomas bipolares e possíveis medidas de dados ativos 32

Figura 4.3 Sintomas bipolares e possíveis medidas de dados passivos 33

Figura 4.4 Instância em Firebase 36

$\begin{array}{lll}\text { Figura 4.5 Usuários ativos durante o período de testes } & 37\end{array}$

Figura 4.6 Interação dos usuários com o BraPolar durante os testes 37

Figura 4.7 Diagrama de nível de componente para o sistema proposto (Shaikh et al. [53]) 38

Figura 4.8 Exemplo de um protótipo de papel desenhado à mão da aplicação BraPolar - Estado de Ânimo (esquerda) e Dashboard (direita) 39

Figura 4.9 Tarefas do projeto organizadas no Trello 39

Figura 4.10 Exemplos de funcionalidades de interface de "Estado de ânimo" (esquerda) e "Dashboard" (direita) no BraPolar 40

Figura 4.11 Usuário usando o teclado do BraPolar em WhatsApp 41

Figura 4.12 Usuário interagindo com a funcionalidade Calibração, digitação correta (esquerda) e incorreta (direita) no BraPolar 42

Figura 4.13 Modos do BraPolar: paciente e especialista 43

Figura 4.14 Funções na categoria Interação Social 43

Figura 5.1 Formulário de Dependência ao Celular em Google Form 46

$\begin{array}{lll}\text { Figura 5.2 Etapas do teste de usabilidade } & 49\end{array}$

Figura 5.3 Preparação do ambiente do teste 53

Figura 5.4 Resultado do QUIS Participantes e categorias avaliadas 56

Figura 5.5 Pontuação obtida no teste de nomofobia pelos participantes. 58

Figura 5.6 Usuários ativos durante o período de testes 60

Figura 5.7 Consumo de recursos nos dispositivos dos participantes P3 e P4 60

Figura 6.1 Perfis dos usuários (Perguntas 1 até 14) 63

Figura 6.2 Perfis dos usuários (Perguntas 15 até 23) 64

Figura 6.3 Resultado do TDC (Perguntas 1 até 11) 64

Figura 6.4 Resultado do TDC (Perguntas 12 até 20) 65

Figura 6.5 Resultado do QUIS Especialistas e categorias avaliadas $\quad 69$

Figura 6.6 Relação entre participantes e pontuação obtida no teste de

nomofobia. $\quad 77$

Figura 6.7 Palavras mais comentadas pelos especialistas na entrevista gerada em WordCloud. $\quad 79$ 


\section{Lista de tabelas}

Tabela 4.1 Comparativa de funcionalidades com BraPolar 35

Tabela 5.1 Caracterização dos participantes do estudo 45

Tabela 5.2 Resultado do teste de dependência ao celular 47

Tabela 5.3 Perguntas que os participantes atribuíram maior peso 48

Tabela 5.4 Correção dos id dos participantes para o seguinte estudo $\quad 59$

Tabela 5.5 Consumo máximo de recursos do BraPolar 61

Tabela 6.1 Caracterização dos especialistas participantes do estudo $\quad 67$

Tabela 6.2 Média dos resultados obtido por participante por categorias 71

Tabela 6.3 Média dos resultados obtido por participante no QUIS 71 


\section{Lista de símbolos}

TAB - Transtorno Afetivo Bipolar

SAA - Sinais de Aviso Antecipado

FD - Fenotipagem Digital

m-Health - Mobile Heatlh

TCC - Terapia Comportamental Cognitiva

TCA - Terapia de Compromisso de Aceitação

OMS - Organização Mundial da Saúde

EWS - Early Warning Signs

ABRATA - Associação Brasileira de Familiares Amigos e Portadores de Transtornos Afetivos

PUC-Rio - Pontifícia Universidade Católica do Rio de Janeiro

UFRJ - Universidade Federal do Río de Janeiro

IPUB/UFRJ - Instituto de Psiquiatria da UFRJ

QUIS - Questionário de Satisfação de Interação do Usuário

$\mathrm{AP}-$ Access Point

BP - BraPolar modo paciente

BE - BraPolar modo especialista

TLCE - Termo de Consentimento Livre e Esclarecido

TDC - Teste de dependência ao celular 
Solo el amor engendra la maravilla.

José Martí, Lo que debes amar. 


\section{1 \\ Introdução}

O Transtorno Afetivo Bipolar (TAB), é uma desordem cerebral, caracterizada por mudanças não usuais no humor, energia, níveis de atividade e na habilidade de realizar as tarefas do cotidiano. As alterações de humor compreendem desde um período de mania (ou euforia), caracterizado por um comportamento mais energizado, até um período depressivo, marcado por um sentimento de tristeza [1].

$\mathrm{Na}$ literatura, o conjunto de comportamentos do paciente que podem prever quando ele pode entrar em uma fase maníaca ou depressiva, são conhecidos como Sinais de Aviso Antecipado (SAA) [2]. A informação dos SAA, durante um período de tempo considerável, pode ser útil para antecipar e detectar uma mudança de estado nos pacientes com TAB [3] antes que esta atinja consequências funcionais extremas. Os principais indicadores são, geralmente, o nível e a repetitividade da atividade física durante o dia, o nível de interação social e o nível de estresse e mudanças de humor.

Acompanhar as alterações dos SAA ao logo do tempo poderia auxiliar aos especialistas para detectar flutuações não usuais no comportamento dos pacientes. Neste sentido, os especialistas utilizam o prontuário de cada paciente, onde deixam gravados os resultados das avaliações clínicas, mas não possuem nenhum registro referente à interação desses pacientes durante o intervalo de uma consulta a outra no período de tratamento. Com isto em mente, propomos usar a fenotipagem digital (FD).

A FD consiste em um campo de ciência multidisciplinar usada para descrever uma nova abordagem para acompanhar a interação dos usuários com seus smartphones e posteriormente poder mapear possíveis transtornos. Isto é realizado através da coleta dos dados gerados pelos sensores do smartphone e o uso do celular da pessoa no seu dia-dia. A fenotipagem digital, dito de outra forma, consiste na análise do comportamento do usuário baseada no uso do celular. O termo foi introduzido pela primeira vez em 2015 num artigo na Nature Biotechnology [4] no qual os autores comentam como principal novidade que a análise da fenotipagem digital podem expandir nossa capacidade de identificar e diagnosticar condições de saúde.

À medida que os smartphones se tornaram onipresentes, seu uso crescente fornece uma oportunidade sem precedentes para medir o humor, a cognição e o comportamento de forma passiva, objetiva e contínua das pessoas que o usam e poderia ser utilizado amplamente no tratamento de doenças mentais. Neste 
sentido, propomos neste trabalho uma ferramenta de auxílio a especialistas de psicologia e psiquiatria no monitoramento remoto de pessoas com TAB em tempo real.

\section{1}

\section{Motivação}

O TAB é um problema de saúde pública declarado pela Organização Mundial da Saúde (OMS). Aproximadamente, a nível global, 25\% dos pacientes com TAB no mundo tentam suicídio em alguma etapa de suas vidas e, entre eles, cerca de 11\% completam este intento. Estima-se que 4,4\% da população adulta dos EUA vão sofrer de transtorno bipolar em algum momento de suas vidas [5], e taxas similares atingem a população brasileira, de acordo com dados divulgados pela Associação Brasileira de Familiares Amigos e Portadores de Transtornos Afetivos (Abrata) [6].

Muitas pessoas afetadas com TAB ao longo da sua vida, principalmente em períodos maníacos, apresentam uma redução na consciência do distúrbio, seus sintomas e seu funcionamento cognitivo e social; tal condição é conhecida como perda de insight [7]. Por sua magnitude, a não adesão ou a baixa adesão terapêutica constituem problemas de saúde pública no Brasil [8].

Embora os pacientes com TAB tenham dificuldade com a adesão a seu tratamento, um estudo realizado por Faurholt-Jepsen et al. [9] demonstrou que pacientes com TAB possuem maior interação social usando seus smartphones e computadores. Neste sentido, a Statista [10], uma das principais empresas de estatísticas com sede no Canadá, realizou um estudo [11] onde mostrou que um brasileiro, em média, o ocupa seu celular pouco mais de quatro horas por dia. Em consonância Martini et al. [12] investigou, por meio de um questionário, os padrões de utilização da Internet de trinta pacientes com TAB e trinta pessoas sem a doença, pareados por idade, gênero e anos de educação. Observou-se que os bipolares, em comparação com as pessoas saudáveis, tinham menos contatos próximos e menos conhecidos no Facebook [13]. No mundo real, os pacientes também tinham um número menor de amigos concordando com o estudo de Faurholt-Jepsen et al. [9].

$\mathrm{Na}$ revisão de literatura, encontramos algumas soluções que são usadas para acompanhar pacientes com TAB [14] [15] [16] [17] [18], entre eles [16] [17] [18], têm algumas características do nosso interesse, como a visualização das informações coletadas e um conjunto de parâmetros que foram analisados para a detecção de flutuações no humor. Outros estudos [15] definem um novo campo que conceitualmente estabelece a coleta de dados na relação do usuário com o uso do smartphone, denominado fenotipagem digital. Portanto, 
a unificação da análise da fenotipagem digital a partir de SAA pode permitir visualizações como marcadores de status e traço de intervenção terapêutica não invasiva. No entanto, nenhum estudo seguindo essa abordagem em tempo real foi encontrado na literatura. Além disso, nenhuma das soluções encontradas incluem todos os recursos necessários propostos pelos especialistas do Instituto de Psiquiatria da Universidade Federal do Rio de Janeiro (IPUB/UFRJ), parceiros deste trabalho.

Considerando os fatos acima, foi concebida a ideia de desenvolver uma solução para o monitoramento remoto do TAB em tempo real, a qual surgiu inicialmente do IPUB/UFRJ, pois na atualidade não é oferecido na rede pública nenhum acompanhamento usando os dispositivos móveis para pessoas com TAB. Portanto, após desenvolver uma solução que contenha todas as exigências abordadas pelos especialistas, concebemos BraPolar, o qual constitui um projeto pioneiro no país onde os especialistas poderão se auxiliar a identificar alterações que o paciente não pode perceber por si mesmo.

\section{2}

\section{Objetivo}

Considerando os fatos acima, nossa solução baseia-se em desenvolver e avaliar o BraPolar, um m-Health para o monitoramento remoto de pacientes com TAB.

Para atingir nosso objetivo, propusemos os seguintes objetivos específicos:

- Estudar as caraterísticas que deve ter uma m-health para o monitoramento remoto em tempo real de pessoas com TAB.

- Desenvolver o protótipo BraPolar para o monitoramento remoto de pessoas com TAB.

- Avaliar a facilidade de uso da solução com participantes.

- Avaliar com especialistas se a solução é apta para o monitoramento remoto em tempo real em pacientes com TAB.

\section{3}

\section{Questão de pesquisa}

Este estudo direciona a seguinte questão de pesquisa: O aplicativo BraPolar pode auxiliar aos especialistas na identificação de mudanças de comportamento nos pacientes com TAB? Para isto, conduzimos a nossa pesquisa com especialistas de psicologia e psiquiatria do IPUB. 


\section{4 \\ Metodologia}

Para atingir o objetivo, no capítulo 3 apresentamos a metodologia de pesquisa utilizada. Nele, comentamos o objetivo a alcançar com esta pesquisa, após, apresentamos o método de pesquisa utilizado e o processo de seleção dos participantes do estudo. Após disso, apresentamos o procedimento dividido em 5 etapas. Pelas características multidisciplinares desta pesquisa, incluímos considerações éticas e riscos associados ao estudo proposto. Numa primeira avaliação, decidimos realizar os testes em pacientes com TAB, mas precisávamos da aprovação prévia do Comitê de Ética de Pesquisa do IPUB e a submissão do projeto na Plataforma Brasil para realizar experimentos com seres humanos. Considerando que este último processo pode demorar um tempo considerável, decidimos realizar este estudo piloto com 6 sujeitos não bipolares, com a autorização do Comitê de Ética do IPUB enquanto o projeto é tramitado na Plataforma Brasil, do Ministério da Saúde.

Depois de aplicar o teste de dependência ao celular e realizar um conjunto de atividades identificamos, por exemplo, que alguns participantes com maior dependência do celular não se sentiam confortáveis ao visualizar as informações armazenadas, um fator que acreditamos ser prejudicial em estudos posteriores em pacientes com TAB. Depois de corrigidas as principais dificuldades do aplicativo propostas pelos participantes, prosseguimos a instalar o aplicativo no seus celulares de maneira exploratória durante 1 mês para a conformação da fenotipagem digital. Em paralelo, desenvolvemos as funcionalidades necessárias para a versão do BraPolar para especialistas.

Após concluir o período de coleta, realizamos um teste com 5 especialistas (2 psiquiatras e 3 psicólogos). Estes especialistas, auxiliados do teste de dependência ao celular, realizaram a avaliação através do BraPolar, confirmando a relevância do conhecimento prévio no teste de dependência ao celular e a fenotipagem digital no monitoramento remoto em tempo real com o BraPolar utilizando as informações apresentadas como marcadores de status e traço de intervenção terapêutica não invasiva em posteriores estudos com pacientes com TAB. Eles também propuseram recomendações e reafirmaram a relevância da continuidade do projeto para futuras avaliações. 


\section{5}

\section{Estrutura do trabalho}

Esta dissertação está estruturada da seguinte forma.

No Capítulo 2 apresentamos informações básicas destinadas a apoiar a compreensão desta pesquisa. Este capítulo também discute trabalhos relacionados a fim de contextualizar esta dissertação com relação à literatura.

No Capítulo 3 apresentamos a metodologia utilizada na pesquisa onde comentamos como foi feita a seleção dos participantes, o procedimento e pela característica desta investigação, incluímos um conjunto de aspectos éticos envolvidos.

No Capítulo 4 explicamos nossa abordagem de aplicativo para o monitoramento de remoto para pessoas com TAB em tempo real e as características solicitadas pelos especialistas na área. Finalmente, apresentamos os resultados obtidos nesta fase.

No Capítulo 5 discutimos o protocolo utilizado para realizar uma primeira avaliação em pessoas não portadoras de TAB conforme características requisitadas pelos especialistas na área e complementando a bibliografia existente. Finalmente, apresentamos os resultados obtidos nesta fase.

No Capítulo 6 comentamos o protocolo e resultados obtidos com os especialistas. Sintetizamos as principais dificuldades e propostas por parte dos especialistas durante a avaliação realizada.

Para encerrar, o Capítulo 7 resume a dissertação. Este capítulo discute nossas principais contribuições e sugere trabalhos futuros a serem incluídos em posteriores versões no BraPolar. 


\section{2}

\section{Contextualização e trabalhos relacionados}

Neste capítulo apresentaremos as bases teóricas da pesquisa e uma análise do estado da arte com o intuito de compreender esta dissertação. Na seção 2.1 comentamos mais detalhes sobre o Transtorno Afetivo Bipolar e como impacta na atualidade, no entanto, abordamos como o IPUB constitui um centro de referência no tratamento e acompanhamento do TAB na região. Na seção 2.2 comentamos como é feito normalmente o acompanhamento dos pacientes no instituto. Após, na seção 2.3, apresentamos alguns estudos sobre a interação de pessoas com doenças mentais e seus dispositivos móveis. Na seção 2.4 descrevemos como a fenotipagem digital poderia nos auxiliar. Finalmente, na seção 2.6 apresentamos algumas soluções existentes no mercado que se assemelham a nosso escopo e como estas podem ser aliadas dos especialistas em prol do bem-estar de pessoas com doenças mentais.

\section{1}

\section{Transtorno Afetivo Bipolar e o IPUB}

O Transtorno Afetivo Bipolar (TAB), é uma doença recorrente, crônica e grave que causa um impacto significativo na qualidade vida dos pacientes, além de grande carga para família e sociedade em geral.

Segundo o Diagnostic and Statistical Manual of Mental Disorders [19], o TAB é classificado em transtornos bipolares tipo I (caracterizados por um ou mais episódios maníacos ou episódios mistos), tipo II (ocorrem um ou mais episódios depressivos maiores acompanhados por, pelo menos, um episódio hipomaníaco), ciclotímicos (caraterizado por perturbação crônica e flutuante do humor), e aqueles sem outra especificação (SOE). Nos SOE os sintomas sugerem o diagnóstico de TAB, mas não são frequentes ou longos o suficiente para classificar a doença em um dos tipos acima [20].

O Instituto de Psiquiatria da Universidade Federal do Rio de Janeiro (IPUB) é um centro multisserviços: instituição de ensino, hospital universitário com ambulatório, possui enfermarias de internação, plantão de emergência e serviços-dia, entre outros. Este centro constitui uma instituição psiquiátrica e mantém pesquisas clínicas em psicanálise. Para desenvolver os trabalhos dos pesquisadores, possuem a participação voluntária de pacientes e, sobretudo, o engajamento da quase totalidade dos investigadores na assistência levada a cabo na instituição prestando atendimento direto ou na forma de supervisão aos pacientes com doenças mentais atendidos no IPUB [21].Uma das áreas que 
possui notável relevância, consiste na consulta e acompanhamento de pessoas com transtornos mentais e TAB.

Para o tratamento de pessoas portadoras de TAB, o IPUB possui uma equipe multidisciplinar que trabalha em parceria com o Departamento de Psicologia da PUC-Rio em distintas pesquisas relacionadas ao TAB [22] [23].

\section{2}

\section{Avaliação convencional de pacientes com TAB}

Usualmente, os pacientes com TAB obtém assistência por parte dos especialistas considerando os seguintes eventos: por decisão própria, por recomendação do seu especialista ou sugerido por um familiar ou acompanhante.

O seguimento é realizado em acompanhamento ambulatorial, em média o paciente vai uma vez por mês, mas isso pode ser mais ou menos frequente em função da gravidade do caso naquele momento. Os especialistas registram em arquivos Excel as informações sobre o paciente, tais como, os dados clínicos pretéritos, o número de internações, polaridade predominante, polaridade do primeiro episódio, número de tentativas de suicídio, etc. Em vários momentos, mas não de forma contínua, são aplicadas escalas de avaliação clínica, especialmente relativas aos sintomas de mania e de depressão, o que fica também registrado. O armazenamento dessa informação prévia do paciente é fundamental, pois os especialistas na hora de avaliar o estado atual do paciente tomam como referência o histórico e evolução da doença ao logo do tempo.

Para as avaliações, as métricas utilizadas pelos especialistas para a avaliação do paciente são, principalmente, a Young Mania Rating Scale (YMRS) para a mania, a de Hamilton Rating Scale for Depression (HRSD) para momentos de depressão, Clinical Global Impression-Bipolar (CGI-BP), e Positive and Negative Syndrome Scale (PANSS) [24] [25].

Em adição, assim que o paciente precisar, pode ser administrado tratamento medicamentoso, sendo o mais habitual o carbonato de lítio [26]. Métodos não medicamentosos utilizados como complemento podem influir positivamente na melhoria dos pacientes. No entanto, a falta de autoconsciência nos pacientes da sua própria doença, dificulta a definição de um diagnóstico, além de influenciar na adesão do paciente no tratamento [27] e impactar no curso da doença, considerando o insight inversamente proporcional com um episódio maníaco. 


\section{3 \\ Pacientes com doenças mentais e tecnologias móveis}

Martini et al. [12] fizeram um estudo onde foram investigados por meio de um questionário, os padrões de utilização da Internet de trinta pacientes com TAB e trinta pessoas sem a doença, pareados por idade, gênero e anos de educação. Observou-se que os bipolares, em comparação com as pessoas saudáveis, tinham menos contatos próximos e menos conhecidos no Facebook [13]. No mundo real, os pacientes também tinham um número menor de amigos concordando com outro estudo de Faurholt-Jepsen et al [9].

Os aplicativos móveis em apoio à saude (m-heatlh) têm ajudado pacientes com doenças mentais, entretanto, muitos deles requerem que o usuário interaja ativamente com o aplicativo. Um fator a ter em conta, é incentivar o uso de aplicativos móveis nesses pacientes, neste sentido Murnane et al. [28] fizeram um estudo para analisar a adoção, adesão e motivos de abandono de m-Health. No estudo, se demonstrou que as pessoas poderiam desinstalar rapidamente o aplicativo no seus dispositivos móveis se o mesmo lhes atrapalha com muitas notificações, causa drenagem de bateria ou simplesmente que não lhes avisa de atividade nenhuma.

Considerando o exposto, marcamos estes fatores como relevantes na hora de tratar com pacientes com TAB. Devemos procurar alternativas para que o aplicativo não lhes atrapalhe no seu dia-dia e obtenha informações mais fidedignas em conjunção com a conscientização do uso do aplicativo no percurso da doença, tanto na coleta de dados ativos (requer que o usuário interaja com a aplicação) quanto nos passivos (dados coletados sem a intervenção do usuário).

Um outro estudo realizado por Bourla [29] recomenda o uso de dados passivos sobre os ativos coletados pelo celular nos m-Health. Ele considera que os dados gerados automaticamente (passivos) reduzem os vieses e limitam a sensação de invasão que os questionários podem causar, entretanto, consideramos que devem ser usados como complemento na avaliação clínica. Baldram [30] mostrou que os pacientes preferiram o aplicativo em vez do antigo sistema de questionários baseado em papel: eles acharam o aplicativo realmente útil, concordando com outro estudo realizado por Faurholt-Jepsen et al. [9], onde observaram que pacientes com TAB interagiam mais por meio de seus dispositivos eletrônicos que no mundo real.

Além de todo o exposto, é importante frisar que, a exemplo do que planejamos no estudo atual, é possível usar ferramentas digitais e tradicionais de forma complementar. Logo, é muito importante que os pacientes do estudo insiram as informações verídicas de seu estado diário, sem atrapalhar seu diadia. 


\section{4}

\section{A fenotipagem digital como nova abordagem no TAB}

$\mathrm{Na}$ introdução comentamos que a fenotipagem digital consiste na avaliação da interação do usuário apoiado do uso dos sensores de seu celular. Diversas pesquisas têm se apoiado nesta definição para tratar doenças mentais.

Um estudo realizado por Carvalho [31] comenta que, através da fenotipagem digital e o uso da tecnologia, podem auxiliar à psiquiatria tradicional no sentido de que a coleta de dados do smartphone nos pacientes poderia permitir descobrir dados comportamentais, como padrões erráticos ou exagerados de envio e resposta de mensagens / chamadas, comportamentos de correr riscos o qual poderia ser corrigido se for rastreado por GPS e até impulsividade com base em dados fisiológicos, por exemplo, frequência cardíaca. Aliás, Carvalho [31] comenta como principal vantagem, poder ter uma referência ao logo do tempo para avaliar em retrospectiva essas pessoas, mas que não existe uma solução que efetivamente capture estes possíveis marcadores comportamentais.

Neste sentido, propomos estabelecer uma relação entre a fenotipagem digital e as Sinais de Aviso Antecipado (SAA) através do qual, ao longo do tempo, poderia auxiliar o especialista a detectar flutuações não usuais no comportamento dos pacientes. No momento de desenvolver esta pesquisa, os especialistas utilizam o prontuário de cada paciente onde deixam gravados os resultados das avaliações clínicas, mas não possuem nenhum registro referente à interação desses pacientes entre o intervalo de uma consulta a outra durante o período de tratamento.

\section{5}

\section{Teste de dependência ao celular como complemento à FD}

Ao fazer uma avaliação clínica, os especialistas fazem um consulta ao prontuário do paciente, se este tiver um histórico prévio, entretanto, se for um novo paciente, sem histórico médico, são realizadas uma serie de perguntas com o intuito de conhecê-lo melhor.

A FD avalia ao longo do tempo as interações de uma pessoa com seu dispositivo móvel, mas não aborda o estado inicial da pessoa. Portanto, propomos utilizar o teste de dependência ao celular (ou nomofobia) proposto por Yildrim [32] o qual visa avaliar o grau de dependência do celular de uma pessoa. Essa avaliação é feita através de um conjunto de perguntas sobre a frequência de uso do celular. Ao finalizar, os resultados do teste são avaliados em uma escala de 0 a 140, onde o score obtido indica o grau de dependência do celular em quatro categorias, de menos a mais grave conforme figura 2.1, onde $\mathrm{R}$ é o resultado após aplicar o teste de dependência. 


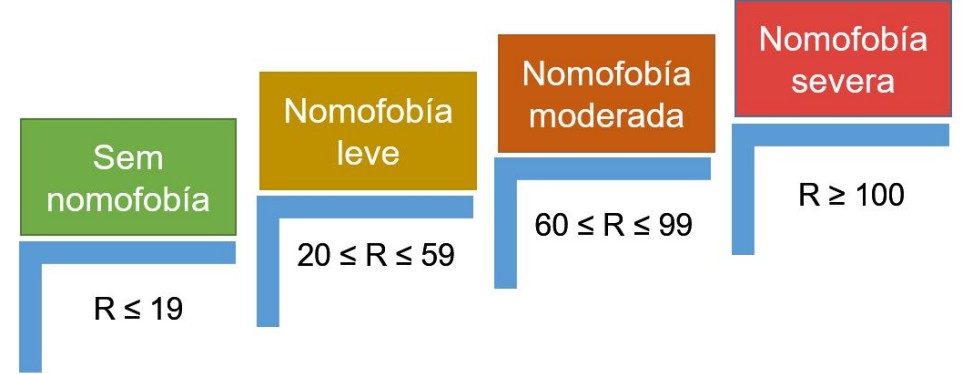

Figura 2.1: Escala de dependência ao celular

O teste é composto por 2 seções: perguntas gerais (22 perguntas) e questionário de nomofobia (19 perguntas). No caso das perguntas gerais, é coletada a informação demográfica e outras informações sobre como ele interage com seu dispositivo móvel. Com esta informação, propomos incorporar ao conceito de fenotipagem digital uma avaliação prévia de como as pessoas comumente interagem com seus dispositivos móveis com o intuito de complementar a posterior análise da fenotipagem digital e incorporá-la ao perfil do usuário.

\section{6}

\section{As $\mathrm{m}$-Health no controle de doenças mentais}

De acordo com Hernández [33], o desenvolvimento de tecnologias e a elevação dos custos da saúde fomentaram uma nova área de fronteira: e-Health, o qual consiste no uso das tecnologias para melhorar o acompanhamento clinico. Neste contexto, várias aplicações para o tratamento de doenças mentais colocaram os dispositivos móveis como dispositivos médicos (m-Health) no apoio ao tratamento de transtornos mentais [14] [15] [34] [35].

Em consonância com os estudos anteriores, outros [16] [17] apresentam experiências para rastrear e coletar informações subjetivas que podem ser usadas por especialistas em benefício de pessoas com necessidades específicas. Alguns deles avaliam as vantagens das aplicações móveis no tratamento de TAB, como BiAffect [16], MONARCA [17], What's Up [18], State Mood Tracking Journal and Diary [36], eMoods Bipolar Mood Tracker [37], os quais são detalhados a seguir:

- BiAffect [16], foi o projeto ganhador do Mood Challenge for Apple's ResearchKit 2017, torneio onde se apresentam soluções de saúde para iOS. É uma aplicação para compreensão do humor e do funcionamento neurocognitivo no TAB, utilizando dinâmicas de digitação, como velocidade de digitação e erros, para acompanhar e prever episódios de humor. Isso porque a problemática na comunicação é um dos principais sintomas das pessoas com TAB. 
- MONARCA [17] é um sistema que ajuda os usuários a monitorar e visualizar seu comportamento. Por exemplo, indica o estado físico dos usuários, lembrando-os de executar tarefas específicas. Ele fornece feedback sobre seus comportamentos e recomenda ações mais saudáveis. Semelhante a outras tecnologias de saúde pessoal, o design do sistema MONARCA utiliza uma aplicação de telefone celular como o principal componente.

- What's Up [18] é uma aplicação para fornecer ferramentas de alívio em caso de depressão. É baseado nos métodos da Terapia Comportamental Cognitiva (TCC) e Terapia de Compromisso de Aceitação (TCA) para ajudar a lidar com a depressão, ansiedade e estresse. O What's Up não tem opções para compartilhar dados ou incluir especialistas em saúde mental no aplicativo, mas pode ser útil para indivíduos com depressão leve a moderada que não têm acesso aos tratamentos tradicionais.

- State Mood Tracking Journal and Diary [36], também conhecido como Moodtrack Diary, é um m-health projetado para usuários que querem acompanhar suas mudanças de humor. O Moodtrack Diary permite que os usuários avaliem seu próprio humor várias vezes ao dia. Ele fornece um calendário para acompanhar os eventos diários e o uso de medicamentos. O aplicativo exibe as informações em gráficos, permitindo aos usuários detectar padrões e gatilhos para seus estados de ânimo. Ele também permite que os usuários exportem um relatório para ver num computador, além de compartilhar seu perfil com profissionais de saúde mental.

- eMoods Bipolar Mood Tracker [37] descreve as classificações de humor diárias em um formulário de lista, e também fornece um gráfico codificado por cores das classificações de gravidade do humor: deprimido ou ansioso. Este aplicativo também tem um blog para ajudar os usuários com perguntas gerais sobre humor e saúde. A versão paga do aplicativo permite marcar um conjunto de lembretes para tomar a medicação e gerar relatórios detalhados sobre a atividade diária.

Após revisar as soluções existentes descritas, e as funcionalidades que contêm, não foi encontrada solução para analisar a fenotipagem digital e a dependência ao celular como marcadores de status e traço de intervenção terapêutica não invasiva no tratamento do TAB, itens relevantes para detectar alterações precoces na autoconsciência do paciente, antes que atinjam consequências funcionais extremas [1]. Além disso, em todas as aplicações, a interação dos pacientes com a aplicação é uma condição necessária para o mapeamento de seu estado, e isso pode causar algum desconforto nos pacientes avaliados.

Com o desenvolvimento do presente trabalho, visamos obter um m-health 
para o monitoramento remoto de pessoas com TAB. Consideramos que a avaliação remota em tempo real dos portadores da doença irá proporcionar aos especialistas uma ferramenta de auxílio apoiada no mapeamento do comportamento através da visualização de um conjunto de indicadores comportamentais nos dados coletados. Em consonância, o reconhecimento de possíveis alterações através SAA por parte dos especialistas, podem servir para lhes auxiliar ao usar as informações coletadas como marcadores que indiquem quando o paciente vai começar com um episódio maníaco ou depressivo [38]. Adicionalmente, a obtenção da informação em tempo real do paciente através do celular dos especialistas, poderá ajudar os pacientes a detectar flutuações antes que estas atinjam consequências extremas. Por outra parte, através da visualização da informação coletada, visamos que os mesmos autoconheçam o estado da sua doença e possam tomar decisões ao respeito, podendo continuar a desenvolver tarefas do cotidiano e cumprir a sua função social.

Neste capítulo apresentamos o estado da arte e trabalhos similares a nosso escopo. Após apresentar os conceitos fundamentais que sustentam esta pesquisa, no seguinte capítulo será apresentada a metodologia usada no desenvolvimento deste trabalho. 


\section{3}

\section{Metodologia}

Para atingir o objetivo, decidimos realizar uma pesquisa para conhecer as características e principais demandas dos especialistas brasileiros considerando as soluções existentes no mercado, e incorporando a abordagem da avaliação de dependência ao celular e análise da fenotipagem digital como marcadores de interesse ao avaliar uma pessoa com TAB. Nas seções 3.1 comentamos o método de pesquisa utilizado e na seção 3.2 apresentamos os participantes do estudo. Após isso, apresentamos o procedimento dividido em 5 etapas (seção 3.3). Pelas características multidisciplinares desta pesquisa, incluímos considerações éticas e riscos associados ao estudo proposto nas seções 3.4 e 3.5 , respectivamente.

\section{1}

\section{Método de pesquisa}

Para responder ao objetivo desta dissertação, o qual consiste em desenvolver e avaliar o BraPolar, um m-Health para o monitoramento remoto de pacientes com TAB, realizamos uma pesquisa qualitativa.

A principal característica da pesquisa qualitativa é que ela é apropriada principalmente para amostras pequenas, pois seus resultados não podem ser completamente mensuráveis ou quantificáveis. Sua principal vantagem e principal diferença sobre a pesquisa quantitativa, é que ela oferece uma descrição e análise mais abrangentes de um participante, sem limitar o escopo da pesquisa e a natureza das respostas dos avaliados [39]. No entanto, a real eficácia da pesquisa qualitativa baseia-se nas habilidades dos pesquisadores. Por ser mais apropriado para amostras pequenas, Bell [40] considera que é arriscado que os resultados de pesquisas qualitativas sejam percebidos como resposta absoluta de uma população em geral.

A abordagem utilizada nesta pesquisa foi a indutiva, na qual os pesquisadores começam com uma observação específica, usada para produzir conclusões generalizadas. A razão para utilizar a abordagem indutiva foi que ela valoriza o esforço da pesquisa, além de ser mais apropriado para pequenas amostras que produzem dados qualitativos. No entanto, a principal limitação da abordagem indutiva é que ela produz teorias e conclusões generalizadas com base apenas em um pequeno número de observações, portanto a confiabilidade dos resultados da pesquisa pode ser questionada [41] [42]. 


\section{2}

\section{Participantes}

Os participantes de nosso estudo estão divididos em dois grupos: especialistas da área da psicologia/psiquiatria e pessoas sem transtornos mentais. Procurar participantes voluntários para esta pesquisa não foi uma atividade trivial, ainda assim 6 pessoas (3 homens e 3 mulheres) participaram do estudo seguindo recomendações do co-orientador deste trabalho. Entretanto, na hora de selecionar os especialistas, utilizamos o método de purposive sampling. De acordo com esse método, que pertence à categoria de técnicas de amostragem não probabilística, os participantes são selecionados com base em seu conhecimento, relacionamento e experiência em relação a um objeto de pesquisa [43].

No presente estudo, os especialistas selecionados possuem uma experiência considerável no escopo sob investigação, experiência profissional suficiente e relevante no campo da psiquiatria/psicologia, atendimento com pacientes com TAB, além de experiência comprovada. Dentro deste contexto, os participantes deste estudo foram 3 psicólogos e 2 psiquiatras que trabalham diretamente com pacientes com TAB ou possuem ampla experiencia em pesquisas relacionadas.

\section{3}

Procedimento

Para atingir nosso objetivo, a realização desta pesquisa constou de 5 etapas principais, descritas a seguir.

- Etapa 1: Estudo de aspectos teóricos de TAB e aplicativos para o controle da saúde mental disponíveis no mercado

Nesta fase, pesquisamos os conceitos fundamentais associados ao domínio de nosso problema. Realizamos estudos sobre os principais tratamentos no TAB e como poderíamos adaptar este ao sistema que visamos desenvolver. Além disso, discutimos como a visualização de informação em tempo real é vital para a análise do fenótipo digital.

No contexto de TAB, estudamos os métodos convencionais de avaliação e acompanhamento clínico nos pacientes com TAB além das SAA. Revisamos a literatura referente à autoconsciência nos pacientes com TAB.

Ao finalizar esta fase, tivemos a base teórica necessária para a continuação do projeto, embora novos itens e conhecimentos foram acrescentados durante todo o percurso da pesquisa.

\section{- Etapa 2: Desenvolvimento do protótipo inicial da solução}

Nesta fase, formulamos uma proposta de protótipo inicial, dividida em duas partes: o aplicativo móvel para pacientes e outro para especialistas. 
Fizemos o levantamento dos requerimentos do aplicativo móvel para ambas versões pelos especialistas. Para o desenvolvimento do aplicativo móvel foi usado Android Studio 3.1.0 e Firebase para o gerenciamento dos dados.

Ao concluir esta fase, tivemos uma solução pronta para ser testada com os participantes.

- Etapa 3: Avaliação com participantes: primeiro estudo

Nesta etapa, dividida em duas fases, apresentamos uma avaliação de usabilidade envolvendo usuários não portadores de TAB, com o objetivo de identificar possíveis falhas na aplicação. Na primeira fase, após assinar o consentimento de participação na pesquisa no anexo 9.1, aplicado o teste de dependência ao celular no anexo 9.2. Na segunda fase os participantes realizaram um conjunto de atividades descritas no anexo $\mathbf{9 . 4}$ e finalmente preencheram o anexo 9.5.

Após, instalamos o BraPolar durante um mês nos celulares dos participantes para coletar a fenotipagem digital e servir de base para a posterior etapa da pesquisa.

\section{- Etapa 4: Avaliação com especialistas: segundo estudo}

Nesta fase, apresentamos uma avaliação do BraPolar, versão especialista. Para isto tomamos como referência os resultados do teste de dependência ao celular no anexo $\mathbf{9 . 6}$ e a fenotipagem digital coletada durante 1 mês pelo BraPolar com os participantes. Depois de assinado o consentimento no anexo 9.7, os especialistas realizaram um conjunto de atividades descritas no anexo 9.9. Finalmente, preencheram os questionários descritos nos anexos 9.10 e 9.11. Obtivemos recomendações valiosas por parte dos especialistas. Os 5 especialistas acharam relevante conhecer com antecedência o grau de dependência ao celular e a fenotipagem digital dos participantes, além de validar a importância de uma solução como BraPolar em posteriores pesquisas da área.

\section{- Etapa 5: Documentação dos resultados}

Esta constitui a etapa final da pesquisa. Nesta fase foram documentadas todas as experiências e resultados obtidos durante o trabalho, comentamos as principais dificuldades no desenvolvimento da pesquisa e as recomendações propostas.

\section{4}

\section{Aspectos éticos e legais da pesquisa}

Neste ponto da pesquisa, definidas as funcionalidades propostas a serem desenvolvidas consideramos a importância da ética ao trabalhar com seres humanos e somos conscientes das exigências éticas regulamentadas neste tipo 
de investigação. Outros fatores subjetivos que envolvem o percurso da pesquisa, embora não estejam regulamentados, contribuem a um melhor olhar das questões éticas compreendidas, entre elas podemos mencionar:

- A experiência do co-orientador com outros estudos realizados envolvendo pessoas com TAB [22] [23] [27] e os projetos desenvolvidos em parceria com o Instituto de Psiquiatria da UFRJ e o Departamento de Psicologia da PUC-Rio.

- O aplicativo foi instalado nos smartphones dos participantes o qual foi projetado para gravar os dados ativos e passivos do telefone descritas em seções anteriores neste capítulo.

- Os dados coletados não contêm informação sensível como texto ou gravações de voz. Somente é contabilizada a quantidade de vezes que o usuário interagiu com as distintas funcionalidades do aplicativo, além de garantir o anonimato das identidades dos pacientes em todo momento.

- Do ponto de vista dos aspectos éticos a serem considerados ao gravar dados dos telefones dos pacientes, nossa pesquisa possui no anexo 9.1 uma cláusula específica, de maneira não genérica, conforme estipula a Lei Geral de Proteção de Dados Pessoais Brasileira (PL 4.060, de 2012) [44] onde o participante concorda com a coleta destes dados para fins científicos.

- De acordo com o Regulamento Geral de Proteção de Dados (GDPR) ${ }^{1}$, "os programadores que coletam ou processam dados de usuários em larga escala ou de certos tipos de dados sensíveis, devem designar um delegado de proteção de dados (DPO)". Neste sentido os dados armazenados na nuvem possuem via Firebase, possuem o Agente de proteção de dados conforme condições do serviço da Google.

\section{5}

\section{Riscos associados}

A participação no estudo não constitui uma inconveniência na vida diária dos participantes, pois não há necessidade de deslocamento à PUC-Rio, além do encontro inicial. O único possível evento adverso é o desconforto com perguntas que podem ser vistas como pessoais pelos participantes. A negativa em respondê-las está garantida pelos pesquisadores e consignada no anexo 9.1 e a liberdade de abandonar a pesquisa em qualquer momento sem prejuízo algum para o participante.

No próximo capítulo comentaremos a proposta BraPolar e como relacionamos a base teórica existente com nossa pesquisa.

\footnotetext{
${ }^{1}$ https://firebase.google.com/support/privacy/dpo_and_eu_rep
} 


\section{4}

\section{O aplicativo BraPolar}

Neste capítulo apresentamos o aplicativo proposto, intitulado BraPolar. Em primeiro lugar, na seção 4.1 comentamos as principais características que deve ter um m-health para o monitoramento remoto e na seção 4.2 as principais funcionalidades requeridas pelos especialistas implementadas no BraPolar. Depois, na seção 4.3 apresentamos uma comparativa de nossa proposta com as soluções existentes no mercado. Na seção 4.4 mostramos a arquitetura e algumas interfaces propostas.

\section{1}

\section{Caraterísticas de um $\mathbf{m}$-health para o monitoramento remoto}

A identificação de alterações no comportamento de pessoas com TAB por parte dos especialistas baseados nos dados coletados não é uma atividade trivial. Neste sentido a pesquisa visa comentar as especificações que definimos no aplicativo, para que possam ser adequadas para o monitoramento remoto de pacientes com TAB. Seguindo os especialistas consultados portanto, as características de um m-health são diversas.

Inicialmente realizamos uma pesquisa que nos levou a atingir nosso primeiro objetivo: definir as caraterísticas deve ter um m-health para o monitoramento remoto em tempo real de pessoas com TAB.

Para isso, tivemos vários encontros de entrevistas e reuniões de brainstorming com os pesquisadores do IPUB durante 3 meses durante os quais mantivemos constante comunicação com a equipe de trabalho. Neste tempo, definimos as principais demandas dos pesquisadores e organizamos os passos a seguir. As demandas dos especialistas do IPUB num primeiro momento foram coletar a quantidade de ligações, mensagens, vezes que o usuário bloqueia/desbloqueia o celular e informação subjetiva do estado de ânimo.

De acordo com as sugestões dos especialistas, as funcionalidades do aplicativo devem considerar que o comportamento dos pacientes com TAB varia de acordo com o estado emocional. Neste sentido, Faurholt-Jepsen et al [45] identificaram um conjunto de estados (gatilhos ou triggers) em pacientes com TAB e sua interação, quando estão em estado deprimido ou maníaco, coincidindo com algumas abordagens propostas pelos especialistas do IPUB e adotadas no BraPolar. No entanto, outros pesquisadores [46] determinaram um conjunto de parâmetros-chave que podem indicar os SAA e servir de base para o estudo longitudinal: (a) sono-vigília / atividade, (b) atividade 
mental e (c) natureza e frequência da interação social. De fato, examinando os critérios para episódios de hipomania e depressão, os principais indicadores do início dos episódios (mudanças na atividade, sono, frequência e intensidade da fala, frequência e intensidade do contato social) podem ser coletados passivamente utilizando o conjunto de sensores e recursos do dispositivo (figura 4.1), disponíveis em todos os smartphones com Android.

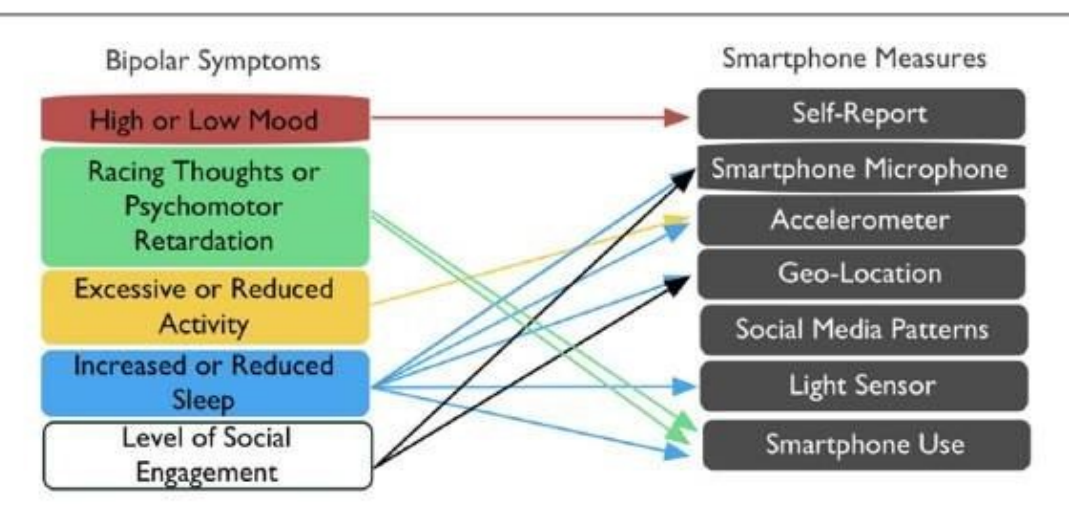

Figura 4.1: Sintomas bipolares e possíveis medidas de smartphone (Matthews et al [47])

Após discutida com os especialistas a abordagem comentada por Matthews et al [47], estes estiveram de acordo em aproveitar esse approach e incorporamos as propostas realizadas pelos profissionais brasileiros, resultando nossa solução com as funcionalidades descritas a seguir.

\section{2}

\section{Funcionalidades requeridas no BraPolar}

Uma vez definidas as principais demandas, selecionamos o Trello [48], para o gerenciamento de projetos e trabalho remoto com os especialistas. Mapas conceituais e prototipagem comentados pelos especialistas foram levados em conta. Nesse processo, concebemos a aplicação BraPolar a qual consiste em uma aplicação que permite aos especialistas monitorar em tempo real os pacientes com TAB, através da coleta e análise dos dados gerados em seu celular. Contrastando com pesquisas relacionadas [14] [15] [17] [46] e outros aspectos comentados na seção 4.1, definimos dois grupos principais: dados ativos (A) (figura 4.2) e dados passivos (P) (figura 4.3) a serem coletados e posteriormente avaliados, reagrupando o foco do estudo nas categorias seguintes: 


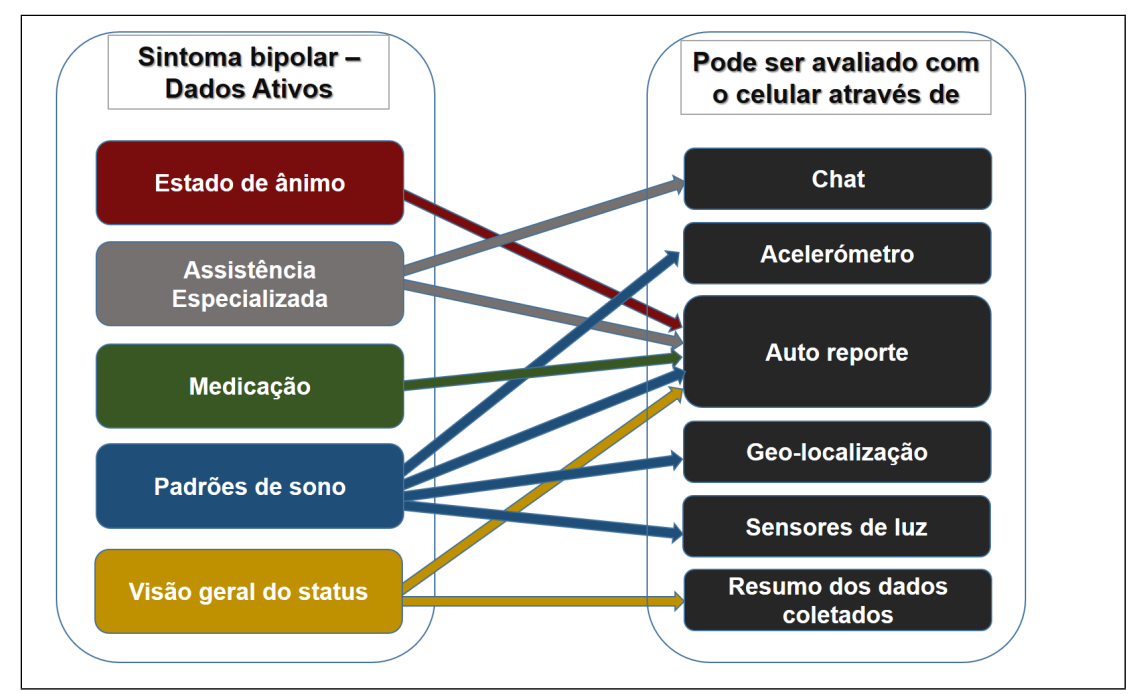

Figura 4.2: Sintomas bipolares e possíveis medidas de dados ativos

- Estado de ânimo (A): O aplicativo permite que o paciente especifique seu estado de ânimo diariamente ou sempre que desejar. Toda interação que ele definir, deverá ser guardada para ter um histórico de como seu estado de ânimo poderia variar.

- Assistência especializada (A): Esse recurso permite contato direto com o especialista. Se o usuário achar que precisa de ajuda, poderá entrar em contato com seu especialista via chat. Esse recurso ficará visível em todas as telas do aplicativo para facilitar o acesso ao usuário.

- Medicação (A): O tratamento usual em pacientes com TAB é o carbonato de lítio. O tratamento e a dosagem podem variar em dependência da gravidade da doença. Neste sentido, tanto o paciente quanto seu especialista, poderá modificar a quantidade de medicação a ser tomada. Como é uma funcionalidade muito sensível, toda modificação feita será gravada.

- Padrões de sono (A): Definimos que o BraPolar, considerando a última vez que o paciente usou seu telefone celular durante a noite e a primeira vez que o usa durante o dia, pergunta ao paciente, por meio de uma notificação, como ele acha que foi sua qualidade de sono na noite anterior. Para isto o aplicativo oferece uma escala de qualidade do sono para o paciente escolher a opção desejada além de confirmar se o intervalo de sono definido está correto.

- Visão geral do status (A): Pacientes e especialistas podem consultar cada um dos parâmetros acima através de um resumo detalhado apresentado em um dashboard na tela inicial do aplicativo. Para os pacientes, eles podem alterar manualmente esses indicadores se o aplicativo capturar qualquer parâmetro anormal. Essa interação também será registrada para a análise por parte dos especialistas. 
Considerando que cada pessoa pode inserir ou não deliberadamente as informações no aplicativo, para incentivar o uso de aplicativos móveis na saúde Munane et al [28] fizeram um estudo para analisar a adoção, adesão e motivos de abandono de tratamento por parte dos pacientes com TAB, o qual faz ênfase na importância da conscientização da doença. Logo, é muito importante incentivar os pacientes do estudo a aderirem e inserirem informações verídicas do seu estado diário. Isto permitirá a coleta de forma não invasiva dos dados referentes ao uso do seu celular visando obter a fenotipagem digital ao longo do estudo. Para isto, consideramos utilizar a quantidade mínima de notificações com os pacientes para eles inserirem as informações no BraPolar.

Em contraste, outro estudo recomenda o uso de dados passivos sobre os ativos no contexto do TAB, porque os dados gerados automaticamente (passivos) reduzem os vieses e limitam a sensação de invasão que os questionários podem causar [29]. Para nosso estudo, nos baseamos nos seguintes dados passivos:

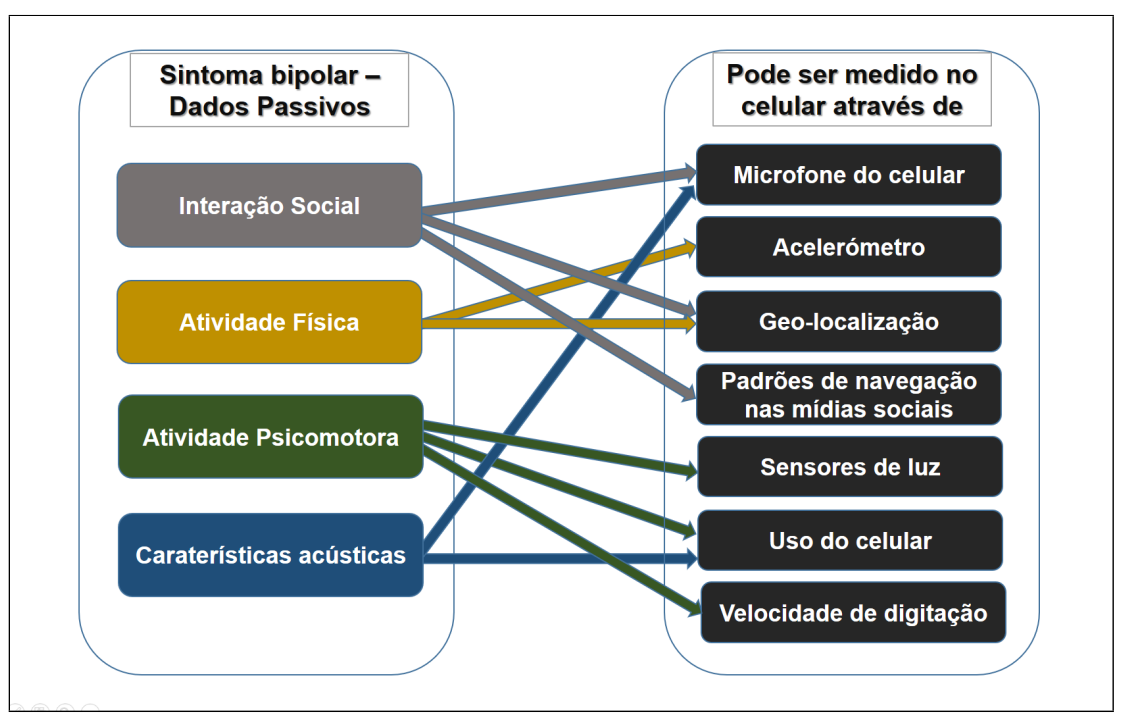

Figura 4.3: Sintomas bipolares e possíveis medidas de dados passivos

- Interação social (P): O jeito como as pessoas interagem com os outros pode variar muito. No entanto, o que as pessoas com TAB têm em comum é que, em uma fase depressiva, o desejo e a capacidade de interação social são reduzidos, enquanto que durante uma fase maníaca, ela é aumentada. Neste sentido, armazenamos nesta categoria o número de mensagens e chamadas realizadas pelo paciente. Para isso, desenvolvemos um teclado virtual que é instalado junto com o aplicativo para capturar as pulsações e a velocidade de escrita, para determinar quanto e com que velocidade o usuário digita tanto nos SMS ou mensagens intercambiadas no 
Whatsapp ou outras mídias sociais. Este teclado substitui o teclado usado em outras aplicações do celular do paciente.

- Atividade física (P): Seguindo as entrevistas com os especialistas, pacientes com depressão tendem a se mover menos, com menos força e mais lentamente, o oposto ocorre em pacientes maníacos. Nesse sentido, usaremos o GPS e as alterações nas torres de celular para determinar quanto o usuário mudou em um dia.

- Atividade psicomotora (P): A maioria das pessoas com TAB tem suas rotinas de deslocamento dominadas por um conjunto de lugares que costumam visitar em um determinado padrão de tempo. Esses padrões tendem a mudar nos estados depressivos e maníacos, tornando-se menos frequentes ou mais erráticos, respectivamente. Além disso, pessoas deprimidas tendem a sair menos de suas casas. Portanto, informações obtidas do acelerômetro e do sensor de luz são relevantes para esse grupo.

- Caraterísticas acústicas (P): Durante uma chamada no celular, pacientes em estado depressivo tendem a falar mais baixo e mais devagar, e o inverso acontece quando eles estão em estado maníaco. Uma abordagem neste sentido foi tratada por Eyben [49] e decidimos incluir este approach, usando openSmile para extrair características acústicas e o estado emocional do falante, como alternativa para este requerimento.

Definimos que o aplicativo BraPolar deve ter dois modos: um para os pacientes e um para os especialistas. Requisitos semelhantes foram solicitados em ambas versões, mas na versão dos especialistas, disponibiliza-se um dashboard (visão geral do status) com o resumo dos indicadores de cada paciente, comentadas na seção 4.5 deste capítulo.

\section{3}

\section{Comparativo das soluções existentes com o BraPolar}

O BraPolar, embora primeiro no Brasil, não é o único em realizar seguimento remoto de pessoas com TAB. Alguns estudos na litertura [16] [17] [18] [36] [37] apresentam algumas similaridades com a solução proposta. Entretanto, preferimos aproveitar todo o conhecimento prévio para complementá-lo e elaborar um novo produto integrado, adaptado ao cenário brasileiro.

A tabela 4.1 apresenta comparativamente as principais funcionalidades das soluções existentes no mercado com as funcionalidades do BraPolar: Estado de ânimo (EA), Interação social (IS), Atividade física (AF), Atividade psicomotora (AP), Padrões de sono (PS), Medicação (M), Caraterísticas acústicas (CA), Assistência especializada (AE), Visão geral do status (VS), 
Tabela 4.1: Comparativa de funcionalidades com BraPolar

\begin{tabular}{llllllllll} 
Aplicativo & EA & IS & AF & AP & PS & M & CA & AE & VS \\
\hline State Mood Tracking & Sim & Sim & Sim & Não & Sim & Não & Não & Não & Sim \\
eMoods Bipolar & Sim & Não & Sim & Não & Não & Sim & Não & Não & Sim \\
BiAffect & Sim & Sim & Não & Não & Não & Não & Não & Não & Sim \\
MONARCA & Sim & Sim & Sim & Sim & Sim & Não & Sim & Não & Sim \\
Whats Up & Sim & Não & Não & Não & Não & Não & Não & Não & Sim \\
BraPolar & Sim & Sim & Sim & Sim & Sim & Sim & Sim & Sim & Sim
\end{tabular}

Conforme a tabela anterior, mesmo que as diversas soluções tenham certo grau de semelhança com o BraPolar, nenhuma inclui todas as funcionalidades propostas pelos especialistas. Além disso, encontramos que nenhuma das soluções utiliza o teste de dependência ao celular e a fenotipagem digital como alternativa de marcadores de status e traço de intervenção terapêutica não invasiva em conjunto com os SAA, itens que consideramos relevantes para detectar alterações precoces nos pacientes, antes que atinjam consequências funcionais extremas. Por outro lado, em algumas soluções apresentadas [18] [36] , a interação ativa dos pacientes com a aplicação é uma condição necessária para o mapeamento de seu estado, e isso pode causar algum desconforto nos pacientes no seu dia-dia.

Com isto em mente, prosseguimos com alguns aspectos éticos e riscos que devemos considerar em nossa pesquisa.

\section{4}

\section{Arquitetura e interfaces do BraPolar}

Nesta seção justificamos a necessidade de utilizar Firebase e como utilizamos em nosso projeto este serviço da Google. Por outra parte, comentaremos na seção 4.4 .1 a justificativa de utilizar Firebase para este projeto e na seção 4.4.2 comentamos aspectos sobre a interface do proposta para BraPolar.

\subsection{1}

\section{Armazenamento de dados em tempo real}

Em aplicativos móveis comumente é utilizado SQLite para armazenar dados pela simplicidade de gerenciamento que ele oferece. Em consonância, algumas pesquisas relacionadas a nosso escopo, a utilizam [17] [37]. Ainda assim, os dados são armazenados no dispositivo do usuário e os mesmos poderiam ser perdidos em caso de problemas com o dispositivo. Nesse sentido, obter informação em tempo real do estado dos pacientes foi um dos requisitos comentado pelos especialistas e a melhor opção encontrada a critério do 
desenvolvedor, foi Firebase. Esta solução, que é um produto gratuito da Google no Plano Spark ${ }^{1}$, possui uma tecnologia conhecida como Realtime Database, o qual consiste num banco de dados NoSQL hospedado na nuvem onde uma alternativa é armazenar o nome das classes em nodos e as instâncias em nodos filhos, conforme na figura 4.4).

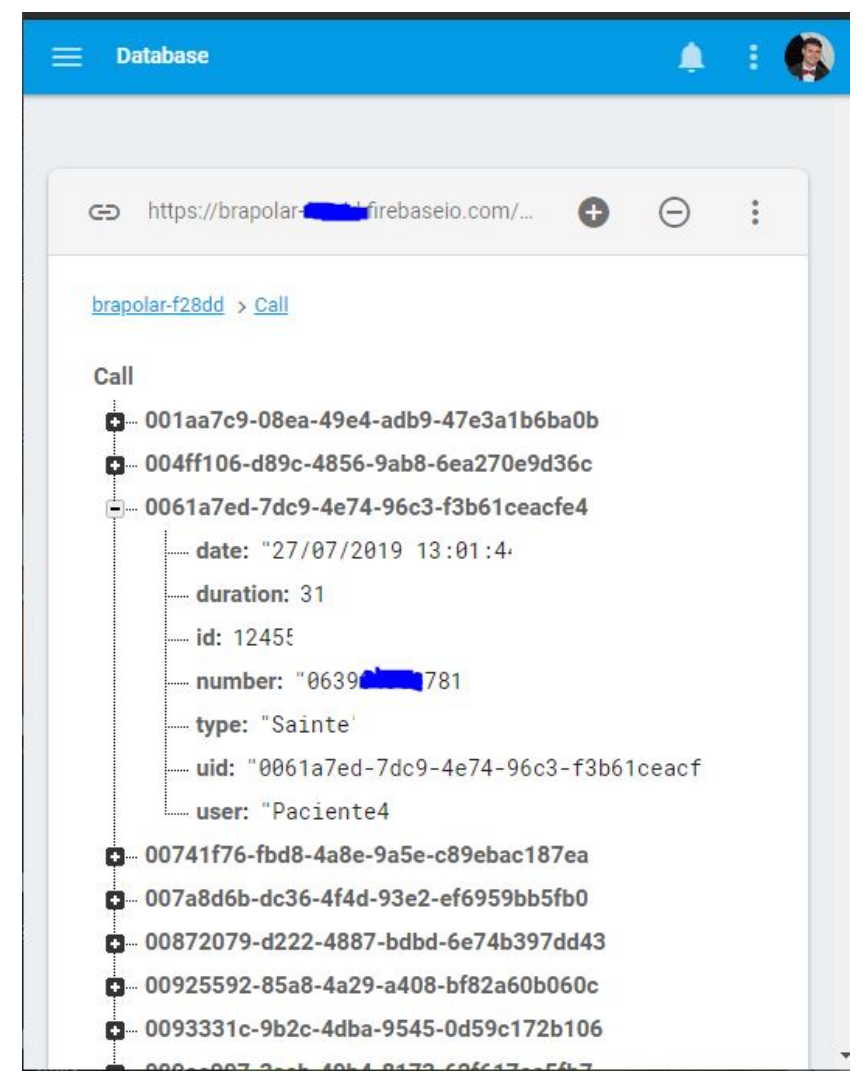

Figura 4.4: Instância em Firebase

Em Firebase, a transmissão de dados é gravada em uma referência do FirebaseDatabase e recuperada ao anexar um ouvinte assíncrono à referência. A grande vantagem de usar este modelo é que se o usuário perder a conexão de rede, o aplicativo continuará a funcionar porque o Firebase mantém a versão interna dos dados ativos em si. Em primeiro lugar, a gravação de dados ocorre localmente e, em seguida, o aplicativo sincroniza esses dados com os servidores remotos. Com isso em mente, para acelerar o processo de desenvolvimento, usamos o MBaaS (Mobile Backend As Service), que é um modelo que fornece aos desenvolvedores uma maneira de vincular seus aplicativos na nuvem [50] sem consumir consideráveis recursos locais. Outros projetos alcançaram resultados satisfatórios com o uso de uma arquitetura apoiada em Firebase [51] [52].

\footnotetext{
${ }^{1}$ https: //firebase.google.com/pricing/?hl=pt-br
} 
Outro diferencial de Firebase é a possibilidade de um dashboard onde é possível visualizar dados de interesse como os usuários ativos (figura 4.5) e a interação que tiveram com as telas do aplicativo (figura 4.6), itens estes que complementam e auxiliam aos pesquisadores durante o processo de desenvolvimento e posteriores análises de comportamento de usuário com as soluções propostas.

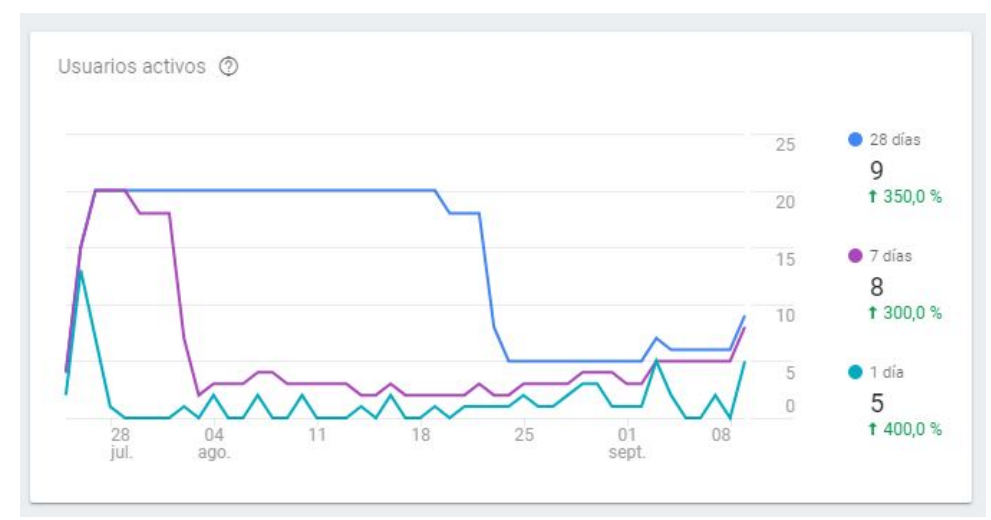

Figura 4.5: Usuários ativos durante o período de testes

\begin{tabular}{|c|c|c|c|}
\hline \multicolumn{3}{|c|}{ Interacción de los usuarios > Clase de pantalla } & \multirow[t]{2}{*}{$\checkmark$} \\
\hline Clase de pantalla & $\%$ del total & $\begin{array}{r}\text { Tiempo } \\
\text { medio }\end{array}$ & \\
\hline MainActivi...ecialista & $55,92 \%$ - & $21 \mathrm{~m} \ldots .6 \mathrm{~s}$ & - \\
\hline LoginActivity & $27,89 \%$ - & $10 \mathrm{~m} \ldots .8 \mathrm{~s}$ & - \\
\hline SocialActivity & $8,59 \% \uparrow 11 \ldots \%$ & $7 \mathrm{mi} . . .01 \mathrm{~s}$ & $\uparrow 2.710,7 \%$ \\
\hline MainActivity & $6,66 \%+93,1 \%$ & $1 \mathrm{mi} . .03 \mathrm{~s}$ & $\uparrow 501,7 \%$ \\
\hline MoodActivity & $0,53 \%$ & $0 \mathrm{mi} . .24 \mathrm{~s}$ & - \\
\hline PhysicalActivity & $0,19 \%$ & $0 \mathrm{mi} . .22 \mathrm{~s}$ & - \\
\hline SleepActivity & $0,13 \%$ & $0 \mathrm{mi} . .23 \mathrm{~s}$ & - \\
\hline MedicationActivity & $0,06 \%$. & $0 \mathrm{mi} \ldots 14 \mathrm{~s}$ & - \\
\hline
\end{tabular}

Figura 4.6: Interação dos usuários com o BraPolar durante os testes

Portanto, no desenvolvimento deste projeto, utilizamos Firebase, que usa o modelo MBaaS para criar aplicativos compatíveis com iOS, Android e Web. Este oferece sincronização automática de dados, serviços de autenticação, sistema de mensagens, armazenamento de arquivos e análise de machine learning. Questões de segurança no manuseio de dados foram abordadas no capítulo 3 e no Termo de consentimento livre e esclarecido no anexo 9.1.

Uma vez definida a abordagem com Firebase, na sequência apresentamos o diagrama de componentes, disponível na figura 4.7. Para este, tomamos como referência a arquitetura proposta por Shaikh in [53], o qual desenvolveu 
uma proposta com Firebase. Neste sentido, o servidor de nuvem é responsável por gerenciar o banco de dados através do Realtime Firebase Database do Google, armazenando e trocando informações. Por outro lado, tanto médicos quanto pacientes podem acessar o aplicativo fazendo login e compartilhando informações graças ao Firebase.

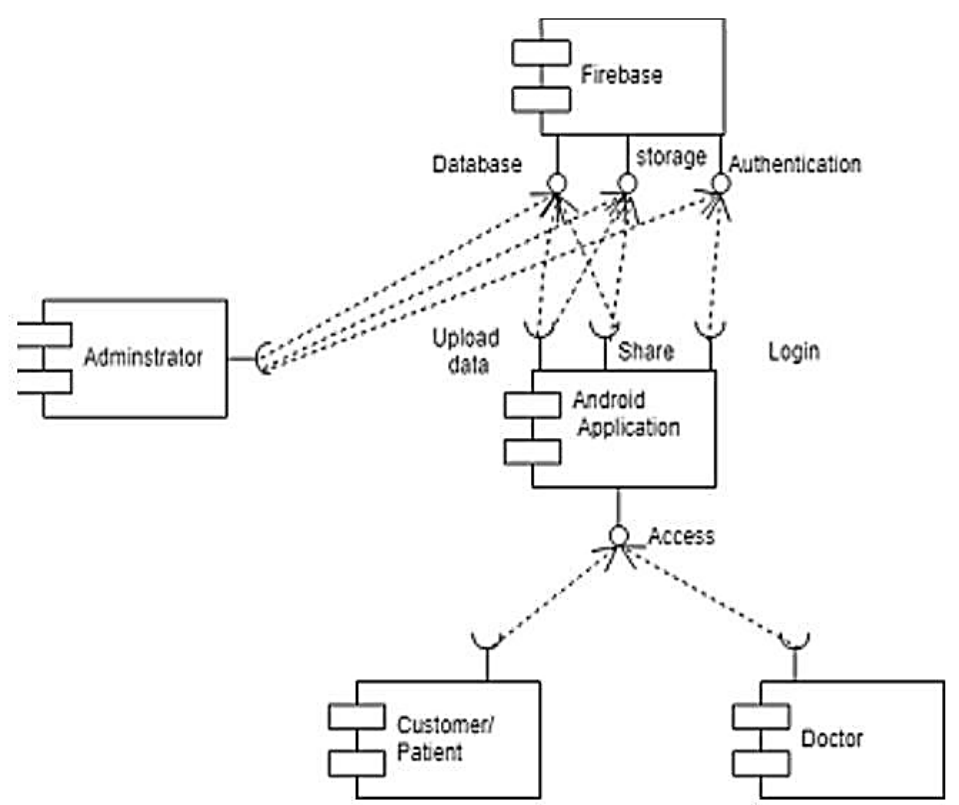

Figura 4.7: Diagrama de nível de componente para o sistema proposto (Shaikh et al. [53])

Na seção a seguir, comentaremos algumas das interfaces no BraPolar.

\subsection{2}

\section{Interfaces no BraPolar}

Para prosseguir com o desenvolvimento da solução nas fases iniciais, fizemos vários protótipos em papel sobre a interface de BraPolar conforme figura 4.8 . 

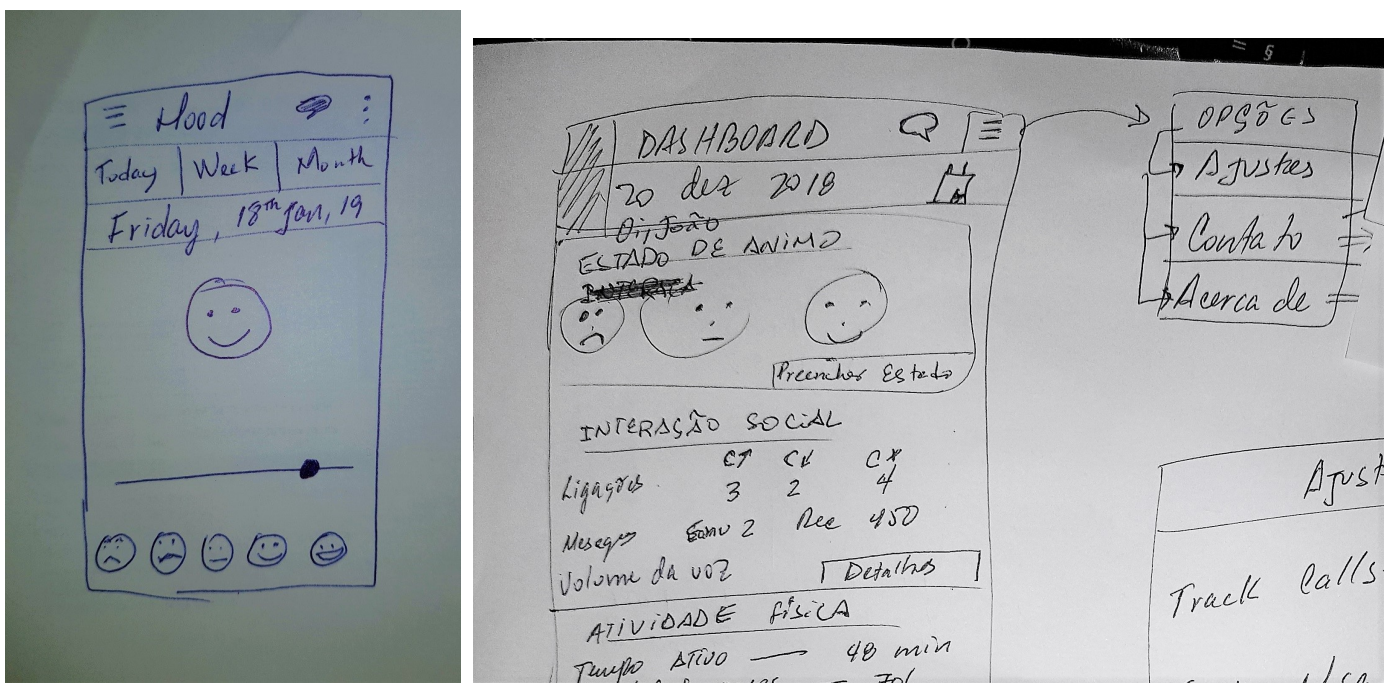

Figura 4.8: Exemplo de um protótipo de papel desenhado à mão da aplicação BraPolar - Estado de Ânimo (esquerda) e Dashboard (direita)

Via Trello, publicamos alguns protótipos de interface a ser adotada no BraPolar (figura 4.9). Os especialistas sugeriram algumas recomendações envolvendo necessidades, preferências e possíveis limitações específicas dos pacientes, como a simplicidade no design da aplicação e a menor quantidade possível de notificações.

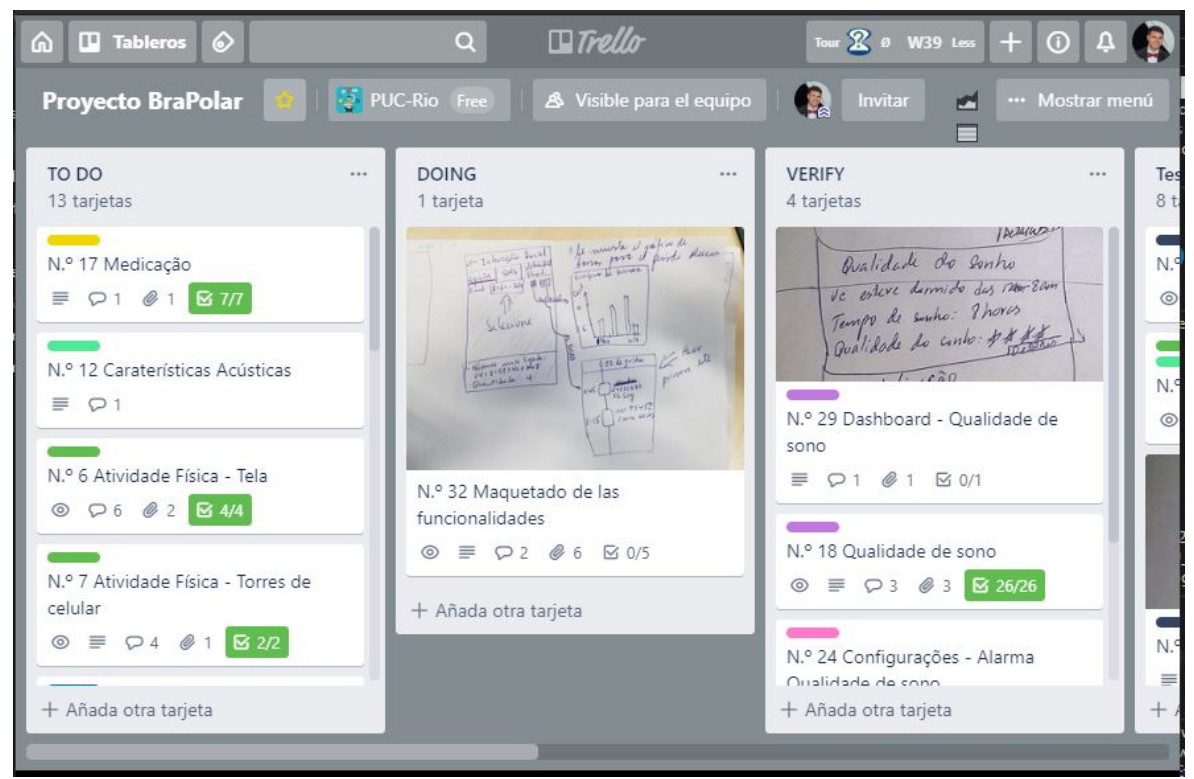

Figura 4.9: Tarefas do projeto organizadas no Trello

Para não sobrecarregar o dispositivo móvel, optamos por uma interface mais simplista, utilizando componentes nativos de Android. Neste sentido, consideramos alguns recursos de aplicativos disponíveis na Play Store citados nos estudos relacionados [16] [17] [36] [37]. 
Como um exemplo, a figura 4.10 apresenta as interfaces das funcionalidades de humor e interação social disponíveis no BraPolar. Como parte da função "Estado de ânimo", o aplicativo mostra um calendário em que o paciente seleciona uma opção no celular que representa como ele se sente em um determinado momento (4.10-esquerda). Como parte do recurso "Visão geral do status" (dashboard), o aplicativo mostra um resumo dos parâmetros usados ao longo do tempo (4.10-direita).

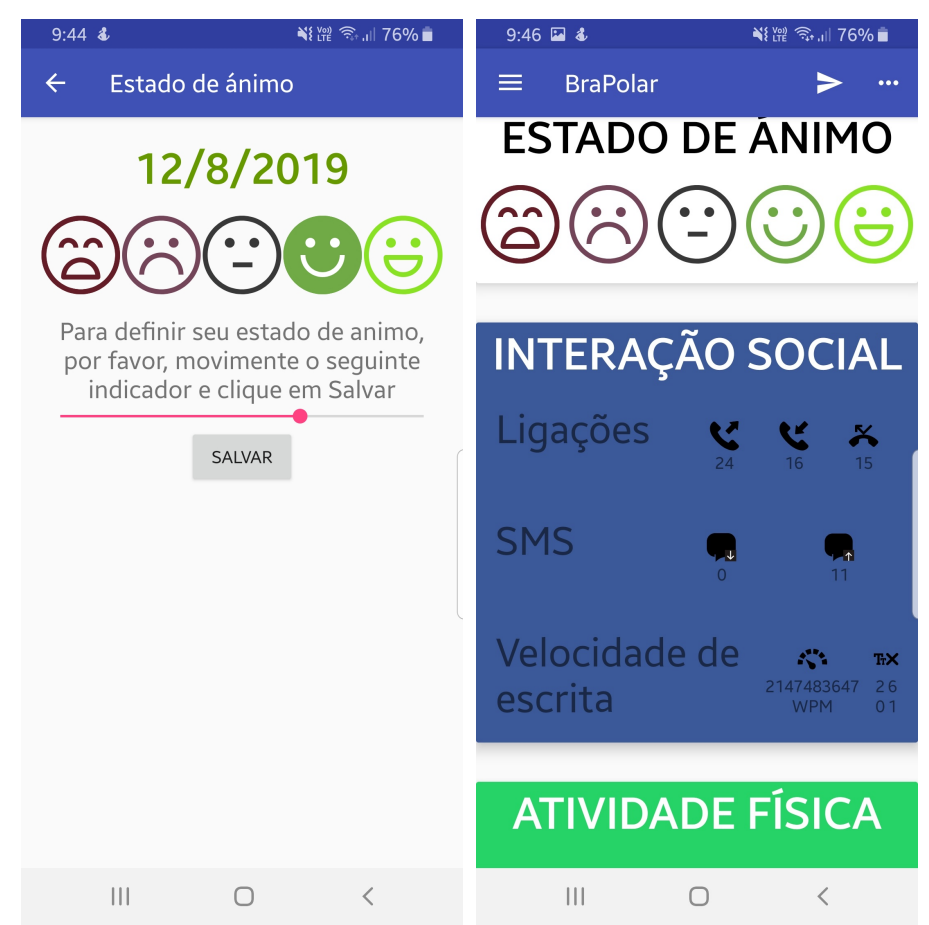

Figura 4.10: Exemplos de funcionalidades de interface de "Estado de ânimo" (esquerda) e "Dashboard" (direita) no BraPolar

Por outra parte, desenvolvemos um teclado personalizado com o objetivo de capturar a velocidade de escrita com que o participante digita no seu dispositivo móvel conforme figura 4.11. 


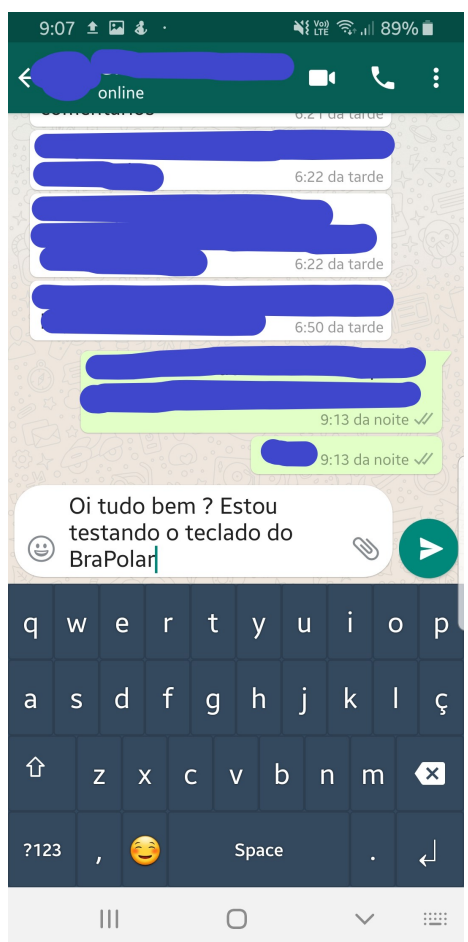

Figura 4.11: Usuário usando o teclado do BraPolar em WhatsApp

Considerando que todas as pessoas digitam com uma velocidade diferente, fizemos uma funcionalidade adicional: Calibração.

O principal motivo de capturar a velocidade de digitação é porque os pacientes, ao estar em estado maniaco, tendem a escrever de forma mais rápida mas não necessariamente corretamente. Entretanto, as pessoas quando estão em fase depressiva, a tendencia é escrever de forma mais devagar, corrigindo em várias ocasiões o texto digitado.

Para isto, em primeiro lugar definimos a funcionalidade Calibração (4.12esquerda) onde o usuário irá digitar o texto que aparece na tela. Na medida que o usuário digite o caractere certo, este mudará de cor e poderá prosseguir com a seguinte palavra do texto, caractere por caractere. 


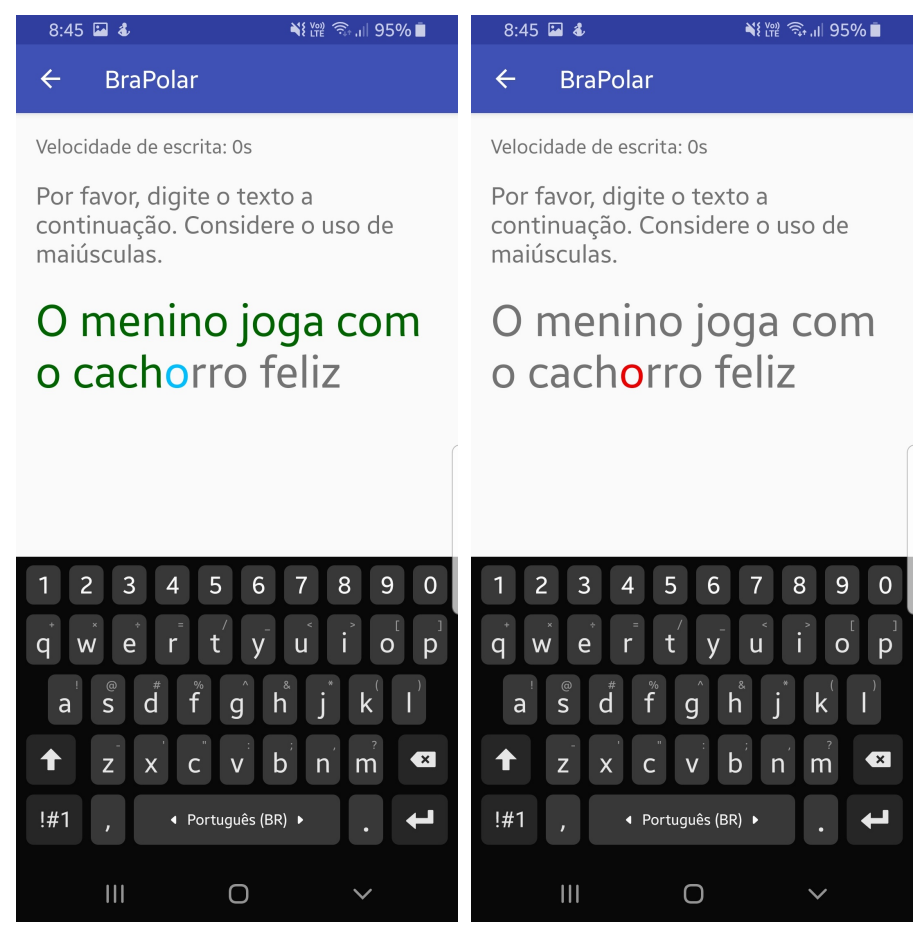

Figura 4.12: Usuário interagindo com a funcionalidade Calibração, digitação correta (esquerda) e incorreta (direita) no BraPolar

Após isso, o usuário pode utilizar o teclado do BraPolar nos diferentes aplicativos do seu celular. Este irá obter a velocidade de digitação em todos os espaços na tela onde o usuário precise escrever. Cabe notar que esta funcionalidade não armazena nenhum dado do participante (cartões de credito, senhas, etc), só a velocidade com que ele digita.

\section{5}

\section{Diferenças entre BraPolar modo paciente e especialista}

Considerando que temos dois tipos de usuários interagindo com o aplicativo, existem diferenças entre eles conforme a figura 4.13. No caso do modo paciente (figura 4.13-esquerda), o usuário poderá estabelecer todas as funcionalidades descritas na seção 4.2 deste capítulo.

No modo especialista (figura 4.13-direita), este poderá visualizar no seu dashboard o status geral dos pacientes que ele atende e, ao clicar em algum deles, poderá navegar nos perfis dos pacientes (figura 4.13-esquerda) além de ter a opção de modificar a medicação para o paciente. 

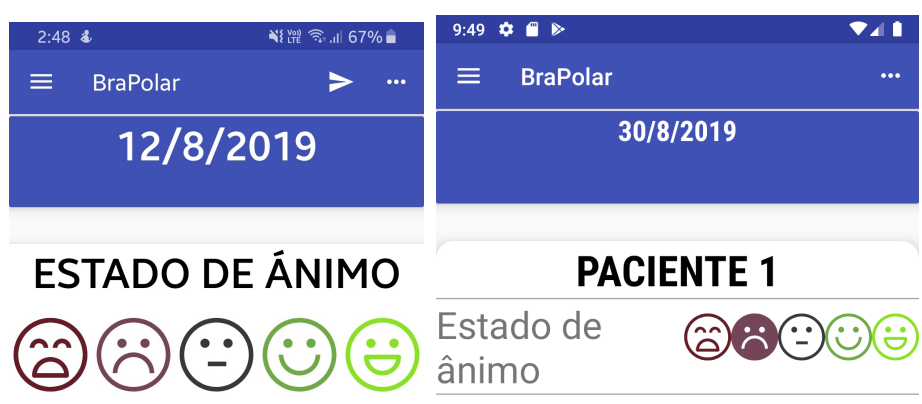

\section{PACIENTE 1}

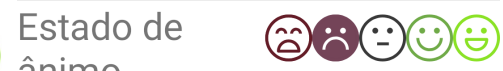

ânimo
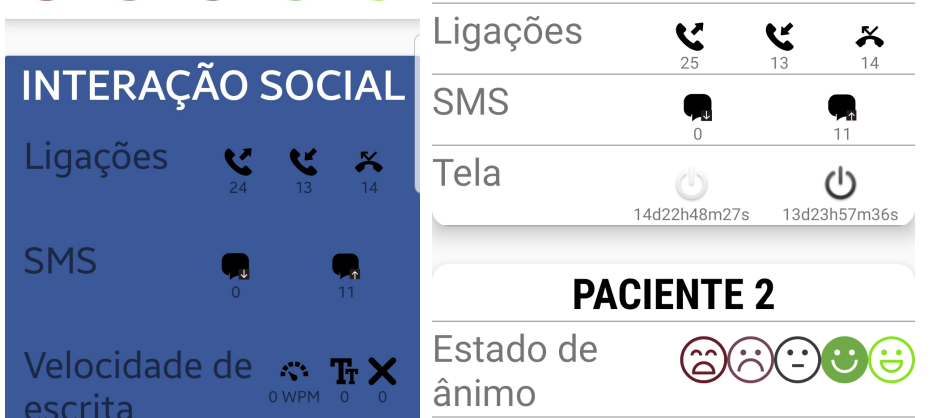

Estado de $\quad$ के) $\odot=\theta:$ ânimo
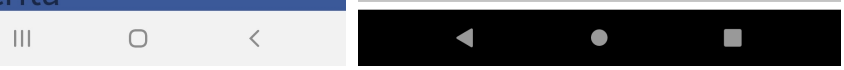

Figura 4.13: Modos do BraPolar: paciente e especialista

Em consonância, ao clicar em Interação Social (4.14), tanto o especialista quanto o paciente, poderá ver os detalhes de cada uma das categorias e os itens que a contem.

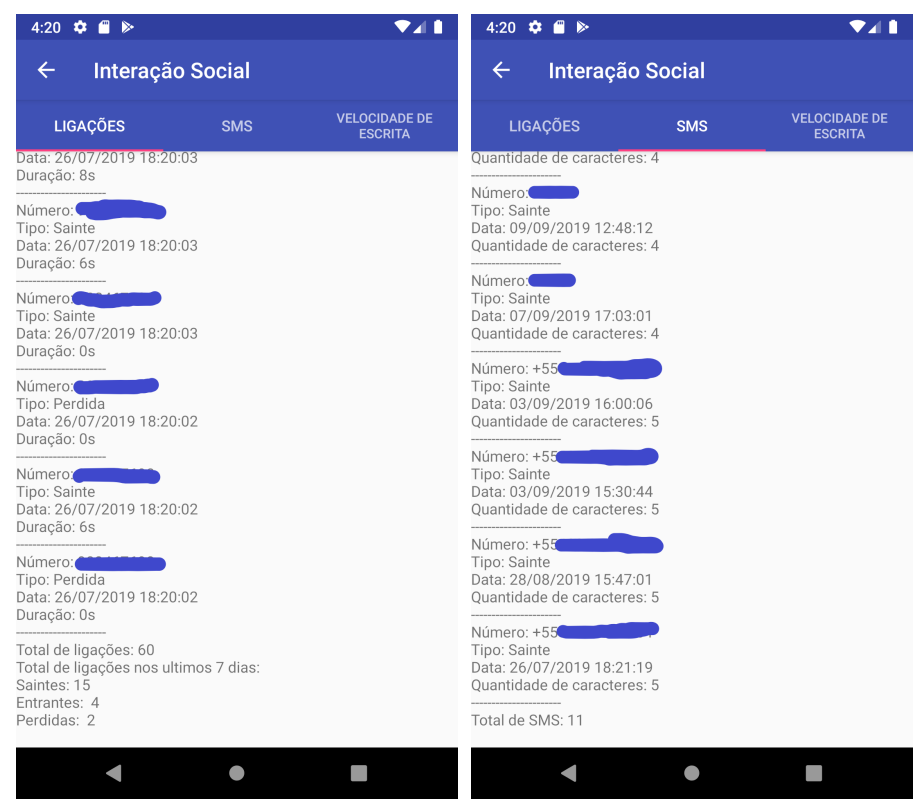

Figura 4.14: Funções na categoria Interação Social

Nos seguintes capítulos, comentamos as avaliações realizadas separadamente nestes dois modos: paciente e especialista. 


\section{5}

\section{Avaliação do modo paciente}

Neste capítulo apresentamos o primeiro estudo realizado com o BraPolar, o qual consiste na avaliação com usuários no modo paciente. Este estudo foi dividido em duas avaliações: teste de dependência ao celular e teste de usabilidade.

Inicialmente, definimos na seção 5.1 os participantes em ambas avaliações. Na seção 5.2 apresentamos o teste de dependência ao celular, incluindo a descrição da necessidade de aplicar o teste e seu procedimento. Após, na seção 5.3 apresentamos os resultados obtidos nesta avaliação. Por outra parte, na seção 5.4, apresentamos os aspectos teóricos sob nossa avaliação de usabilidade, o processo de planejamento e execução do mesmo. Ao concluir, apresentamos a análise de resultados na seção 5.5.

Finalmente, discutimos as principais observações realizadas durante a execução dos testes na seção 5.6, comentamos a publicação realizada ao longo da pesquisa na seção 5.7 e, pelas características deste trabalho (monitoramento remoto), descrevemos na seção 5.8 o procedimento da coleta dos dados que utilizaremos no segundo estudo do BraPolar, apresentado no capítulo seguinte.

\section{1}

\section{Participantes das avaliações}

Inicialmente, decidimos realizar os testes em pacientes com TAB, mas precisávamos da aprovação prévia de um Comitê de Ética de Pesquisa e de outros órgãos governamentais para realizar experimentos com seres humanos, um processo que levaria alguns meses, por isso decidimos realizar este estudo piloto com sujeitos não bipolares, para os quais o processo de aprovação é mais simples. Para isto, consultamos os especialistas para incluir pessoas sãs na faixa etária aproximada de nossos futuros usuários-alvo e decidimos incluir a mesma quantidade de homens e mulheres para nossa pesquisa.

Ressalvado este tópico, selecionamos seis usuários (3 mulheres e 3 homens) com faixa etária de 26 a 54 anos que participaram da avaliação. Estimase que essa quantidade de usuários seja suficiente [54] para realizar testes de usabilidade em pesquisas qualitativas. Os participantes foram identificados aqui como P1 a P6. Normas éticas e legais foram seguidas durante o desenvolvimento deste estudo conforme seção 3.4. Na tabela 5.1 apresentamos a caracterização dos participantes. 
Tabela 5.1: Caracterização dos participantes do estudo

\begin{tabular}{lll} 
Participante & Sexo & Idade \\
\hline P1 & M & 53 \\
P2 & F & 26 \\
P3 & F & 54 \\
P4 & F & 35 \\
P5 & M & 51 \\
P6 & M & 47
\end{tabular}

\section{2}

\section{Teste de dependência ao celular}

Consideramos necessário realizar o teste de dependência ao celular para ser utilizado em um posterior estudo com especialistas para que estes se auxiliem na hora de realizar a avaliação dos participantes. Para isto, propomos aos especialistas incorporar um teste de dependência ao celular para melhorar a análise da fenotipagem digital e acharam que conhecer como as pessoas comumente interagem com seus dispositivos moveis poderia ser relevante na hora de avaliá-las. Para conduzir este estudo, nas seções seguintes detalharemos o processo de avaliação.

\subsection{1}

\section{Planejamento}

A fase de planejamento constitui o primeiro passo ao realizar qualquer avaliação. Nesta seção, comentamos o processo seguido para realizar o teste de dependência com os participantes do estudo. Em primeiro lugar definimos o objetivo do teste, os participantes, e finalmente criamos os formulários necessários para a avaliação.

\section{Objetivo}

Considerando que cada participante possui distinto grau de dependência ao celular, realizamos esta avaliação com o objetivo de identificar quão dependentes são ao celular os participantes.

\section{Participantes do estudo}

Os participantes para este estudo foram definidos na seção 5.1 deste capítulo e foram os mesmos para ambos estudos, comentado previamente neste capítulo. 


\section{Instrumentos de avaliação}

Uma vez definidos os participantes, prosseguimos à criação dos formulários do teste.

Para isto, utilizamos o teste de dependência ao celular [32] e após traduzi-lo ao português (anexo 9.2), fizemos o mesmo no Google Form e realizamos o Termo de Consentimento Livre e Esclarecido (TLCE) disponível no anexo 9.1. Na primeira tela do formulário em Google Form encontra-se o TLCE (anexo 9.1), condição necessária para prosseguir a pesquisa.

Por outra parte, o teste de dependência ao celular é composto por 2 seções: perguntas gerais (22 perguntas) e questionário de nomofobia (19 perguntas). Para nossa pesquisa, o total consta de 15 páginas em Google Form nas quais colocamos as 41 perguntas. Estas, são avaliadas numa escala de 1 até 7 , sendo 1 'discordo totalmente' e 7 'concordo totalmente' sobre o quanto concorda ou discorda com afirmações, conforme a figura 5.1.

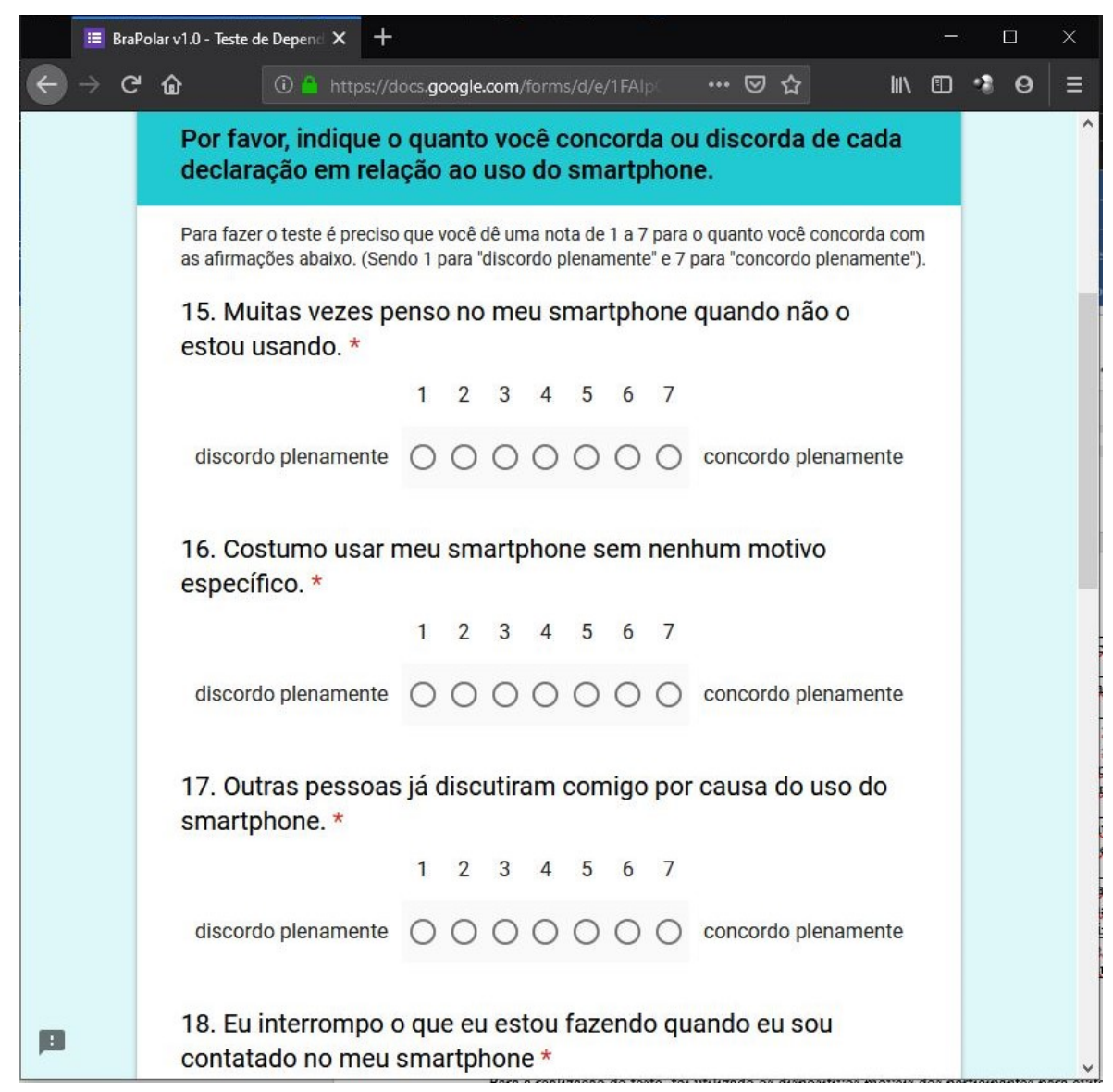

Figura 5.1: Formulário de Dependência ao Celular em Google Form

Ao finalizar o teste, o resultado é adicionado e avaliado numa escala de 0 a 140, conforme comentado no início deste capítulo e representado na figura 2.1. 


\section{2 .2}

\section{Execução}

Para prosseguir com a avaliação de dependência ao celular, enviamos o formulário de dependência ao celular (anexo 9.2) aos participantes via e-mail. No e-mail, enviamos o link de acesso ao Google Form e comentamos que se preferir, poderiam fazer o teste presencial. Todos os participantes preferiram prosseguir a avaliação online.

A execução do teste demorou aproximadamente 20 minutos por cada participante. Cada um, realizou o teste de forma remota e ao concluir, o pesquisador recebeu uma notificação via e-mail de Google Form, informando que o participante tinha concluído o preenchimento do formulário. No Google Form estavam disponíveis as indicações para a realização do teste e, pela simplicidade do mesmo, não recebemos dúvidas por parte dos participantes durante a execução do teste.

Após todos os participantes concluírem, abrimos o arquivo de resposta de associado ao Google Form e prosseguimos a processar os resultados de cada, descritos na seção a continuação.

\section{3}

\section{Resultados do teste de dependência ao celular}

Com o intuito de atender o objetivo traçado na seção 5.2.1, obtivemos uma caracterização do grau de dependência ao celular de cada um dos participantes de nosso estudo, apresentado na tabela 5.2.

Tabela 5.2: Resultado do teste de dependência ao celular

\begin{tabular}{lllll} 
Participante & Sexo & Idade & Pontuação & Nomofobia \\
\hline P1 & M & 53 & 80 & Moderada \\
P2 & F & 26 & 35 & Leve \\
P3 & F & 54 & 106 & Severa \\
P4 & F & 35 & 68 & Moderada \\
P5 & M & 51 & 41 & Leve \\
P6 & M & 47 & 92 & Moderada
\end{tabular}

Nos resultados, identificamos que dois participantes (P2, P5) foram categorizados como levemente dependentes, três com dependência moderada (P1, P4, P6) e apenas um participante com dependência severa (P3). Utilizamos esses resultados para identificar em um posterior estudo se o grau de dependência do celular é um fator que pode influenciar a usabilidade do aplicativo BraPolar, descrita na seção a seguir. 
Outra abordagem que obtivemos com o teste, considerando que cada Pergunta [Pergunta1...Pergunta40] pode ser atribuído um peso [1...7] e cada participante [Participante1...Participante6] forneceu um peso diferente para cada pergunta respondida, agrupamos as perguntas e somamos o total respondido por cada usuário onde a Pergunta(n) pode ter um valor máximo de 42 pontos (6 usuários x peso 7 da pergunta), organizado de forma decrescente. $\mathrm{O}$ resultado anterior, é representado na tabela 5.3, a seguir:

Tabela 5.3: Perguntas que os participantes atribuíram maior peso

\begin{tabular}{ll} 
Pergunta & SPP \\
\hline Pergunta 10 & 35 \\
Pergunta 2 & 33 \\
Pergunta 9 & 30 \\
Pergunta 12 & 29 \\
Pergunta 14 & 28 \\
Pergunta 1 & 28 \\
Pergunta 4 & 26 \\
Pergunta 7 & 25
\end{tabular}

Onde:

- SPP - É a soma dos pesos das respostas de todos os participantes para cada pergunta.

Pergunta 10 - Eu me sentiria ansioso porque não conseguia me comunicar instantaneamente com minha família e / ou amigos.

- Pergunta 2 - Eu ficaria chateado se eu não pudesse procurar informações no meu smartphone quando eu quisesse fazê-lo.

- Pergunta 9 - Se eu não conseguisse checar meu smartphone por um tempo, eu sentiria o desejo de verificá-lo.

- Pergunta 12 - Eu me sentiria nervoso porque não conseguiria receber mensagens de texto e chamadas.

- Pergunta 14 - Eu ficaria nervoso porque não saberia se alguém tentou me contatar.

- Pergunta 1 - Eu me sentiria desconfortável sem acesso constante a informações através do meu smartphone.

- Pergunta 4 - Eu ficaria chateado se eu não pudesse usar meu smartphone e / ou suas capacidades quando eu quisesse fazê-lo.

- Pergunta 7 - Se eu não tivesse um sinal de dados ou não conseguisse me conectar ao Wi-Fi, verificaria constantemente se eu tinha um sinal ou se poderia encontrar uma rede $\mathrm{Wi}-\mathrm{Fi}$. 
Os resultados anteriores nos indicam que mesmo que os usuários possuam distinto grau de dependência ao celular, todos (exceto P4 que indicou peso 3 na pergunta 10), apresentaram a necessidade ansiosa de se comunicar com seus familiares (peso 6 ou 7). A segunda pergunta com maior pontuação foi relativa a procurar informação na hora que eles quiserem. Concluímos então que poderíamos identificar com o teste de nomofobia, além do grau de dependência ao celular, possíveis manias como a ansiedade. Item este que será avaliado em posteriores estudos com uma população mais abrangente desde a área de psicologia.

Ao concluir o teste de dependência ao celular, prosseguimos a realizar o teste de usabilidade, apresentado na seguinte seção.

\section{4}

\section{Teste de usabilidade}

Boa parte dos métodos de avaliação de interface baseiam-se em engenharia cognitiva. O objetivo destes é a criação de sistemas computacionais que exijam do usuário uma carga cognitiva baixa para serem utilizados, em outras palavras, que sejam fáceis de aprender, de usar e que sejam agradáveis para os usuários. Ao mensurar estas características e propriedades do sistema com a finalidade de verificar o nível de aceitação da interface pelo usuário, estaremos verificando a usabilidade desta interface [55] ou bem a percepção que os usuários têm com a interface apresentada.

Uma forma de descobrir problemas de usabilidade num sistema, é através de avaliações de usabilidade. Medir a percepção que os usuários têm de uma interface envolve não apenas medir questões relativas às funcionalidades de um software, mas também a facilidade de seu uso como ferramenta de trabalho, tendo como um dos principais desafios a redução do tempo necessário para aprendermos a utilizar o sistema [55] [56].

Com o intuito de avaliar as funcionalidades do BraPolar no modo do paciente, seguimos o processo de avaliação de usabilidade sugerido por Costa [46]. Este autor recomenda realizar o teste em quatro etapas: planejamento, execução, coleção e análise (figura 5.2).

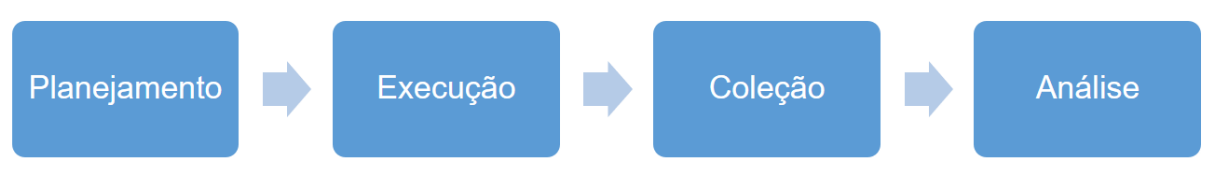

Figura 5.2: Etapas do teste de usabilidade 
Para conduzir este estudo, na fase de planejamento (seção 5.4.1) definimos os objetivos, atividades e formulários a serem utilizados. Após, na etapa de execução (seção 5.4.2) comentamos como preparamos o ambiente e como realizamos a avaliação. É valido mencionar que decidimos fundir as etapas de Coleção de problemas repetidos e Análise dos resultados na seção Apresentação de Resultados (seção 5.5) onde discutimos os principais resultados obtidos após a execução do teste.

\subsection{1}

\section{Planejamento}

Considerando a relevância e nosso intuito de saber o que os participantes acham de BraPolar, visamos realizar um estudo exploratório direcionado a conhecer qual é a percepção que os participantes têm do aplicativo

\section{BraPolar.}

\section{Definição da lista de atividades}

Para responder a esse objetivo, visamos identificar melhor a experiência de interação do participante com o aplicativo em conjunto com a execução das seguintes tarefas:

T1: Instalar o aplicativo BraPolar.

T2: Indicar no BraPolar qual é seu estado de humor a qualquer momento.

T3: Estabelecer que o BraPolar capture suas interações com o celular durante o teste.

T4: Configurar o teclado BraPolar e enviar um email usando outro aplicativo fora do BraPolar.

T5: Fazer uma ligação e enviar um SMS para verificar se o BraPolar interrompe a interação com outros aplicativos instalados em seu telefone.

T6: Estabelecer o número de horas que o usuário dormiu na última noite.

T7: Visualizar os dados coletados.

Deve-se notar que, para esta fase, adotamos o Questionário de Satisfação de Interação do Usuário (QUIS em inglês) (anexo 9.5) o qual constitui uma ferramenta que inclui um conjunto de perguntas para estimar a satisfação subjetiva dos usuários com foco em aspectos específicos da interface humanocomputador [32]. O QUIS foi adaptado ao nosso contexto, incluindo perguntas sobre os aspectos mencionados acima para identificar a usabilidade do usuário e a experiência do usuário com o BraPolar.

As tarefas mencionadas acima (anexo 9.5), compostas por várias perguntas, as quais foram respondidas numa escala de 1 até 5 onde 1 é a menor classificação e 5 a maior, permitiu coletar informações subjetivas dos participantes 
tais como: reação do aplicativo, tela, terminologia e informações, aprendizado, dados coletados e capacidade do sistema.

A seguir comentamos cada um dos aspectos anteriormente mencionados:

- Reação ao aplicativo: nesta atividade, composta por um conjunto de perguntas, o participante comentou se usar o aplicativo foi fácil ou difícil na execução das tarefas solicitadas.

- Tela do aplicativo: avaliamos a percepção dos usuários com respeito às cores e o tamanho das fontes usadas no aplicativo, a quantidade de informações exibidas por cada tela e a transição entre as telas do aplicativos.

- Terminologia e informações da aplicação: foi avaliado como as informações no aplicativo são apresentadas ao usuário. As informações ou mensagens de erro geradas após uma interação foram examinadas, bem como os elementos de iconografia que representam as tarefas que o usuário pode executar no aplicativo.

- Aprendizado e utilização: foi avaliado o grau de dificuldade que tiveram os usuários ao interagir com a aplicação e na execução de tarefas. Neste ponto, avaliamos a interação com o teclado personalizado do BraPolar e se o aplicativo interfere na interação do usuário com outros aplicativos instalados no telefone.

- Dados coletados: observamos a reação dos participantes ao visualizar seus dados coletados no intervalo de avaliação e a facilidade do aplicativo ao enviar as informações para a equipe de pesquisa.

- Capacidade do sistema: identificamos a percepção dos participantes sobre como o aplicativo funciona e como é fácil recuperar erros.

Considerando o conjunto de tarefas comentadas no começo desta seção, e as categorias apresentadas no parágrafo acima, durante a execução das tarefas, os participantes tiveram que interagir com o aplicativo e nos permitiu avaliar as categorias acima mencionadas como um todo. Como exemplo disto, apresentamos a seguir a Tarefa 2:

- Tarefa 2: Indicar no BraPolar qual o seu estado de humor a qualquer momento Reação com o aplicativo: ao ter que deslizar o slider para poder definir seu estado de ânimo. Tela do aplicativo: teve que interagir com o aplicativo e avaliar as fontes e cores em que foi apresentada a informação. Terminologia e informações da aplicação: compreensão do usuário com as instruções ao definir seu estado de ânimo. Aprendizado e utilização: o participante teve que definir seu Estado de ânimo mais de uma vez. Dados coletados: qual foi a reação do usuário ao visualizar o estado de ânimo salvo? Capacidade do sistema: percepção do usuário caso ele tenha saído por erro da funcionalidade. 


\section{Definição dos perfis e seleção dos usuários}

Os participantes desta avaliação são os mesmos descritos na seção 5.1. Os 6 participantes estiveram de acordo em prosseguir com este teste.

\section{Construção dos formulários}

Nesta etapa, elaboramos os formulários a serem utilizados durante este teste. Considerando que o Formulário de Consentimento Livre e Esclarecido disponível no anexo 9.1 foi previsto para ambos testes, no qual os participantes aceitaram durante a execução do teste de dependência ao celular (seção 5.2), prosseguimos a elaborar os outros formulários para o teste de usabilidade. Em primeiro lugar, fizemos as orientações gerais ao participante (anexo 9.3) onde explicamos detalhadamente como iríamos conduzir todo o processo de pesquisa e as atividades a serem desenvolvidas (anexo 9.4), comentadas na seção 5.4.1. Finalmente fizemos o QUIS, disponível no anexo 9.5.

\section{4 .2}

\section{Execução}

A fase de execução é composta por duas etapas: preparação do ambiente e realização do teste. Na seção 5.4.1, descrevemos como planejamos o teste para não ter imprevistos durante a seguinte fase. Nesta fase de execução, comentaremos como procedemos durante a realização do teste com os participantes.

\section{Preparação do ambiente de teste}

A preparação do local para realizar o teste constitui um aspecto fundamental para não ter distorção nos dados e expor aos participantes a um ambiente padronizado para obter resultados mais confiáveis. Com esta premissa, decidimos preparar o local RDC523 no Departamento de Informática da PUCRio para receber aos participantes (figura 5.3). No dia do teste preparamos o ambiente com a seguinte instrumentação:

- Caneta esferográfica preta.

- Termo de Consentimento Livre Esclarecido (anexo 9.1) impresso.

- Roteiro do teste com as orientações (anexo 9.3) impresso.

- Atividades a ser realizadas (anexo 9.4) impresso.

- Questionário pós-teste (anexo 9.5) impresso.

Embora os participantes tiveram lido e aceito o Termo de Consentimento Livre Esclarecido no estudo anterior, decidimos trazer o documento impresso para lê-lo mais uma vez e deixar claro o direito e liberdade de abandonar o estudo quando quiser. 


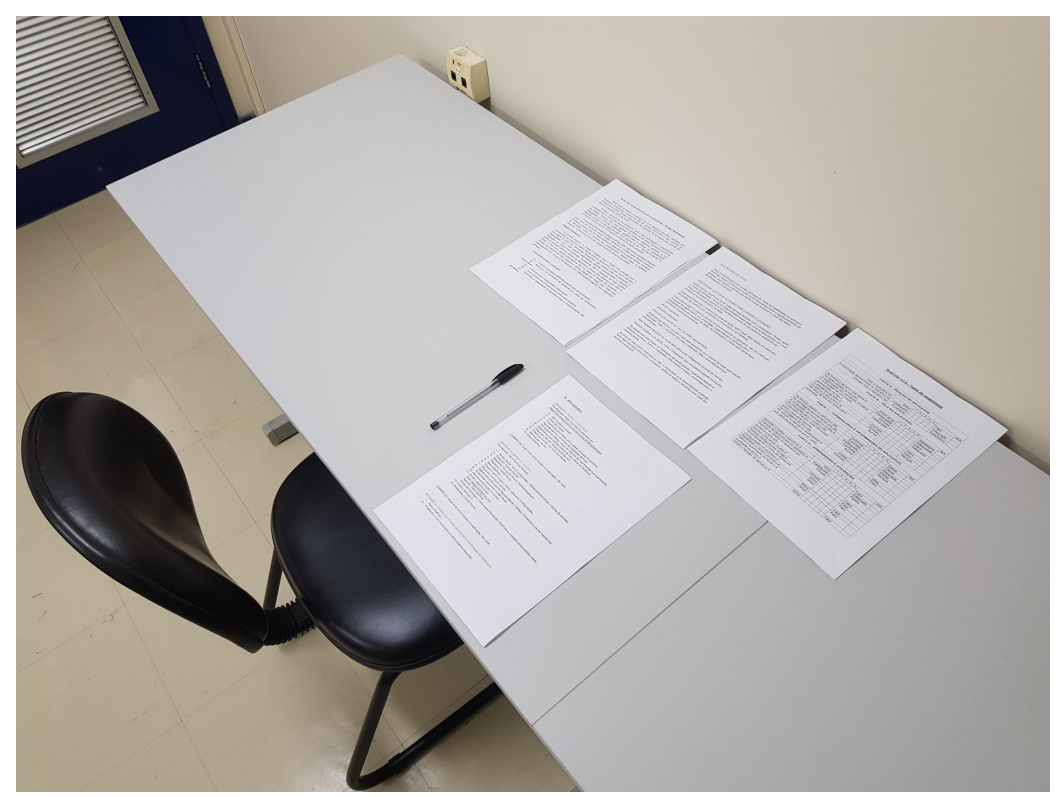

Figura 5.3: Preparação do ambiente do teste

Como a realização do teste esteve prevista a ser realizada usando a rede Wi-Fi, criamos um Access Point (AP) para fornecer ao usuário conexão a internet durante a execução da avaliação. Entretanto, considerando que durante a execução do teste a rede Wi-Fi poderia falhar, disponibilizamos um AP alternativo usando os dados móveis do autor do trabalho com o intuito de não interromper o processo.

Foi combinado via e-mail o melhor dia/horário para ser realizado o teste e duas horas antes à execução do mesmo, verificamos que todos os artefatos mencionados anteriormente estiveram disponíveis e operáveis para evitar distrações durante o percurso da avaliação.

\section{Realização do teste}

Para a execução do teste, foram utilizados os dispositivos móveis dos participantes e evitar problemas de adaptação se fosse usado outro dispositivo ao qual não estava habituado. Ressalvadas as obervações e preparado o ambiente conforme descrito na seção anterior, procedemos a executar o teste com os participantes.

Após a chegada do participante, foi entregue o TCLE (anexo 9.1) e assinado. Depois, procedemos a explicar o roteiro do teste (anexo 9.3) e as atividades (anexo 9.4). Também conectamos o celular do participante ao Access Point criado com antecedência, verificando o correto funcionamento e disponibilidade da rede. Finalmente, realizamos as tarefas propostas (anexo 9.4), descritas a seguir:

Em primeiro lugar descrevemos aos participantes o seguinte cenário: 
Você é um paciente e precisa deixar gravada toda a informação possivel das suas atividades no dia-dia. A continuação você irá receber um conjunto de cenários e realizará um conjunto de tarefas. Muito importante: fale em voz alta o que estiver pensando durante toda a avaliação.

\section{T1: Instalar o aplicativo BraPolar}

O moderador lhe enviou um link onde você precisa descarregar o aplicativo BraPolar para prosseguir com o monitoramento das suas atividades. Faça o download do aplicativo e forneça as permissões necessárias conforme vão aparecer na tela do seu celular. Ao finalizar, reinicie seu dispositivo móvel.

T2: Indicar no BraPolar qual o seu estado de humor ao visualizar a notificação de estado.

Como você acordou animicamente hoje? No BraPolar você consegue definir seu estado de ânimo, o qual é enviado automaticamente aos especialistas que poderão lhe auxiliar se for necessário! Abra o BraPolar e clique na seção Estado de Ânimo, após, movimente o slider e salve seu estado atual. Considere que em qualquer momento o aplicativo poderá lhe perguntar como está se sentindo.

T3: Estabelecer que o BraPolar capture suas interações com o celular durante o teste.

Considerando a velocidade que você digita, o BraPolar poderá capturar essa informação e ajudar os especialistas a detectar as flutuações na rapidez da escrita. Para configurar isto, você vai fazer o seguinte:

1- No seu celular, vai à Configuração > Gerenciamento Geral > Idioma de entrada.

2- Clique em Teclado Padrão.

3- Selecione: Português (Brasil) BraPolarKeyboard.

T4: Configurar o teclado BraPolar e enviar um e-mail usando outro aplicativo fora do BraPolar.

Agora precisamos configurar o teclado BraPolar e enviar um e-mail. Para isto, abra o BraPolar, acesse Configurações / Calibrar teclado e siga as instruções da tela.

Ao finalizar, abra seu e-mail e envie o seguinte: Para: amondejar@inf.pucrio.br, Assunto: Teste BraPolar Corpo da mensagem: Estou experimentando o BraPolar e o teclado personalizado deste.

T5: Fazer uma ligação e enviar um SMS para verificar se o BraPolar interrompe a interação com outros aplicativos instalados em seu telefone.

Opa! Você esqueceu de ligar para alguém próximo de você! Ligue agora mesmo para o número 21-965XXXXXX. Se a pessoa não te responder, envie 
um SMS a esse mesmo número com o texto 'Testando BraPolar'.

T6: Estabelecer o número de horas que o usuário dormiu na última noite.

Você conseguir dormir a noite toda desde as 23:00 de ontem até 07:00 hoje e acordou cheio de energia. Abra BraPolar e defina na funcionalidade Sono, esta informação.

\section{T7: Visualizar os dados coletados.}

Você está curioso por saber o que aconteceu durante toda a avaliação? Abra o BraPolar e navegue pelas funcionalidades apresentadas na tela inicial. Ao concluir, avise ao moderador.

Ao finalizar, aplicamos o questionário pos-teste (anexo 9.5).

É válido mencionar que o processo todo durou em média 35 minutos por cada participante. Solicitamos a eles que falassem em voz alta para identificar melhor a experiência de interação com o aplicativo, e obtivemos um conjunto de resultados que ressaltamos em seções posteriores deste capítulo.

\section{5 \\ Resultados do teste de usabilidade}

Na seção 5.4 realizamos o teste de usabilidade e na tabela 5.2 apresentamos o resultado do mesmo, onde os participantes responderam através do QUIS sua percepção do BraPolar. Nesta seção comentaremos os principais resultados obtidos durante o teste.

Coleção e redução de problemas repetidos. Nesta etapa, realizamos a redução dos problemas repetidos (problemas encontrados por mais de um participante).

As dificuldades em comum dos participantes durante o teste foi em relação à terminologia utilizada, em particular com o vocabulário técnico médico utilizado. Outra questão a ter em conta é que, embora simples, o aplicativo não era muito atrativo para eles, então, lhes comentamos que por se tratar de uma versão experimental, decidimos fazer mais ênfase na funcionalidade sem desmerecer padrões básicos de uma aplicação Android.

Ao concluir esta etapa, com o intuito de responder à pergunta proposta na seção 5.2.1 a qual consiste em avaliar:

\section{Q1 - Qual é a percepção que os participantes têm do aplicativo BraPolar? \\ Após concluir a execução online do teste de dependência, obtivemos uma caracterização do grau de dependência ao celular de cada um dos participantes de nosso estudo por categoria (Reação com o aplicativo, Tela do aplicativo,}


etc) para cada participante (P1...P6). Cada categoria foi avaliada numa escala de 1 até 5 , onde 1 é menos satisfeito e 5 muito satisfeito. Estes resultados são apresentados na figura 5.4. Para facilitar a identificação com os cores monocromáticas, as barras estão identificadas na mesma sequência que na legenda.

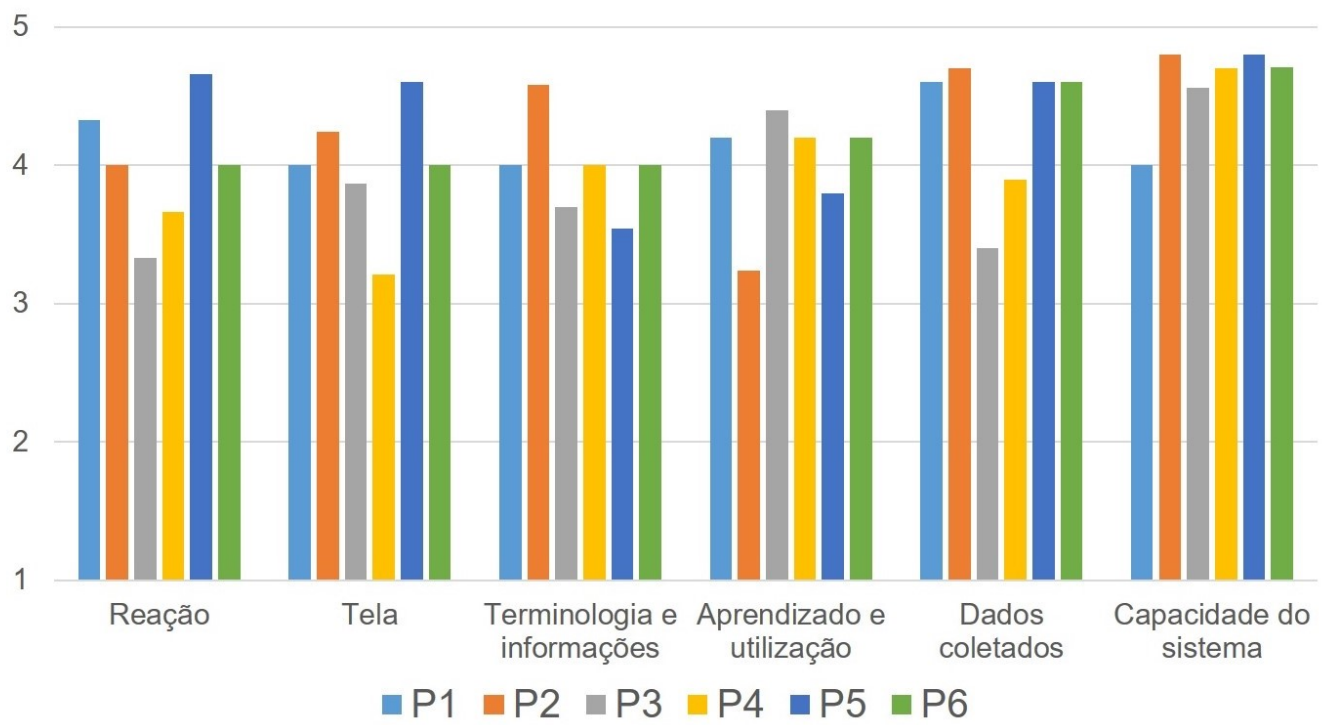

Figura 5.4: Resultado do QUIS Participantes e categorias avaliadas

Com a descrição gráfica anterior, comentamos as categorias mencionadas a continuação:

- Reação com o aplicativo: os participantes sinalizam que o aplicativo é fácil de usar, mantendo a similaridade com outros aplicativos Android que eles já têm usado. Em relação ao nível de nomofobia, não encontramos divergências quanto ao comportamento em usuários dependentes (P1, P3, P4, P6) e pessoas menos nomofóbicas (P2, P5).

- Tela do aplicativo: Os seis participantes classificaram como claras as sequências e afirmações apresentadas no BraPolar. Entretanto P3, P4 e P5 consideraram que o design do aplicativo poderia melhorar.

- Terminologia e informações da aplicação: O uso do vocabulário técnico na aplicação acabou por ser claro para todos os participantes exceto P3 e P5. Os que responderam favoravelmente conseguiram realizar as atividades sem consultar o moderador. No entanto, observou-se que dois participantes, um com um grau severo de nomofobia (P3) e o outro com nomofobia leve ou moderada (P5), exigiam instruções em momentos específicos da atividade, porque não estavam familiarizados com a m-Health. Quanto às mensagens (notificações) que apareceram durante a avaliação no aplicativo, os participantes as conseguiram compreender pois as atenderam e realizaram a atividade reque- 
rida, entretanto, a terminologia técnica na 'Atividade Psicomotora' resultou confusa para os participantes de maior idade.

- Aprendizado e utilização: Para os 6 participantes, o sistema foi considerado fácil de aprender e operar por tentativa e erro. As tarefas exigidas foram quase sempre realizadas de forma sequencial. Os participantes com média ou alta nomofobia (P1, P3, P4 e P6) foram mais propensos a lembrar termos do que os participantes menos familiarizados. Portanto, precisamos incluir instruções na interface nas próximas versões na primeira vez que o aplicativo for executado.

- Dados coletados: identificamos que os participantes dependentes (P1, P3, P4, P6) e não dependentes (P2, P5) consideraram que visualizar os dados colectados é desnecessário. P3 e P4 mencionaram se sentir desconfortáveis com a visualização de seus dados armazenados no aplicativo. Portanto, precisamos ter cuidado ao apresentar os dados coletados para os participantes, já que estes, mesmo conhecendo o comportamento do aplicativo, ficaram incomodados com o fato de um aplicativo estar rastreando-os, embora tenham assinado o TCLE, descrito no anexo 9.1. Acreditamos que isso pode ser prejudicial para pacientes com alguma doença mental e avaliaremos posteriormente com os especialistas em outros estudos em profundidade.

- Capacidade do sistema: os participantes comentaram que o aplicativo é rápido e a transição entre as telas tem uma ordem lógica. O teclado personalizado foi bem aceito devido à facilidade de correção de erros. O aplicativo foi projetado para atender a todos os níveis de usuários tanto experientes quanto iniciantes.

\section{6}

\section{Discussão}

Independentemente do nível de dependência ao celular dos participantes (figura 5.5), o aplicativo provou ser fácil de usar. No entanto, alguns aspectos precisam ser melhorados, como terminologia e dados apresentados na tela. Percebemos que os participantes mais jovens demonstraram uma maior habilidade de realizar as tarefas indicadas. Em contrapartida, o participante P3 com 54 anos e nomofobia severa, achávamos que poderia compreender mais fácil as tarefas por tentativa/erro no BraPolar por causa de ser dependente ao celular, no entanto, foi necessário explicar-lhe o funcionamento da tarefa T6:

\section{Estabelecer o número de horas que o usuário dormiu na última noite} pois não foi capaz de fazê-la sozinha. 


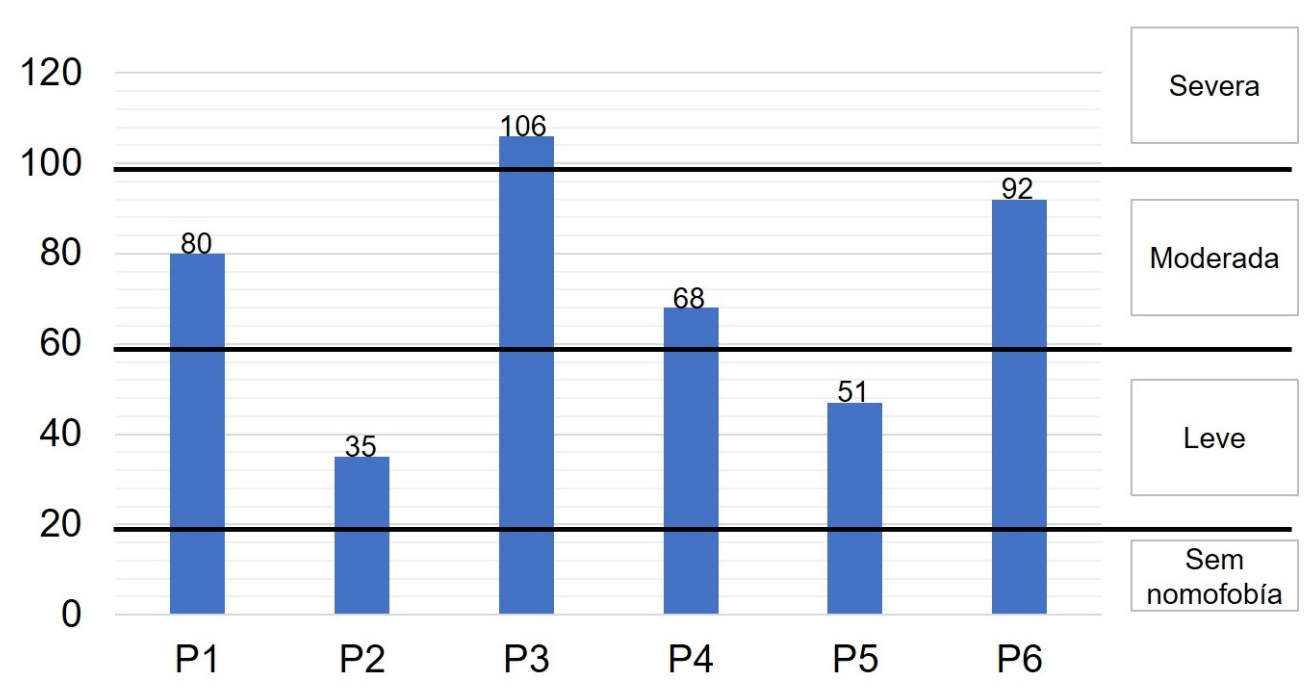

Figura 5.5: Pontuação obtida no teste de nomofobia pelos participantes.

Em relação à compreensão por parte dos participantes com a interface, eles demonstraram entender os itens e a iconografia que foram apresentados no aplicativo interface. Sua reação foi observada antes e durante a interação. Embora o tempo de resposta do aplicativo tenha sido satisfatório, os participantes com mais idade (P1, P3) tiveram dificuldade de instalar o aplicativo, solicitando informações mais detalhadas no início do teste. Mesmo assim, eles realizaram todas as atividades. Isso nos permitiu identificar alguns recursos que precisam ser melhorados, como terminologia e clareza nos dados apresentados na aplicação. Acreditamos que isso poderia causar algum inconveniente em pacientes com TAB.

De acordo com os resultados obtidos, atualizamos a versão do BraPolar corrigindo os problemas recorrentes dos usuários, apresentado na seção 5.2.1. Esperamos que a nova versão do BraPolar permita uma melhor experiência do usuário e, assim, maior confiabilidade dos dados recebidos pelos especialistas. Desta forma, pretendemos que o monitoramento remoto com os especialistas auxilie na detecção de alterações nos testes e posterior normalização do humor.

\section{7}

\section{Publicações}

Durante o desenvolvimento da pesquisa, apresentamos os resultados obtidos até este ponto, na Yth International Conference on Serious Games and Applications for Health, IEEE SeGAH 2019. Apresentamos o artigo intitulado BraPolar: an M-Health Application for Remote Monitoring of People with Bipolar Disorder sob a autoria de Abel González Mondéjar, Greis Francy M. Silva-Calpa, Alberto Barbosa Raposo e Daniel Correa Mograbi (certificado 
disponível no anexo 9.12). No momento de defesa desta dissertação, o artigo mencionado encontra-se aceito e pendente para publicação. Cabe notar que as principais observações e recomendações feitas na revisão do paper, foram solucionadas antes de prosseguir com o seguinte estudo.

\section{8}

\section{Preparação para o próximo estudo}

Ao concluir a primeira fase do estudo, prosseguimos mantendo instalado o aplicativo nos celulares dos participantes por 30 dias conforme descrito no Termo de Consentimento (anexo 9.1). Cabe mencionar que o participante P4 não conseguiu participar na segunda fase da pesquisa pois informou que iria trocar de dispositivo móvel nas datas previstas à avaliação. Neste sentido, as seguintes avaliações contam com 5 participantes, realizando a seguinte correção na tabela 5.4, apresentada a continuação.

Tabela 5.4: Correção dos id dos participantes para o seguinte estudo

\begin{tabular}{ll} 
Id estudo anterior & Id estudo seguinte \\
\hline Participante 1 & Participante 1 \\
Participante 2 & Participante 2 \\
Participante 3 & Participante 3 \\
Participante 4 & - \\
Participante 5 & Participante 4 \\
Participante 6 & Participante 5
\end{tabular}

Na figura 5.6 percebemos que estiveram ativos 20 usuários, entretanto isto é uma distorção devido a que, enquanto coletávamos dados dos participantes, estávamos fazendo algumas correções no BraPolar e criamos novas instâncias de usuários, mas isso não interferiu na coleta da fenotipagem digital (coleta de dados) com os demais 5 participantes. Durante todo este tempo de coleta de dados, monitoramos que o aplicativo estivesse em execução através de Firebase, utilizando o recurso Usuários Ativos (figura 5.6) e não interromper em nenhum momento a coleta de dados. 


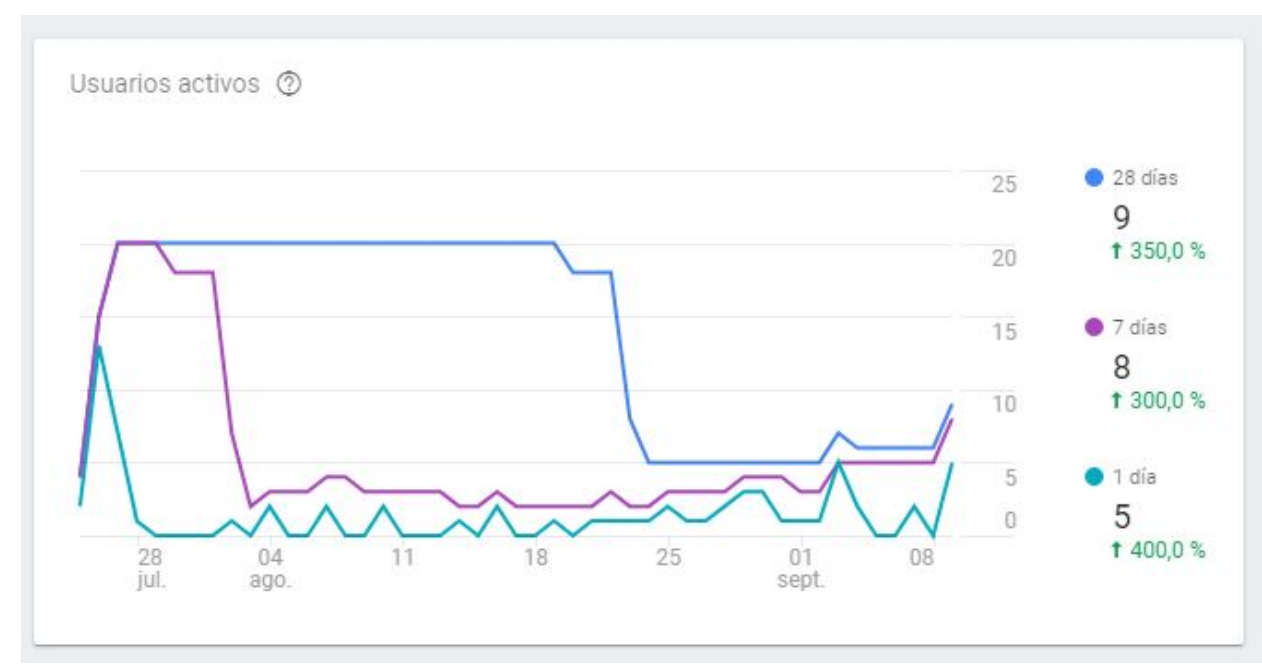

Figura 5.6: Usuários ativos durante o período de testes

Outro fator que nos preocupou, foi o consumo de dados e recursos nos celulares dos participantes por parte de BraPolar. Neste sentido, ao finalizar os 30 dias de coleta verificamos o consumo de memória RAM, Bateria e Armazenamento. Solicitamos aos participantes P3 e P4 do estudo, que nos enviassem uma captura de tela do consumo de recursos do aplicativo P3 (figura 5.7-esquerda) e P4 (figura 5.7-direita).

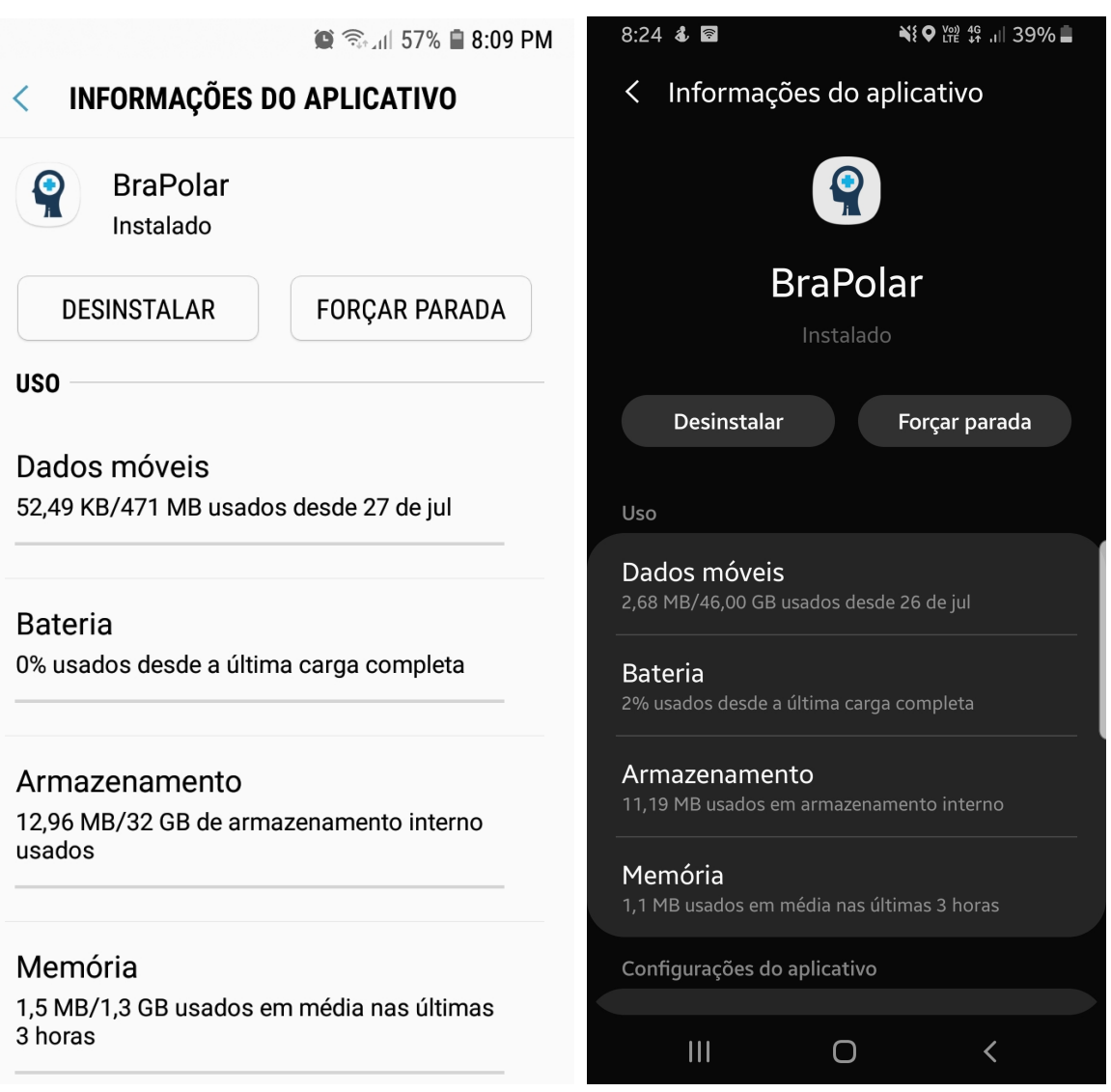

Figura 5.7: Consumo de recursos nos dispositivos dos participantes P3 e P4 
Conforme a figura anterior e a tabela 5.5, percebemos que durante os 30 dias de coleta de dados, BraPolar não consumiu recursos consideráveis dos dispositivos móveis nos participantes e não foi reportada nenhuma incidência de lentidão nem consumo de dados por parte de BraPolar.

Tabela 5.5: Consumo máximo de recursos do BraPolar

\begin{tabular}{llll} 
Participante & Dados $(\mathrm{Kb})$ & Armazenamento $(\mathrm{Mb})$ & Memória $(\mathrm{Mb})$ \\
\hline Participante 1 & 84,75 & 11,80 & 2,95 \\
Participante 2 & 64,15 & 9,70 & 3,15 \\
Participante 3 & 52,49 & 12,96 & 1,5 \\
Participante 4 & 57,15 & 14,41 & 2,41 \\
Participante 5 & 60,30 & 16,58 & 1,90
\end{tabular}

\section{9}

\section{Conclusões do capítulo}

Neste capítulo realizamos a primeira avaliação do estudo, dividido em duas partes.

Num primeiro momento, realizamos um teste de dependência ao celular com 6 participantes durante o qual detectamos que um deles possui nomofobia severa. Numa segunda parte, realizamos um teste de usabilidade para avaliar a percepção que os participantes têm do aplicativo BraPolar no modo paciente e após, comentamos a relação que encontramos entre os testes de dependência ao celular e usabilidade que aplicamos com 6 participantes. Embora um dos participantes tenha se recusado a participar da coleta de dados por um mês por motivo de força maior, coletamos a fenotipagem digital de 5 participantes durante um mês e verificamos que o BraPolar não consumia recursos consideráveis nos seus dispositivos. No capítulo a seguir, apresentamos a avaliação realizada com especialistas e os resultados obtidos com o BraPolar, no modo especialista. 


\section{6}

\section{Avaliação do modo especialista}

Este capítulo descreve o protocolo de estudo utilizado para avaliar o aplicativo BraPolar com especialistas. Na seção 6.1 providenciamos o objetivo do teste, na seção 6.2 apresentamos os instrumentos usados na avaliação, e na seção 6.3 mostramos os perfis dos participantes. Após, na seção 6.4, detalhamos o procedimento do experimento e nas seções 6.5 e 6.6 comentamos as principais obervações realizadas durante a execução da avaliação.

\section{1}

\section{Definição do objetivo do teste com especialistas}

Depois de coletar a fenotipagem digital dos 5 participantes viáveis (usuários do primeiro estudo no papel de pacientes), prosseguimos a realizar a avaliação com especialistas. Esta avaliação visou conhecer a percepção que os especialistas têm do BraPolar, além de identificar se o monitoramento remoto da fenotipagem digital em tempo real os auxilia na detecção de mudanças no comportamento.

Como já mencionamos em seções anteriores, BraPolar captura a interação das pessoas com seus dispositivos móveis criando a fenotipagem digital e estabelecendo uma linha base ao longo do tempo. Com isto, especialistas podem se apoiar para detectar mudanças no comportamento através das visualizações propostas no aplicativo em tempo real. O aplicativo contém dois modos: um para pacientes e outro para especialistas. No capitulo 5 realizamos uma primeira avaliação e neste, iremos avaliar o BraPolar no modo especialista. Em consequência, definimos duas perguntas a serem respondidas através do estudo exploratório:

Q1 - Qual é a percepção que os especialistas têm de cada funcionalidade oferecida pelo BraPolar?

Para responder esta pergunta, realizamos uma avaliação de usabilidade do aplicativo com os especialistas. Para isto, planejamos um cenário e um conjunto de atividades a serem realizadas com o BraPolar. A avaliação foi similar ao estudo realizado no modo paciente, com a diferença que neste não precisamos realizar o teste de dependência ao celular [32] pois não era nosso interesse conhecer o grau de dependência nos especialistas. Aqui avaliamos as principais funcionalidades do BraPolar e aplicamos o questionário pósteste QUIS descrito abaixo na subseção Instrumentação (seção 6.2). Além disso, decidimos avaliar a ordem em que o especialista revisou cada uma das 
funcionalidades com o intuito de identificar se eles acharam algum indicador que os levara a avaliar cada participante.

\section{Q2 - Como o monitoramento remoto e a fenotipagem digital} poderiam auxiliar os especialistas a detectar flutuações no compor-

\section{tamento?}

Para responder esta pergunta consideramos a relevância do monitoramento remoto em pessoas com problemas mentais em tempo real por parte dos especialistas. Neste sentido, após concluir as atividades da Q1, analisamos as sugestões feitas pelos especialistas através das respostas no anexo 9.10 onde verificamos como o BraPolar poderia lhes auxiliar a detectar as flutuações em pacientes com TAB através de um conjunto de perguntas que comentamos na seção 6.5.2.

\section{2}

\section{Instrumentação}

Para conduzir este estudo, utilizamos os seguintes instrumentos:

(A) - O teste de dependência ao celular (TDC) realizado na avaliação com participantes no papel de "pacientes" para a visualização dos perfis dos usuários (figuras 6.1 e 6.2). Isto para que o especialista possa ter uma ideia do perfil de cada usuário a ser avaliado .

\begin{tabular}{|c|c|c|c|c|c|}
\hline \multicolumn{6}{|c|}{ TESTE DE DEPENDÊNCIA AO CELULAR } \\
\hline Atividade $\backslash$ Paciente & P1 & $\mathbf{P 2}$ & P3 & P4 & P5 \\
\hline 1. Idade & 53 & 26 & 54 & 35 & 47 \\
\hline 2. Sexo & Masculino & Feminino & Feminino & Feminino & Masculino \\
\hline $\begin{array}{l}\text { 3. Há quanto tempo você usa um } \\
\text { smartphone? }\end{array}$ & 5 anos ou mais & 5 anos ou mais & 5 anos ou mais & 5 anos ou mais & 5 anos ou mais \\
\hline $\begin{array}{l}\text { 4. Você tem um plano de dados móveis que } \\
\text { permite acessar a Internet através do } \\
\text { smartphone? }\end{array}$ & Sim & Sim & Sim & Sim & Sim \\
\hline $\begin{array}{l}\text { 5. Aproximadamente quanto tempo por dia } \\
\text { (horas) você acha que gasta usando seu } \\
\text { smartphone? }\end{array}$ & 5 & 1 & 3 & 3 & 5 \\
\hline $\begin{array}{l}\text { 6. Em média, quantas vezes por dia você } \\
\text { acha que checa seu smartphone? }\end{array}$ & 30 & 2 & 6 & 10 & 30 \\
\hline $\begin{array}{l}\text { 7. Com que frequência você costuma } \\
\text { checar seu smartphone? }\end{array}$ & A cada 30 minutos & A cada 3 horas & A cada 15 minutos & A cada hora & A cada 2 horas \\
\hline $\begin{array}{l}\text { 8. Número de chamadas telefônicas que } \\
\text { você recebe por dia: }\end{array}$ & 2 & 1 & 20 & 10 & 2 \\
\hline $\begin{array}{l}\text { 9. Número de mensagens de texto } \\
\text { enviadas por dia: }\end{array}$ & 30 & 0 & 300 & 20 & 30 \\
\hline $\begin{array}{l}\text { 10. Número de mensagens de texto } \\
\text { recebidas por dia: }\end{array}$ & 500 & 4 & 300 & 800 & 250 \\
\hline $\begin{array}{l}\text { 11. Número de e-mails que vocé envia por } \\
\text { dia: }\end{array}$ & 3 & 0 & 3 & 2 & 2 \\
\hline $\begin{array}{l}\text { 12. Número de e-mails que você recebe por } \\
\text { dia: }\end{array}$ & 40 & 4 & 6 & 5 & 25 \\
\hline $\begin{array}{l}\text { 13. Aproximadamente, quantos aplicativos } \\
\text { você tem em seu smartphone? }\end{array}$ & 20 & 20 & 15 & 10 & 36 \\
\hline $\begin{array}{l}\text { 14. Para quais dos seguintes fins você } \\
\text { costuma usar seu smartphone? (Por favor } \\
\text { selecione tudo que se aplica) }\end{array}$ & $\begin{array}{l}\text { Verificar e-mail, Fazer } \\
\text { anotaçōes, Verificar mídias } \\
\text { sociais, Receber notícias, } \\
\text { Passar o tempo, Procurar } \\
\text { informaçōes na Internet, } \\
\text { Ouvir música, Agendar } \\
\text { reuniōes e eventos, Falar } \\
\text { com a família ou amigos, } \\
\text { Trocar mensagens com } \\
\text { familia ou amigos } \\
\end{array}$ & $\begin{array}{l}\text { Procurar informaçōes } \\
\text { na Internet, Falar com a } \\
\text { famillia ou amigos }\end{array}$ & \begin{tabular}{|l} 
Verificar e-mail, Fazer \\
anotaçōes, Receber \\
noticias, Passar o \\
tempo, Procurar \\
informaçôes na Internet. \\
Agendar reuniōes e \\
eventos, Falar com a \\
famillia ou amigos, \\
Trocar mensagens com \\
famillia ou amigos \\
\end{tabular} & \begin{tabular}{|l} 
Verificar e-mail, Fazer \\
anotaçōes, Verificar mídias \\
sociais, Jogar, Receber \\
noticiass, Passar o tempo, \\
Procurar informaçōes na \\
Internet, Ouvir música, \\
Agendar reuniōes e \\
eventos, Falar com a \\
família ou amigos, Trocar \\
mensagens com família ou \\
amigos
\end{tabular} & $\begin{array}{l}\text { Verificar e-mail, Fazer } \\
\text { anotações, Receber } \\
\text { notícias, Procurar } \\
\text { informaçōes na Internet, } \\
\text { Agendar reuniōes e } \\
\text { eventos, Falar com a } \\
\text { família ou amigos, Trocar } \\
\text { mensagens com família } \\
\text { ou amigos }\end{array}$ \\
\hline
\end{tabular}

Figura 6.1: Perfis dos usuários (Perguntas 1 até 14) 


\begin{tabular}{|c|c|c|c|c|c|}
\hline \multicolumn{6}{|c|}{ TESTE DE DEPENDÊNCIA AO CELULAR } \\
\hline Atividade \ Paciente & P1 & P2 & P3 & P4 & P5 \\
\hline $\begin{array}{l}\text { 15. Em qual dos seguintes contextos você } \\
\text { usaria seu smartphone? (Por favor } \\
\text { selecione tudo que se aplica) }\end{array}$ & 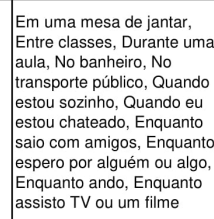 & Quando estou sozinho & \begin{tabular}{|l} 
No banheiro, Quando \\
estou sozinho, \\
Enquanto espero por \\
alguém ou algo
\end{tabular} & $\begin{array}{l}\text { Em uma mesa de jantar, No } \\
\text { banheiro, No transporte } \\
\text { publico, Quando estou } \\
\text { sozinho, Enquanto espero } \\
\text { por alguem ou algo, } \\
\text { Enquanto ando, Enquanto } \\
\text { assisto TV ou um filme }\end{array}$ & 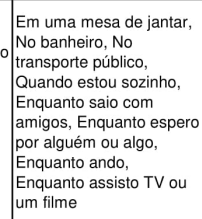 \\
\hline $\begin{array}{l}\text { 16. Muitas vezes penso no meu } \\
\text { smartphone quando não o estou usando. }\end{array}$ & 5 & 1 & 1 & 2 & 1 \\
\hline $\begin{array}{l}\text { 17. Costumo usar meu smartphone sem } \\
\text { nenhum motivo especifico. }\end{array}$ & 6 & 1 & 1 & 2 & 2 \\
\hline $\begin{array}{l}\text { 18. Outras pessoas já discutiram comigo } \\
\text { por causa do uso do smartphone. }\end{array}$ & 2 & 1 & 7 & 1 & 4 \\
\hline $\begin{array}{l}\text { 19. Eu interrompo o que eu estou fazendo } \\
\text { quando eu sou contatado no meu } \\
\text { smartphone }\end{array}$ & 5 & 3 & 7 & 5 & 4 \\
\hline $\begin{array}{l}\text { 20. Eu me sinto conectado aos outros } \\
\text { quando uso meu smartphone. }\end{array}$ & 5 & 2 & 7 & 5 & 2 \\
\hline $\begin{array}{l}\text { 21. Eu perco a noçăo do quanto estou } \\
\text { usando meu smartphone. }\end{array}$ & 6 & 2 & 7 & 1 & 3 \\
\hline $\begin{array}{l}\text { 22. O pensamento de estar sem meu } \\
\text { smartphone me deixa angustiado. }\end{array}$ & 5 & 1 & 1 & 2 & 1 \\
\hline $\begin{array}{l}\text { 23. Näo consigo reduzir o uso do } \\
\text { smartphone. }\end{array}$ & 5 & 1 & 1 & 2 & 2 \\
\hline
\end{tabular}

Figura 6.2: Perfis dos usuários (Perguntas 15 até 23)

(B) - O teste de dependência para a visualização das respostas a cada questão do teste (figuras 6.3 e 6.4). Isto para que os especialistas conheçam o grau de nomofobia que os avaliados possuem.

\begin{tabular}{|c|c|c|c|c|c|}
\hline \multicolumn{6}{|c|}{ TESTE DE DEPENDÊNCIA AO CELULAR } \\
\hline Atividade $\backslash$ Paciente & P1 & P2 & P3 & P4 & P5 \\
\hline $\begin{array}{l}\text { 1. Eu me sentiria desconfortável sem acesso constante a } \\
\text { informaçōes através do meu smartphone. }\end{array}$ & 4 & 2 & 7 & 3 & 6 \\
\hline $\begin{array}{l}\text { 2. Eu ficaria chateado se eu não pudesse procurar } \\
\text { informaçōes no meu smartphone quando eu quisesse } \\
\text { fazê-lo. }\end{array}$ & 6 & 1 & 7 & 3 & 7 \\
\hline $\begin{array}{l}\text { 3. Ser incapaz de obter as noticias (por exemplo, } \\
\text { acontecimentos, clima, etc) no meu smartphone me } \\
\text { deixaria nervoso. }\end{array}$ & 3 & 2 & 6 & 2 & 3 \\
\hline $\begin{array}{l}\text { 4. Eu ficaria chateado se eu não pudesse usar meu } \\
\text { smartphone e / ou suas capacidades quando eu } \\
\text { quisesse fazê-lo. }\end{array}$ & 5 & 1 & 6 & 3 & 5 \\
\hline 5. Ficar sem bateria no meu smartphone me assustaria. & 3 & 1 & 7 & 2 & 5 \\
\hline $\begin{array}{l}\text { 6. Se eu ficasse sem créditos ou atingisse meu limite } \\
\text { mensal de dados, entraria em pânico. }\end{array}$ & 3 & 1 & 6 & 1 & 7 \\
\hline $\begin{array}{l}\text { 7. Se eu não tivesse um sinal de dados ou não } \\
\text { conseguisse me conectar ao Wi-Fi, verificaria } \\
\text { constantemente se eu tinha um sinal ou se poderia } \\
\text { encontrar uma rede Wi-Fi. }\end{array}$ & 4 & 2 & 6 & 2 & 4 \\
\hline $\begin{array}{l}\text { 8. Se eu não pudesse usar meu smartphone, teria medo } \\
\text { de ficar preso em algum lugar. }\end{array}$ & 4 & 1 & 7 & 2 & 4 \\
\hline $\begin{array}{l}\text { 9. Se eu não conseguisse checar meu smartphone por } \\
\text { um tempo, eu sentiria o desejo de verificá-lo. }\end{array}$ & 6 & 3 & 7 & 3 & 4 \\
\hline $\begin{array}{l}\text { 10. Eu me sentiria ansioso porque não conseguia me } \\
\text { comunicar instantaneamente com minha familia } \mathrm{e} / \mathrm{ou} \\
\text { amigos. }\end{array}$ & 6 & 6 & 7 & 3 & 7 \\
\hline $\begin{array}{l}\text { 11. Eu ficaria preocupado porque minha familia e / ou } \\
\text { amigos não poderiam me contatar. }\end{array}$ & 6 & 1 & 7 & 2 & 4 \\
\hline
\end{tabular}

Figura 6.3: Resultado do TDC (Perguntas 1 até 11) 


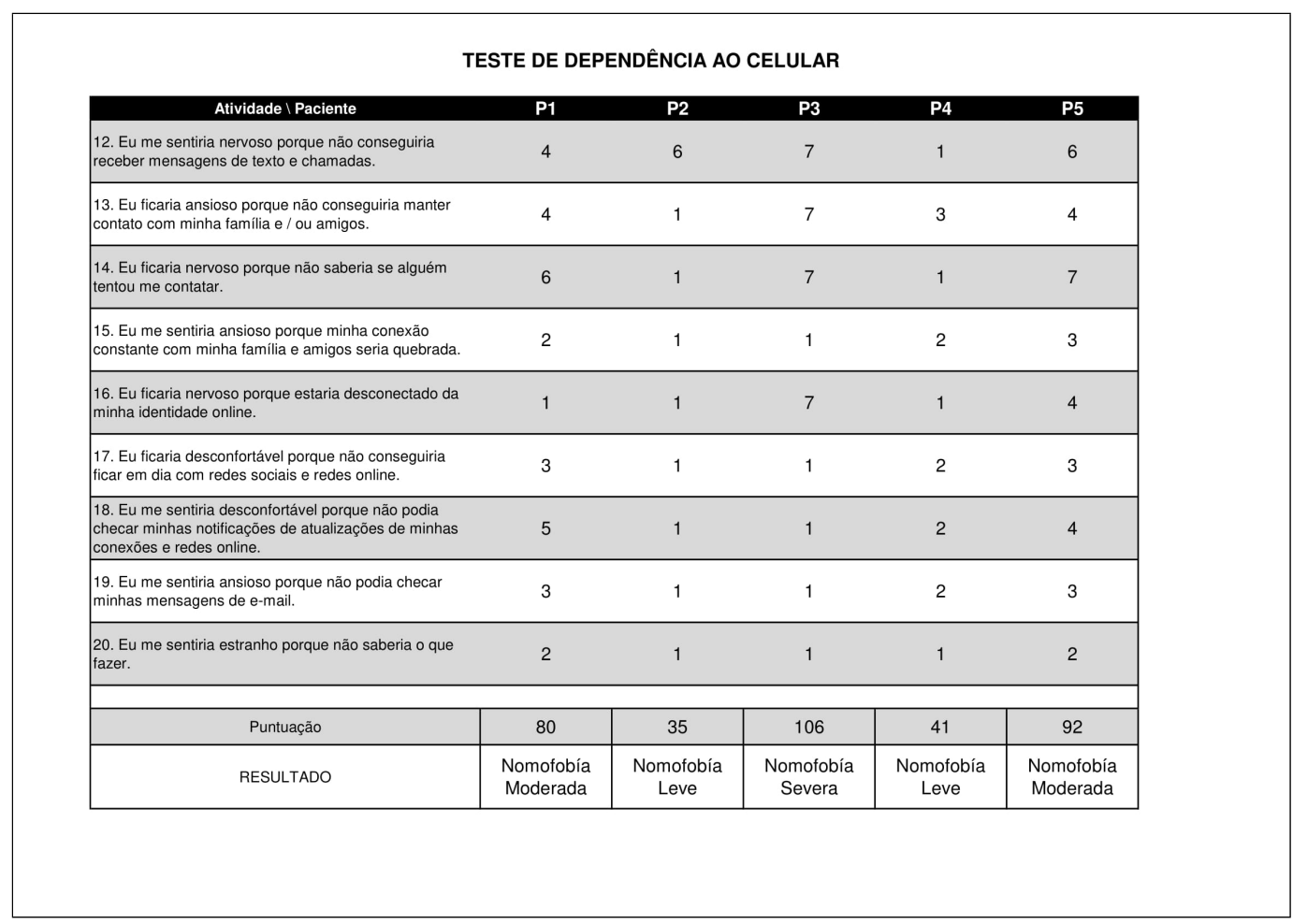

Figura 6.4: Resultado do TDC (Perguntas 12 até 20)

(C)- Dois dispositivos móveis Android: um com o aplicativo BraPolar no modo paciente e outro com o modo especialista. O dispositivo móvel com o login paciente foi utilizado pelo moderador (o pesquisador) na condução da avaliação. O dispositivo com o login de especialista, foi utilizado pelo especialista para realizar um conjunto de atividades descritas na seção 6.4.

(D) - Orientações gerais e lista de atividades a serem realizadas.

Foram proporcionadas as orientações das atividades a serem realizadas durante o teste (ver em detalhe no anexo 9.8). Explicamos para o especialista a importância de realizar o teste e contextualizamos nos aspectos de fenotipagem digital e dependência ao celular. Explicamos sobre a realização das atividades do teste e fizemos especial ênfase para que executassem uma atividade por vez e que solicitassem ajuda caso haja problemas na execução de alguma atividade. Ao final, comentamos para descontrair o momento, que quem estava sendo testado era o aplicativo e não eles.

Além das orientações, apresentamos a lista das atividades a serem realizadas (anexo 9.9). Nela apresentamos um hipotético cenário onde os especialistas estariam avaliando um conjunto de pacientes. Neste teste, orientamos realizar duas atividades: login e um conjunto de tarefas. Durante a execução das tarefas, visamos que os especialistas escrevam a ordem em que foram avaliando cada um dos "pacientes" do estudo. 
(E) - Formulários pós-teste.

Ao concluir a avaliação, utilizamos os questionários pós avaliação e de usabilidade apresentados nos anexos 9.10 e 9.11, respectivamente. No primeiro formulário, fizemos um conjunto de perguntas subjetivas para conhecer como o BraPolar auxiliou o especialista ao longo da avaliação e como a solução apresentada poderia ser utilizada em posteriores estudos no transtorno bipolar. Já no segundo formulário avaliamos alguns aspectos de usabilidade, similar ao estudo comentado no capítulo 5, com a diferença na Parte F - Dados coletados, pois neste casso, avaliamos a relevância para os especialistas coletar as informações de estado de ânimo, ligações, etc.

Uma vez definida a instrumentação, passamos a definir o perfil dos especialistas que participaram das avaliações.

\section{3}

\section{Seleção dos especialistas participantes}

Para conduzir esse experimento, recrutamos 5 psicólogos e psiquiatras selecionados pelo co-orientador deste trabalho (que também participou), especialistas do IPUB e colaboradores do Departamento de Psicologia da PUCRio. Seguindo recomendações do co-orientador deste trabalho, para que um especialista seja escolhido como participante ele precisa atender aos seguintes requisitos:

- Conhecimento básico de aplicações Android.

- Formado em psicologia ou ciências médicas.

- Experiência de pelo menos 2 anos com pacientes com TAB.

- Ter participado em projetos de pesquisa relacionados com TAB.

Após vários encontros, o co-orientador selecionou cinco especialistas (3 psicólogos e 2 psiquiatras) com pelo menos 2 anos de experiência médica trabalhando com pacientes com TAB ou pesquisas relacionadas. Convidamos via e-mail e eles aceitaram participar do estudo (tabela 6.1), sendo um deles o próprio co-orientador e os demais pessoas externas à equipe de pesquisa. Para facilitar a compreensão, os identificamos em dois grupos: psicólogos (POn) e psiquiatras (PAn) onde n é o identificador para cada um. 
Tabela 6.1: Caracterização dos especialistas participantes do estudo

\begin{tabular}{llll} 
Especialista & Anos de Experiência & Grau acadêmico & Área de atuação \\
\hline PO1 & 2 & MSc & Psicologia \\
PO2 & 3 & MSc & Psicologia \\
PO3 & 15 & Dr & Psicologia \\
PA1 & 11 & Dr & Psiquiatria \\
PA2 & 31 & Dr & Psiquiatria
\end{tabular}

É válido mencionar que os psicólogos PO1 e PO2 embora possuam 3 ou menos anos de experiência, no momento que esta dissertação é apresentada, encontram-se realizando doutorado em Psiquiatria e Saúde Mental na PUCRio.

\section{4 \\ Procedimento do teste}

A execução deste experimento aconteceu durante três semanas. Durante a primeira semana, caracterizamos e selecionamos os sujeitos seguindo recomendações do co-orientador deste trabalho, como detalhado na seção anterior. Na segunda semana foi enviado para cada participante o convite para participar do teste, solicitando que estes preenchessem via Google Sheets o dia e horário do encontro. Para agilizar a compreensão de nossa pesquisa com o BraPolar, lhes enviamos o artigo publicado na conferência SeGAH 2019, comentado na secção 5.7, que envolve a avaliação do primeiro estudo.

Considerando que cada especialista trabalha na área e seus horários são comprometidos, decidimos flexibilizar a data da entrevista e local sem detrimento à qualidade da mesma na terceira semana. A seguir, apresentamos uma descrição detalhada das atividades que ocorreram durante o experimento.

- Seleção dos especialistas: na primeira semana selecionamos os especialistas participantes, comentado na seção 6.3, e entramos em contato com eles confirmando a aceitação no estudo.

- Treinamento sob os conceitos: na segunda semana, antes do experimento, consideramos importante esclarecer os termos utilizados no estudo. Para isso, lhes enviamos via e-mail as características de BraPolar, comentadas no capítulo 5 com o intuito de esclarecer as dúvidas antes da avaliação.

- Treinamento do uso do BraPolar: no dia da avaliação combinado com cada especialista, foi apresentado o aplicativo nas duas versões do BraPolar: paciente $(\mathrm{BP})$ e especialista $(\mathrm{BE})$. O treinamento foi organizado em duas partes: a apresentação do aplicativo (15 minutos) onde o autor desta dissertação lhes comentou sobre as funcionalidades do BraPolar e discussão aberta 
para esclarecer dúvidas (10 minutos). Na apresentação lhes mostramos com dois celulares as principais diferenças entre as versões BP e BE e como as mudanças eram refletidas na BE quando na versão BP era modificado algum parâmetro.

Cabe mencionar que, para melhorar a experiência na execução dos testes, usamos os dados móveis. Antes de fazer a primeira avaliação, testamos sob a rede Wi-Fi e percebemos que existia uma latência de uns 2 segundos para a visualização dos dados em tempo real, o qual poderia dificultar a experiência durante a execução do teste. Após concluir o treinamento com o especialista, foi entregue o celular com a versão BE e o moderador ficou com o outro celular com a versão BP.

- Execução do teste: os objetivos desta avaliação são conhecer a percepção que os especialistas têm sobre o aplicativo BraPolar e como o monitoramento remoto em tempo real e a fenotipagem digital poderiam auxiliar os especialistas a detectar flutuações no comportamento dos pacientes. Para atingir estes objetivos, os especialistas receberam os resultados do teste de dependência ao celular de cada participante do primeiro estudo (item A da seção 6.2). A intenção foi que os especialistas conhecessem o perfil dos avaliados. Depois disso, o especialista foi convidado a realizar as atividades descritas no item D da seção 6.2 neste capítulo. Aliás, avaliamos a relevância que possui a apresentação da informação em tempo real e como poderia influir na detecção antecipada de mudanças em pessoas com TAB.

Para avaliar o comportamento do especialista com a modificação em tempo real dos parâmetros dos pacientes, realizamos o seguinte: considerando que o especialista tem o BraPolar (modo especialista) e o moderador tem o BraPolar (modo paciente), o moderador fez login como Paciente1. Após, enquanto o especialista interagia com o BraPolar no seu celular, o moderador modificava seus parâmetros de Estado de ânimo, e estes refletiam automaticamente no celular do especialista. As reações do especialista ao visualizar estas mudanças serão comentadas na seção Resultados (seção 6.5.2).

- Questionários pós-teste: após realizadas todas as atividades descritas no item D da seção 6.2, cada especialista completou um questionário QUIS (anexo 9.11) adaptado ao nosso contexto, simplificando termos para melhorar sua compreensão e obter um feedback da sua percepção com o BraPolar. Além disso, lhes pedimos que relatassem a utilidade de cada funcionalidade de acordo com sua percepção e comentassem, como o monitoramento remoto e a fenotipagem digital poderiam lhes auxiliar a detectar flutuações no comportamento em posteriores estudos com pacientes com TAB. 


\section{5}

\section{Resultados da avaliação}

Nesta última etapa, apresentamos os resultados encontrados durante as avaliações dos questionários pós-teste. Para isso, apresentamos nas seções 6.5.1 e 6.5.2 as sugestões de melhoria propostas pelos especialistas, detalhamos as principais dificuldades e apresentamos a resposta para cada pergunta.

\subsection{1}

\section{Resultados do QUIS}

Considerando a pergunta a ser respondida com esta avaliação:

Q1 - Qual é a percepção que os especialistas têm de cada funcionalidade no BraPolar?

Para respondê-la, aplicamos o teste QUIS (anexo 9.11) ao finalizar a sessão de testes. Decidimos agrupar por cada uma das partes (Reação com o aplicativo, Tela, etc.) e comentar a percepção que os 5 especialistas (3 psicólogos e 2 psiquiatras) tiveram por cada item. Por ser uma amostra de 5 especialistas, decidimos não segmentar por especialidades os resultados e avaliá-las em conjunto especificando alguma diferença se for necessário (figura 6.5).

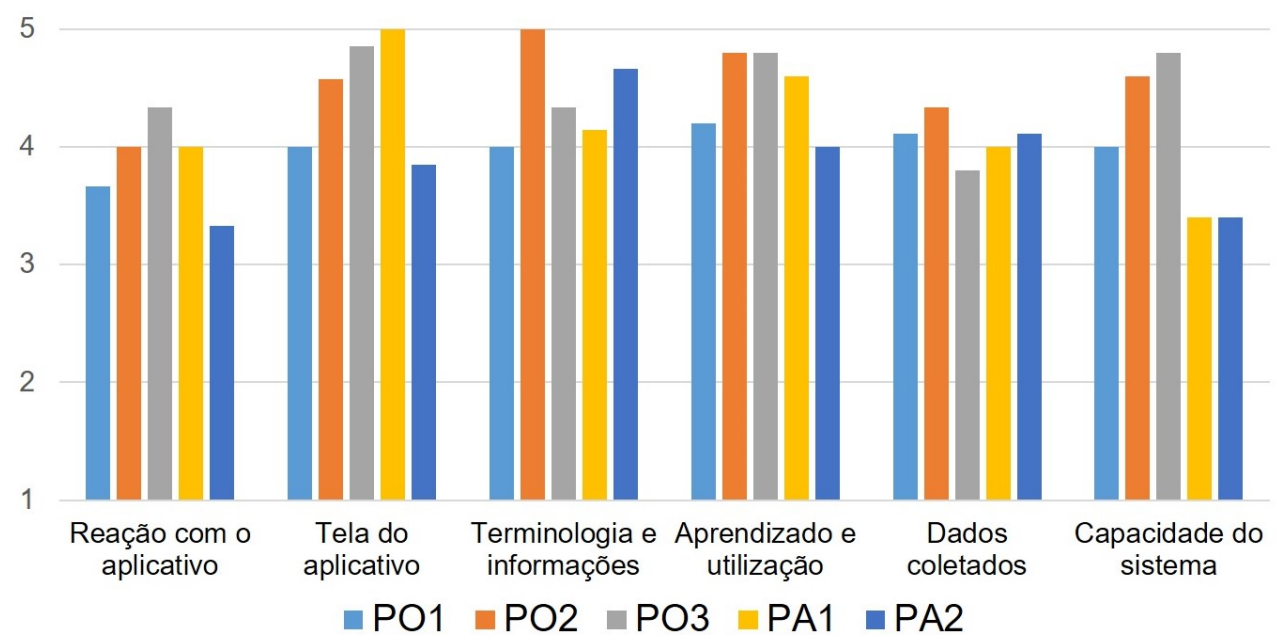

Figura 6.5: Resultado do QUIS Especialistas e categorias avaliadas

Com a representação gráfica anterior, comentamos as categorias mencionadas:

- Reação de aplicativo: tanto os psicólogos quanto os psiquiatras concluíram que o aplicativo foi fácil de usar. Os participantes mencionaram que BraPolar possui similaridade com outras soluções Android com os que anteriormente já tinham trabalhado. Mesmo os especialistas que tinham um dispositivo 
com iOS, não comentaram sentir diferença durante a experiência com o BraPolar. Entretanto, PO1 e PA2 consideraram que a informação apresentada pelo aplicativo poderia ser melhorada, reagrupando a funcionalidade Velocidade de Escrita na categoria Atividade Psicomotora.

- Tela do aplicativo: os 5 especialistas classificaram como claras as sequências e afirmações apresentadas no BraPolar. Entretanto PO2, PO3 e PA2 consideraram que as cores usadas na tela poderiam melhorar. Neste sentido, tomamos as sugestões propostas e descritas no final deste capítulo.

- Terminologia e informação de aplicação: O termos médicos utilizados em BraPolar resultaram claros e úteis para todos os especialistas, contrastando com a avaliação realizada no primeiro estudo.

- Aprendizado e uso: para os 5 especialistas, o sistema foi considerado fácil de aprender e operar por tentativa e erro. Durante a execução da primeira tarefa (anexo 9.9), os especialistas PO3, PA1 e PA2 demoraram alguns instantes a mais que os participantes PO1 e PO2. Por outra parte, todos os especialistas executaram as tarefas exigidas, sempre de forma sequencial, conforme aparecem na lista de atividades.

- Dados coletados: em relação à forma que os dados são apresentados, embora seja relevante para todos os especialistas, cada um dos psicólogos atribuiu um peso diferente para cada categoria. Os especialistas PO1 e PO2 consideraram que a funcionalidade estado de ânimo constitui um marcador mais relevante na hora de avaliar um paciente, entretanto PO3 atribuiu que para ele, a atividade física constituiu um indicador mais relevante resultando em critérios divergentes na hora avaliar pacientes com TAB. Entretanto, os especialistas consideraram relevante analisar os indicadores como um todo na hora de realizar uma avaliação com os pacientes, pois uma flutuação fora dos parâmetros normais, poderia ser o indicio de um câmbio de comportamento nos pacientes com TAB.

- Capacidade do sistema: O BraPolar demonstrou funcionar de forma rápida, segundo os especialistas. Comentaram que o aplicativo é rápido e a transição entre as telas tem uma ordem lógica. Entretanto, PO2, PA1 e PA2, consideraram que o aplicativo poderia ser medianamente complexo para usuários com pouca experiencia e, no caso do PA2, o resultado mais baixo obtido foi porque não compreendeu a pergunta. É válido mencionar que estes especialistas são os mais experientes no campo da saúde mental dos especialistas consultados.

Como resultado adicional, decidimos tabular os resultados e obter a média geral por cada parte do teste com os especialistas. Para isto, consideramos cada uma das seções do teste (Dados coletados, Capacidade do sistema), 
somamos o resultado obtido de cada subitem e dividimos pela quantidade, resultando na seguinte tabela 6.2 :

Tabela 6.2: Média dos resultados obtido por participante por categorias

\begin{tabular}{lccccc} 
Categoría / Especialista & PO1 & PO2 & PO3 & PA1 & PA2 \\
\hline Reação com o aplicativo & 3,66 & 4,00 & 4,33 & 4,00 & 3,33 \\
Tela do aplicativo & 4,00 & 4,57 & 4,85 & 5,00 & 3,85 \\
Terminologia e informações & 4,00 & 5,00 & 4,33 & 4,14 & 4,66 \\
Aprendizado e utilização & 4,20 & 4,80 & 4,80 & 4,60 & 4,00 \\
Dados coletados & 4,11 & 4,33 & 3,80 & 4,00 & 4,11 \\
Capacidade do sistema & 4,00 & 4,60 & 4,80 & 3,40 & 3,40
\end{tabular}

Após, definimos a relação entre os anos de experiência e as médias obtidas por cada especialista, pois no percurso da pesquisa achamos que poderia existir uma relação entre a experiencia na área com a média das categorias, as quais são apresentadas na tabela 6.3 a continuação:

Tabela 6.3: Média dos resultados obtido por participante no QUIS

\begin{tabular}{lll} 
Especialista & Anos de Experiência & Média \\
\hline PO1 & 2 & 3,995 \\
PO2 & 3 & 4,550 \\
PO3 & 15 & 4,485 \\
PA1 & 11 & 4,190 \\
PA2 & 31 & 3,891
\end{tabular}

Com os resultados apresentados anteriormente, independentemente da idade, a experiência do especialista ou a especialidade, os resultados foram favoráveis. Só com os especialistas PO1 e PA2 obtivemos resultados inferiores a 4, entretanto, obtivemos uma média geral de 4,22 (u) nesta avaliação o qual consideramos favorável.

Após concluir este teste, prosseguimos a realizar outro conjunto de perguntas as quais nos forneceram uma informação mais subjetiva de como o monitoramento remoto poderia lhes auxiliar.

\subsection{2}

\section{Resultados do segundo questionário pós-teste}

Após os especialistas concluírem o teste QUIS, passaram a responder o segundo questionário pós-teste com o objetivo de responder à seguinte pergunta: 
Q2 - Como o monitoramento remoto e a fenotipagem digital poderiam auxiliar aos especialistas a detectar flutuações no comportamento?

Para respondê-la, fragmentamos a pergunta nas seguintes:

Q2.1 - Considerando a ordem que você definiu na tabela anterior, que informação apresentada levou você a avaliar nessa sequência? Preencha a continuação o porquê da sua seleção para cada participante?

Ao referi-nos a "tabela anterior", queremos dizer à tabela das atividades (anexo 9.9). Nela, pedimos que o especialista colocasse a ordem em que avaliou cada uma das funcionalidades e os participantes, com o intuito de verificar se o grau diferente de dependência ao celular de cada participante poderia lhe fornecer informação relevante na execução das funcionalidades.

Durante a execução do teste, todos os especialistas começaram olhando o teste de dependência ao celular e leram as tarefas a serem executadas. Das atividades realizadas pelos especialistas, observamos que eles não deram prioridade na ordem que realizaram as avaliações para cada um dos participantes e avaliaram os pacientes de forma sequencial, exceto PA2 que considerou interessante que o paciente P3 possuía nomofobia severa e percebeu a relação com a quantidade de ligações e SMS enviados. Os demais especialistas avaliaram os participantes na mesma ordem que foi apresentada pelo aplicativo. No entanto, os especialistas não deram prioridade à ordem em que realizaram as tarefas. Eles comentaram que embora tenham em mãos os resultados do teste de dependência e este possam ser úteis, não conheciam com certeza o padrão normal desse paciente ao longo do tempo. Aspecto este que tomamos como referência para um posterior estudo.

Q2.2 - Como BraPolar poderia auxiliar você na detecção de flutuações em tempo real no comportamento / estado de humor dos pacientes com TAB? Como detectaria quando intervir?

Os especialistas comentaram como favorável o fato do aplicativo disponibilizar um histórico de humor do paciente, bem como os dados de sua interação social os quais, em conjunto com o teste de nomofobia, poderiam lhes auxiliar na identificação se o paciente está em fase de mania ou depressão.

Por sua vez, PO1 comentou que o monitoramento remoto auxiliaria especialmente na identificação de aumento ou diminuição de energia, características fundamentais dos ciclos do transtorno, através das funções de deslocamento, interação social, sono e humor. A detecção de quando intervir seria a 
partir de dados que me indicassem uma alteração do padrão global de funcionamento do paciente.

O especialista $\mathrm{PO} 2$ indicou que é comum que um paciente em fase de mania tenha avidez pela interação social, uma maior atividade e juízo satisfatório do próprio humor. Entretanto, nos casos de depressão o embotamento afetivo, a falta de vontade de se engajar em atividades, sobretudo as sociais, são características marcantes. Essas afirmações sugerem que o aplicativo poderia lhe auxiliar na percepção destas alterações bruscas no paciente, bem como monitorar possíveis oscilações. PO2 acrescentou: seria prudente intervir quando o paciente oscilasse para longe de sua própria média de interações sociais (tanto diminuindo-as drasticamente, quanto aumentando-as de forma aberrante), principalmente fazendo correlação destas com uma possivel mudança repentina de humor. Os dados referentes ao uso do celular (tempo com a tela ligada) e movimentação do paciente, podem ajudar a identificar comportamentos diferentes, desde que tenhamos como base um dado médio da população, para facilitar a análise dos especialistas.

Por outra parte PO3 comentou o aplicativo pode indicar alterações sutis de humor que, se consistentes ao longo do tempo, podem auxiliar como preditor do estado clínico do paciente. A intervenção se daria a partir de mudanças drásticas e/ou graduais mas consistentes ao longo do tempo. PA1 ressaltou que o aplicativo lhe poderia ajudar na detecção precoce de crise, o que pode gerar intervenção precoce. Entretanto, PA2 ressaltou que BraPolar poderia lhe auxiliar evidenciando alterações nos parâmetros coletados de Interação Social, Medicação, etc.

Nesta questão, os 5 especialistas resumiram e confirmaram a importância na detecção de flutuações em tempo real no acompanhamento dos pacientes com TAB. Todos concordaram em estabelecer uma linha base mais ampla para poder identificar como normalmente se comportam os pacientes e poder ter um ideia de quando intervir. Possuir esta informação em tempo real constitui uma informação valiosa na detecção precoce de um período de mania ou depressão.

\section{Q2.3 - Você considera importante conhecer o grau de depen-} dência ao celular dos pacientes? Por quê? É útil fazer o seguimento dos pacientes através da fenotipagem digital?

Nesta parte, PO1 considerou que pode ser relevante identificar o grau de dependência ao celular do paciente para ter como uma linha de base do que é habitual para ele, podendo utilizar esse parâmetro para interpretar flutuações de seu padrão. 
Por sua vez PO2 concordou, afirmando que conhecer o grau de dependência é importante, pois a considera uma informação relevante devido a que se uma pessoa é dependente de celular e a outra é usuária menos frequente, suas informações podem diferir drasticamente no aplicativo, mesmo que ambas estejam em fases de mania ou depressão. É provável que diferente do paciente com maior dependência de celular, o outro indivíduo em fase de mania, por exemplo, tenha utilizado menos o celular e também tenha o carregado menos consigo. Desta forma, saber do paciente (e se possivel de um familiar) o grau de uso do aparelho é fundamental para uma interpretação mais acurada dos resultados.

Por sua vez, PO3 destacou que é uma informação importante, mas dispensável caso uma linha de base em eutimia seja tomada. Ao referir-se à eutimia, quer dizer que o paciente bipolar encontra-se estável. Por sua vez, PA1 comentou que o aplicativo pode aumentar a fidedignidade das informações numa avaliação clínica e PA2 ressaltou que o considera relevante pois em tese, na mania, o número de ligações efetuadas e mensagens enviadas seria maior, assim como maior deslocamento. No caso da depressão esperaríamos o oposto. Em relação à fenotipagem digital todos os especialistas concordaram a relevância de uma linha base com esta abordagem para melhorar o seguimento em pacientes com TAB.

Neste ponto, os especialistas comentaram que conhecer com antecedência o grau de dependência ao celular constitui uma ferramenta de apoio interessante, pois teriam uma ideia de como usualmente os pacientes interagem com seus smartphones e poderiam usá-lo, em conjunto com a fenotipagem digital coletada ao longo do tempo, como um possível indicador de retomada de normalização de humor.

\section{Q2.4 - Como o uso do BraPolar poderia complementar os testes} de avaliação clínica convencionais ou outros padrões a avaliação psiquiátrica?

O participante PO1 argumentou que o BraPolar auxiliaria na identificação de informações mais minuciosas do dia-a-dia do paciente que muitas vezes passam despercebidas em avaliações padrões, pois os familiares/cuidadores ficam orientados para descrever as alterações de comportamento mais graves, não se atentando para os detalhes, enquanto que os pacientes, especialmente na mania, têm muito pouco insight sobre sua condição, não percebendo a disfuncionalidade dessas alterações. Com isso, o processamento automático de informações do app torna-se especialmente importante para o monitoramento dos indicativos de início de um ciclo em um determinado paciente, podendo servir como uma avaliação preventiva de suas oscilações de humor e energia. 
Assim, na atividade clínica poderia ajudar a realizar uma intervenção precoce no estado no paciente, evitando a necessidade do agravamento de seu quadro para ser percebido.

Por sua vez, PO2 disse que o BraPolar poderia auxiliar no sentido de fornecer dados quantitativos e diários acerca do que geralmente é relatado pelos pacientes e familiares no momento da consulta, de forma retrospectiva. Estas informações podem ser interpretadas em conjunto com a anamnese, o autorrelato dos pacientes e escores ou resultados de outros instrumentos de avaliação clínica. Ao se referir a anamnese, quer dizer avaliação clínica. Em consonância, PA3 comentou que poderia usar o aplicativo como uma medida comportamental/implícita, pois usualmente muita das informações não são acessíveis pelo discurso do paciente. Por sua vez, PA1 falou que BraPolar poderia lhe auxiliar a aumentar a fidelidade das entrevistas e PA2 achou que poderia ser um bom aliado na avaliação convencional.

Nesta questão, os especialistas acharam que poderiam utilizar o aplicativo como complemento devido a que os testes convencionais (Young Mania Rating Scale (YMRS) para a mania, a de Hamilton Rating Scale for Depression (HRSD) para momentos de depressão, Clinical Global Impression-Bipolar (CGI-BP), e Positive and Negative Syndrome Scale (PANSS) [24] [25]) fornecem informação retrospectiva dos pacientes. Entretanto, as respostas obtidas durante a avaliação clínica podem não ser completamente verídicas (o paciente pode não lembrar de como se sentia). Com o BraPolar, os pacientes poderão levar um seguimento diário de seu estado e os especialistas poderão avaliar em tempo real para tomar alguma decisão a respeito de forma mais rápida. Por outra parte, com o aplicativo, poderão contrastar as respostas obtidas nas entrevistas convencionais através dos métodos anteriormente descritos e o estado anímico que os pacientes definiram no aplicativo.

Q2.5- Você acha que os aspectos apresentados pelo BraPolar são suficientes para fazer um seguimento no tratamento? O que você incluiria ou retiraria da versão atual do BraPolar? Neste ponto os especialistas foram claros: PO1 e PA1 consideraram que não existe obra humana completa, entretanto BraPolar poderia ser um primeiro passo no intuito de acompanhar dia-dia aos pacientes con TAB.

O especialista PO2 por sua vez nos comentou que a principio não é suficiente, pois existem muitas variáveis que interferem no resultado, como por exemplo a assiduidade do uso do aplicativo, a frequência de uso do celular entre outras. Porém guardado as devidas proporções e ponderamentos, o aplicativo pode vir a ser um aliado. Em concordância com PO3 que considera um primeiro passo no assunto e irá continuar assessorando o projeto em posteriores 
versões em consonância com PA1 e PA2, os quais fizeram algumas sugestões apresentadas em seções posteriores e consideram BraPolar uma ferramenta promissória na qual todos se mostraram com intenção de colaborar em futuras versões.

Os especialistas consideraram que o BraPolar pode ser utilizado considerando as limitações que um estudo destes pode conter. Entretanto, consideraram a solução como um primeiro passo concreto em vias de auxiliar no acompanhamento deste problema de saúde pública.

\section{Q2.6- Gostaria de deixar algum comentário ou sugestão adicio-} nal para futuras versões do projeto? Sua opinião é muito importante.

Neste ponto final, PO1 comentou que uma apresentação gráfica mais clara das oscilações do paciente tornaria mais fácil para o clinico acompanhar múltiplas pessoas ao mesmo tempo, evitando ter que acessar o perfil de cada paciente e checar em cada função os registros daqueles dias; isso também serviria como um elemento para psico-educação do paciente, ajudando-o a reconhecer suas flutuações em uma linha do tempo e perceber padrões do que usualmente acontece quando está entrando em mania ou depressão. A flexibilidade da quantidade de avisos pode ser importante para os pacientes em mania, pois apresentam maior irritabilidade e isso poderia prejudicar sua adesão ao uso do aplicativo. Acho que para as informações de autorrelato, seria interessante que o paciente indicasse não apenas seu estado de humor, mas que também pudesse ter um checklist dos sintomas habituais do transtorno, pois isso o ajudaria a compreender seu quadro e ficar mais atento ao que é importante de se rastrear. Além disso, considero fundamental que familiares e/ou cuidadores, previamente indicados pelo paciente, possam ter acesso ao aplicativo e também enviar informações ao clínico, pois o insight prejudicado do paciente irá afetar o quão acurado são os dados inseridos na plataforma. Para projetos futuros, seria interessante a construção também de ferramentas de autocuidado, regulação emocional e possibilidade de acionamento direto de pessoas, caso o paciente esteja em uma crise e precise de ajuda. O rastreio de tempo de diagnóstico e aceitação deste pelo paciente, bem como a psicoeducação sobre o trastorno, podem ser variáveis que afetarão a adesão maior ou menor do paciente ao aplicativo.

Por sua vez, PO2 sugeriu que em etapas futuras tente conseguir dados para traçar uma média dos usuários através de um banco de dados do feedback de cada celular (se possivel classificando por idade, gênero, escolaridade e outros dados sociodemográficos). Esses dados da população geral, permite aos especialistas interpretarem não só o comportamento do paciente em comparação com ele mesmo ao longo do tempo, como também fornece informações do 
quão sintonizado ou desviante o comportamento deste está da população geral. Em consonância, PO3 se manifestou favorável a colaborar no projeto mais na frente incorporando novos especialistas que poderiam adicionar valiosos aportes ao estudo. Por outra parte, PA1 comentou que seria interessante informar a predominância do estado de ânimo em determinado período. Informar o médico sobre mudança de comportamento do paciente. e PA2 recomendou incluir uma nova funcionalidade para complementar o Estado de ânimo chamada Níveis de Energia com o intuito de obter uma avaliação de vivência subjetiva de energia.

Neste último ponto, os especialistas comentaram em ampliar a forma em que a informação é apresentada para poder obter uma ideia mais ampla do comportamento dos pacientes ao longo do tempo em períodos de dias, semanas e meses. Todas as sugestões e como pretendemos resolvê-las, as comentamos nas conclusões da dissertação.

\section{6}

\section{Discussão}

Independentemente da especialidade dos participantes, o aplicativo provou ser fácil de usar para eles conforme figura 6.6.

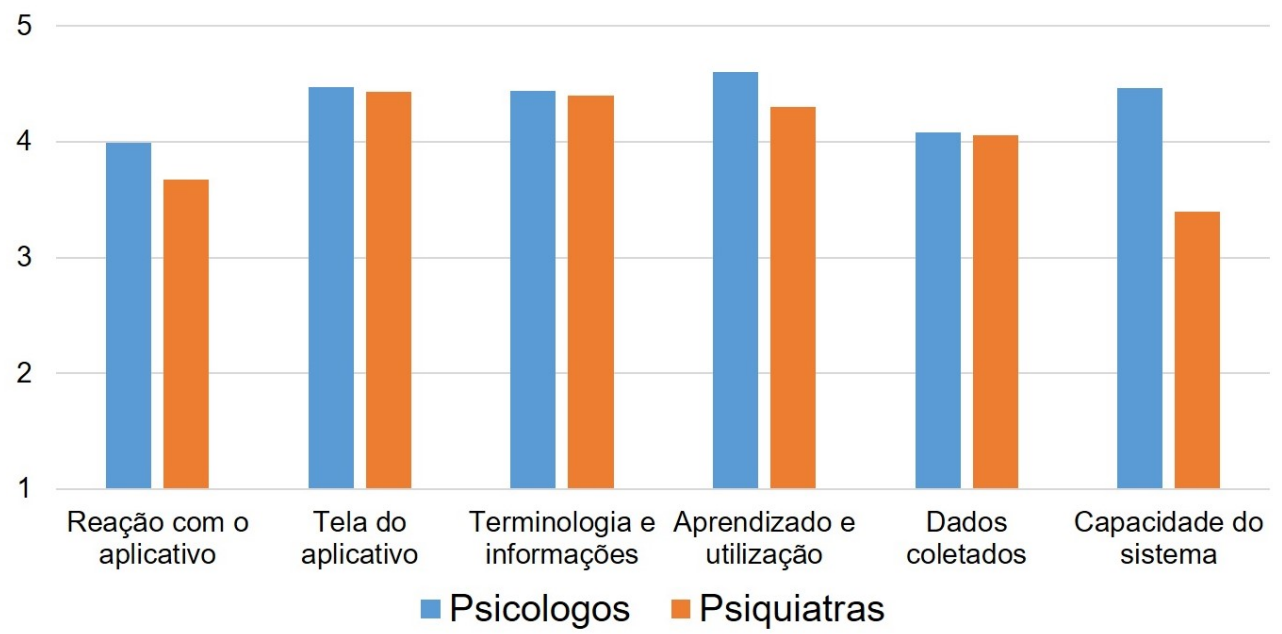

Figura 6.6: Relação entre participantes e pontuação obtida no teste de nomofobia.

Lembrando que foram 3 psicólogos e 2 psiquiatras os participantes deste estudo, na figura anterior podemos comentar que os psicólogos tiveram uma avaliação em média de 4,34 (u) e os psiquiatras 4,04 (u) para uma média geral de 4,19 (u). No caso das avaliações embaixo da linha média, por parte da 
categoria "Reação com o aplicativo", refere-se a que os psiquiatras consideraram que a informação apresentada no aplicativo pode ser melhorada conforme recomendações feitas em seções posteriores deste trabalho, concordando com a média obtida por parte dos psicólogos. Por outra parte, na categoria "Capacidade do sistema" a qualificação baixou devido a que um dos psiquiatras classificou o item "Corrigir erros ao usar o aplicativo é" como Não Aplica, logo, ao fazer a média, este resultado abaixou a média geral. Entretanto, achamos este issue, poderia ter acontecido por falta de clareza no formulário.

Coincidindo com o estudo realizado com participantes no capítulo 5, percebemos que os participantes mais jovens demonstraram uma maior habilidade de realizar as tarefas indicadas que os especialistas mais experientes. Mesmo assim, eles realizaram todas as atividades. No entanto, achamos que poderíamos melhorar as instruções ao operar o BraPolar pela primeira vez incluindo um assistente que explique à pessoa que vai operar com o aplicativo, o funcionamento das funcionalidades do mesmo.

Em relação a como o monitoramento remoto em tempo real, apoiados da fenotipagem digital, tanto psicólogos e psiquiatras concluíram que o BraPolar pode ser uma solução interessante para acompanhar os pacientes no percurso da sua doença após avaliar os 5 "pacientes" no teste. Neste sentido, conhecer com antecedência o grau de dependência ao celular, pode ser um aliado nas fases precoces da pesquisa e ajuda a complementar o perfil do usuário pois nessas fases iniciais se conhece muito pouco de como o usuário usualmente interage com seu dispositivo móvel. Entretanto eles comentaram que poderia ser melhorada a forma em que é apresentada a informação no aplicativo com o auxílio de gráficos para perceber a flutuações de cada indicador coletado ao longo do tempo. Por outra parte, eles consideraram que um maior tempo de dados coletados através da fenotipagem digital poderia lhes auxiliar a melhorar a acurácia nos resultados em tempo real.

Considerando as funcionalidades desenvolvidas em BraPolar, os especialistas concordaram que, embora o aplicativo ainda não seja uma solução completa devido à complexidade do assunto entretanto, poderia se tornar um grande aliado na detecção oportuna de flutuações no comportamento antes que estas atinjam alguma consequência severa na vida dos pacientes com TAB. Nesse sentido, eles comentaram que seria relevante incluir a análise de média de uso de cada uma das funcionalidades do BraPolar, para obter uma linha base de como eles se comportam ao longo do tempo. Também comentaram que seria interessante incorporar no atendimento, um familiar próximo ao paciente e que este possa monitorar o comportamento do paciente em conjunto com o especialista e, sobretudo, engajar os pacientes através de técnicas que 
induzam a inserir informações verídicas no aplicativo além de incorporar mais uma funcionalidade no aplicativo intitulada Níveis de Energia com o intuito de obter um indicador de estado de ânimo complementar.

Finalmente, na imagem 6.7, gerada com WordCloud ${ }^{1}$ podemos perceber as palavras mais mencionadas por parte dos especialistas onde o foco é, sempre, o paciente.

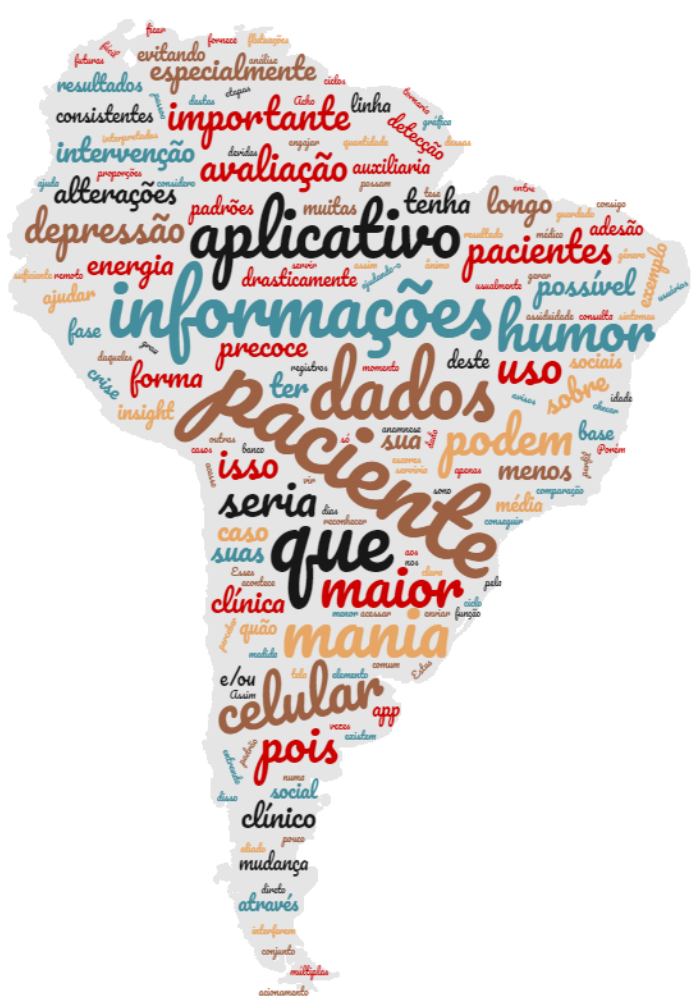

Figura 6.7: Palavras mais comentadas pelos especialistas na entrevista gerada em WordCloud.

Com o anterior, torna-se evidente, portanto, a relevância que o BraPolar poderia oferecer como complemento no dia-dia de pessoas com TAB, ressalvadas as limitações que este possui.

\section{7}

\section{Conclusões do capítulo}

Neste capítulo realizamos duas avaliações com o intuito de conhecer qual é a percepção que os especialistas têm de cada funcionalidade desenvolvida no BraPolar e como o monitoramento remoto e a fenotipagem digital poderiam auxiliar os especialistas a detectar flutuações no comportamento.

Para conhecer a percepção que os especialistas têm sobre o BraPolar, realizamos um teste o qual consistiu em expor um cenário e um conjunto

\footnotetext{
${ }^{1}$ https : //www. wordclouds.com/
} 
de tarefas, após, avaliamos através de um QUIS um conjunto de indicadores tais como reação do uso com o aplicativo, terminologia e aprendizado, os quais foram oportunamente descritos em seções anteriores. Nele, obtivemos que tanto psicólogos quanto psiquiatras consideraram o BraPolar fácil de usar mas deixaram algumas recomendações a ser implementadas em posteriores versões do projeto. Numa primeira avaliação, consultamos como o monitoramento remoto e a fenotipagem digital poderiam lhes auxiliar a detectar flutuações no comportamento. Para conduzir este estudo, fragmentamos esta pergunta em 6 sub-questões nas quais obtivemos que os especialistas avaliaram cada um dos pacientes seguindo as orientações descritas no roteiro de teste. Nos resultados, obtivemos que os especialistas podem se apoiar do BraPolar como ferramenta de suporte nas avaliações clínicas convencionais, ressalvadas as limitantes do mesmo.

No próximo capítulo apresentamos as conclusões gerais da dissertação e fornecemos sugestões para trabalhos futuros. 


\section{Conclusões e trabalhos futuros}

Nesta dissertação apresentamos a solução BraPolar como proposta para o monitoramento remoto em tempo real de pessoas com TAB apoiados da fenotipagem digital. Para conduzir este estudo, realizamos um conjunto de testes com voluntários e especialistas em psicologia/psiquiatria com o intuito de validar a solução proposta e concluímos que o BraPolar constitui uma ferramenta de apoio aos especialistas em psicologia/psiquiatria . Cientes de que toda obra humana possui limitações, neste capítulo abordaremos as principais contribuições obtidas na pesquisa e comentamos um conjunto de limitantes e propostas a serem realizadas em posteriores pesquisas.

\section{1}

\section{Principais contribuições}

O desenvolvimento deste trabalho foi conduzido através de um estudo empírico. Inicialmente realizamos uma revisão da literatura, e após isso propusemos e desenvolvemos uma solução. Finalmente, realizamos um conjunto de experimentos com voluntários e especialistas na saúde mental. A seguir resumimos e comentamos nossas principais considerações:

Estudar as caraterísticas que deve ter uma m-health para o monitoramento remoto em tempo real de pessoas com TAB. Num primeiro momento, fizemos uma revisão da literatura para nos familiarizarmos com o tratamento de doenças mentais e as principais dificuldades abordadas na literatura médica a respeito do TAB [19] [20]. Com o intuito de conhecer as soluções existentes, realizamos uma pesquisa na qual encontramos um conjunto de soluções [14] [15] [16] [17] [18] com certo grau de semelhança ao que pretendíamos desenvolver. Neste sentido, na seção 2 apresentamos os resultados da revisão bibliográfica realizada para esta pesquisa e na seção 3 como conduzimos o estudo. Em futuras pesquisas poderão ser incorporados novos requerimentos para complementar a solução proposta.

Desenvolver e avaliar o BraPolar para o monitoramento remoto de pessoas com TAB. Baseados nos resultados da revisão da literatura, identificamos um conjunto de características que uma m-Health deve possuir para o monitoramento remoto de pessoas com TAB, coincidindo várias características com as propostas realizadas pelos colaboradores do IPUB e sintetizadas na proposta BraPolar. Após, realizamos todo o processo de desenvolvimento onde selecionamos a arquitetura para nossa proposta considerando Firebase para 
a coleta da fenotipagem digital em tempo real, o que nos permitiu otimizar parte do processo de desenvolvimento da solução. Este processo, foi descrito com mais detalhes no capítulo 4 desta dissertação. Ao finalizar, para validar a solução proposta, realizamos dois testes com voluntários e especialistas os quais foram comentados nos capítulos 5 e 6 , respectivamente. Considerando a complexidade do produto com Firebase e o baixo consumo de recursos, constitui um modelo a seguir em posteriores pesquisas relacionadas.

Após desenvolver o BraPolar, conduzimos nosso estudo com 6 pessoas não bipolares. Realizamos um teste de dependência ao celular onde descobrimos que uma das participantes possuía nomofobia severa. Depois fizemos um teste de usabilidade onde detectamos que não existe uma relação direta entre o nível de dependência ao celular e a facilidade com que as pessoas realizam as atividades num teste de usabilidade. No teste de usabilidade obtivemos resultados positivos com as tarefas feitas pelos participantes.

Após realizar a avaliação com pacientes, realizamos a coleta da fenotipagem digital por um mês. Após disso, realizamos a avaliação com psicólogos e psiquiatras. Aplicamos um teste de usabilidade com eles e consultamos as principais dificuldades que eles tiveram. No teste, descobrimos que tanto a análise da fenotipagem digital quanto o conhecimento prévio do nível de nomofobia poderiam ser usados como indicadores para auxiliar os especialistas no acompanhamento dos pacientes. Por outra parte, BraPolar pode ser usado como um método inovador para dar seguimento aos pacientes com TAB no Brasil mas, pela complexidade do assunto e considerando as devidas limitações, o aplicativo pode vir a ser um aliado. Podemos concluir, portanto, que o objetivo geral desta pesquisa foi cumprido, considerando as seguintes limitações e recomendações.

\section{Inclusão ao conceito de fenotipagem digital, o teste de depen-} dência ao celular. Considerando que cada pessoa, independentemente se portadora ou não de TAB, possui distinto grau de dependência ao celular, propomos aplicar o teste de nomofobia para que os especialistas pudessem obter o perfil do usuário, baseado no teste de dependência. Este teste, ao adicioná-lo à fenotipagem digital, permite obter um marcador inicial do padrão normal para cada pessoa e após feita a coleta da fenotipagem digital, estes como um todo auxiliam no acompanhamento por parte dos especialistas, aos pacientes que atendem. Desta forma, monta-se um perfil do usuário mais completo. 


\section{2}

\section{Limitações}

A continuação apresentamos as principais limitações desta dissertação e propomos como abordá-las em trabalhos futuros.

Limitações teóricas Essas limitações incluem as ameaças aos aspectos teóricos que afetam o estudo, eventuais deficiências de nossa revisão de literatura sobre abordagens de TAB e tópicos relacionados.

- BraPolar foi concebido através de um trabalho interdisciplinar entre os Departamentos de Informática e Psicologia da PUC-Rio e o uso de alguns termos para ambas áreas resultou um desafio com o qual a equipe teve que superar. Por outra parte, não podemos generalizar com os resultados obtidos irão acontecer da mesma forma com pacientes com TAB. Em consequência, um fator a ter em conta, é que cada paciente pode ter diferentes níveis dependência ao celular (ao usar seu dispositivo móvel) e, pode influenciar no resultado da pesquisa. Portanto, em dependência do momento que for realizado este teste em pessoas com TAB, a informação obtida poderia ter distorção se o teste for aplicado quando o paciente se encontrasse em estado maníaco ou depressivo. Neste sentido, o acompanhamento por parte de um dos familiares do paciente, poderia auxiliar a obter resultados mais fieis.

- Conjunto limitado de participantes: 6 participantes na primeira avaliação e 5 na segunda. Consideramos que uma amostra maior provavelmente aumentaria a confiabilidade da pesquisa o que pode ter afetado a generalidade de nossas conclusões. A amostra dos participantes de ambos os estudos podem não ser suficientes para alcançar resultados conclusivos, pois esse tamanho da amostra não nos permitiu alcançar resultados estatisticamente significativos além de uma abordagem geral da solução proposta.

Limitações com BraPolar Essas limitações incluem as ameaças às avaliações realizadas nos capítulos 5 e 6 que afetam o estudo.

- Durante o desenvolvimento do trabalho, uma das principais limitações do estudo foram os longos períodos sugeridos pelos especialistas na avaliação da aplicação com pessoas com TAB, o que implica um tempo maior para obtenção de resultados confiáveis. Entretanto, consideramos que para efeitos de uma pesquisa piloto com pessoas não bipolares, é suficiente. Consideramos também que num posterior estudo, uma grande quantidade de tempo é necessária para avaliar se a qualidade de vida dos pacientes envolvidos melhorará após o uso da aplicação e como isso ajudará os especialistas no processo de monitoramento remoto. 
- A atual versão de BraPolar é compatível apenas com Android 4.0 (Ice Cream Sandwich) e versões posteriores. Consideramos utilizar versões anteriores para aumentar a gama de dispositivos compatíveis mas perderíamos a compatibilidade com Firebase.

- A utilização de componentes externos como MiBand ou outros dispositivos poderia ter sido usado para melhorar a precisão dos dados coletados por possíveis distorções no acelerômetro ou GPS dos celulares dos participantes. Concluímos que poderia ser um inconveniente utilizá-los em pessoas de idade mais avançada ou em pessoas que não tenham costume em usá-lo quando estiverem em estado maníaco ou depressivo. Tanto os psicólogos quanto psiquiatras coincidiram em dispensar o uso destes dispositivos para esta pesquisa.

Disclaimer: a equipe de trabalho não se responsabiliza por um uso exclusivo de BraPolar no tratamento de doenças mentais. Consideramos que a solução proposta constituiu uma ferramenta de apoio aos especialistas no monitoramento remoto de seus pacientes e não deve ser utilizado de forma exclusiva como alternativa nesta ou outra doença.

\section{3}

\section{Trabalhos futuros}

Considerando as anteriores contribuições e limitações sinalizadas, existem várias sugestões para trabalhos futuros com base nos objetivos alcançados desta dissertação. A seguir apresentamos algumas sugestões que ajudam a abordar as limitações comentadas na seção anterior.

- Nos próximos estudos, após aprovação do projeto na Plataforma Brasil do Ministério da Saúde, conduzir o estudo com o IPUB e pacientes com transtorno bipolar do tipo II, seguindo os critérios do DSM-IV. Será estabelecida uma linha de base de 3 meses onde será coletada a fenotipagem digital e os especialistas irão monitorar em tempo real as variações no comportamento de pacientes enquanto estes profissionais realizam o atendimento convencional com o intuito de poder monitorar como o paciente se comporta de uma consulta a outra.

- Conseguir dados para traçar uma média da dependência ao celular em pessoas sãs e utilizá-la como referência para um posterior estudo com pessoas com TAB. Após, estabelecer o vínculo entre eles identificando a relação de dependência ao celular das pessoas sãs sobre aos portadores de TAB ou outras doenças psicológicas.

- Considerando que os pacientes com TAB podem processar informação inconscientemente, propomos utilizar BraPolar como ferramenta de normalização de autoconsciência. Considerando que os pacientes têm acesso às infor- 
mações coletadas, propor estratégias de normalização do insight, através de conselhos psicoeducativos nas distintas fases críticas: mania, e depressão com o intuito de alcançar a estabilização do humor.

- Estabelecer sistema de alerta antecipado. Considerando que cada especialista atende a mais de um paciente e cada paciente possui distinto grau de dependência ao celular, visamos utilizar a fenotipagem digital coletada por 3 meses para criar um sistema de alertas onde o especialista ou familiar acompanhante recebam uma notificação quando, por exemplo, o paciente saia do seu padrão normal para seu perfil nomofóbico, conforme comentado com os especialistas e concretizados pelo autor desta dissertação.

- Finalmente, visamos utilizar estratégias de engajamento para inserir informações que requerem a interação ativa por parte dos pacientes com o aplicativo sem interferir notavelmente no seu dia-dia.

Torna-se evidente, portanto, que a proposta BraPolar constitui uma ferramenta para o apoio ao monitoramento remoto em pessoas com TAB e o primeiro passo para pesquisas futuras de $\mathrm{m}$-Health de apoio a doenças mentais. 


\section{8}

\section{Referências bibliográficas}

[1] ALVES FONSECA, F.; MOGRABI, D. ; LANDEIRA-FERNANDEZ, J.. O insight implícito em pacientes com Transtorno Bipolar. $\mathrm{PhD}$ thesis, Pontifícia Universidade Católica do Rio de Janeiro, 2018. 1, 2.6

[2] CENTER FOR CLINICAR INTERVENTIONS. Detecting Early. Detecting Early Warning Signs, 2015. 1

[3] PUIATTI, A.; MUDDA, S.; GIORDANO, S. ; MAYORA, O.. Smartphonecentred wearable sensors network for monitoring patients with bipolar disorder. Proceedings of the Annual International Conference of the IEEE Engineering in Medicine and Biology Society, EMBS, p. 3644-3647, 2011. 1

[4] JAIN, S. H.; POWERS, B. W.; HAWKINS, J. B. ; BROWNSTEIN, J. S.. The digital phenotype. Nature Biotechnology, 33:462, may 2015. 1

[5] NATIONAL INSTITUTE OF MENTAL HEALTH. Transforming the understanding and treatment of mental illnesses, 2017. 1.1

[6] ACADEMIA NACIONAL DE MEDICINA. ANM realiza Simpósio sobre psicopatologia e análise clínica do Transtorno Bipolar, 2017. 1.1

[7] INSIGHTS, B.. Mental Healt Education Center, 2016. 1.1

[8] INOCENTI, A.; HELENA, S.; CASSIANI, D. B. ; PEDR, L. J.. Transtorno afetivo bipolar e a ambivalência em relação à terapia medicamentosa. 45(2):433-441, 2011. 1.1

[9] FAURHOLT-JEPSEN, M.; BUSK, J.; PÓRARINSDÓTTIR, H.; FROST, M.; BARDRAM, J. E.; VINBERG, M. ; KESSING, L. V.. Objective smartphone data as a potential diagnostic marker of bipolar disorder. Australian \& New Zealand Journal of Psychiatry, 53(2):119-128, 2018. 1.1, 2.3

[10] FOLEY, C.. The Alberta Library, 2018. 1.1

[11] STATISTA - THE STATISTICS AND STUDIES PORTAL. Smartphone Addiction Tightens Its Global Grip, 2017. 1.1 
[12] WOLLENHAUPT-AGUIAR, B.; PEREIRA, C. S.; VIANNA-SULZBACH, M.; GOI, P. D. ; ANNA, M. K.-S.. Bipolar Disorder Affects Behavior and Social Skills on the Internet. PLOS ONE, 8(11), 2013. 1.1, 2.3

[13] CHENIAUX, E.; LAGE GONÇALVES, L.; SPEAR KING, A. L. ; EDIGIO NARDI, A.. NOVOS HUMANOS 2030: Como será a humanidade convivendo com as tecnologías digitales. 2019. 1.1, 2.3

[14] OSMANI, V.; MAXHUNI, A.; GRÜNERBL, A.; LUKOWICZ, P.; HARING, C. ; MAYORA, O.. Monitoring activity of patients with bipolar disorder using smart phones. p. 85-92, 2014. 1.1, 2.6, 4.2, 7.1

[15] BARDRAM, J. E.; FROST, M.; SZÁNTÓ, K.; FAURHOLT-JEPSEN, M.; VINBERG, M. ; VEDEL KESSING, L.. Designing Mobile Health Technology for Bipolar Disorder: A Field Trial of the MONARCA System. In: SIGCHI CONFERENCE ON HUMAN FACTORS IN COMPUTING SYSTEMS, p. 2627-2636, Paris, 2013. 1.1, 2.6, 4.2, 7.1

[16] ZULUeTA, J.; PISCITEllo, A.; RASIC, M.; EASTER, R.; BABU, P.; LANGENECKER, S. A.; MCINNIS, M.; AJILORE, O.; NELSON, P. C.; RYAN, K. ; LEOW, A.. Predicting mood disturbance severity with mobile phone keystroke metadata: A biaffect digital phenotyping study. Journal of Medical Internet Research, 20(7):1-10, 2018. 1.1, 2.6, 4.3, 4.4.2, 7.1

[17] PRISCIANDARO, J. J.; TOLLIVER, B. K.. An item response theory evaluation of the young mania rating scale and the montgomeryasberg depression rating scale in the systematic treatment enhancement program for bipolar disorder (STEP-BD). Journal of Affective Disorders, 205:73-80, 2016. 1.1, 2.6, 4.2, 4.3, 4.4.1, 4.4.2, 7.1

[18] HEALTHLINE. The Best Bipolar Apps of 2018, 2018. 1.1, 2.6, 4.3, $4.3,7.1$

[19] HILTY, D. M.; BRADY, K. T. ; HALES, R. E.. A Review of Bipolar Disorder Among Adults. Psychiatric Services, 50(2):201-213, 2014. $2.1,7.1$

[20] ANTIN, A. I. D. A. S.; ERESÉR, K. E. C.. Adesão ao tratamento no transtorno bipolar Compliance to Treatment in Bipolar Disorder. Rev. Psiq. Clín, p. 105-109, 2005. 2.1, 7.1 
[21] FIGUEIREDO, A. C.; TENÓRIO, F.. O diagnóstico em psiquiatria e psicanálise. Revista Latinoamericana de Psicopatologia Fundamental, 5(1):29-43, 2002. 2.1

[22] DA SILVA, R. D. A.; MOGRABI, D. C.; SILVEIRA, L. A. S.; NUNES, A. L. S.; NOVIS, F. D.; CAVACO, P. A.; LANDEIRA-FERNANDEZ, J. ; CHENIAUX, E.. Mood self-assessment in bipolar disorder: a comparison between patients in mania, depression, and euthymia. Trends in Psychiatry and Psychotherapy, 35(2):141-145, 2013. 2.1, 3.4

[23] DE ASSIS DA SILVA, R.; MOGRABI, D. C.; SILVEIRA, L. A. S.; NUNES, A. L. S.; NOVIS, F. D.; LANDEIRA-FERNANDEZ, J. ; CHENIAUX, E.. The reliability of self-assessment of affective state in different phases of bipolar disorder. Journal of Nervous and Mental Disease, 202(5):386390, 2014. 2.1, 3.4

[24] ROHAN, K. J.; ROUGH, J. N.; EVANS, M.; HO, S. Y.; MEYERHOFF, J.; ROBERTS, L. M. ; VACEK, P. M.. A protocol for the Hamilton Rating Scale for Depression: Item scoring rules, Rater training, and outcome accuracy with data on its application in a clinical trial. Journal of Affective Disorders, 200:111-118, 2016. 2.2, 6.5.2

[25] LIMA, M. S. D.; GARCIA, B.; SOARES, D. O.; PAOLIELLO, G.; VIEIRA, R. M.; MARTINS, C. M.; IGNÁCIO, J.; FERRÃO, Y.; SCHIRMER, D. A. ; VOLPE, F. M.. The Portuguese version of the Clinical Global Impression - Schizophrenia Scale : validation study Versão em português da Impressão Clínica Global - Escala de Esquizofrenia : estudo de validação. 29(3):246-249, 2007. 2.2, 6.5.2

[26] AVELAR FERREIRA, C. A.; AZEVEDO GUIMARÃES, H. A.; GUATIMOSIM AZEVEDO, M. A. ; GATTI MENEZES, F.. Identificação Dos Potenciais Ao Carbonato De Lítio Em Um Identification of Potential Risks of Adverse Reactions To Lithium Carbonate in a Public. REVISTA DE SAÚDE PÚBLICA DO SUS/MG, 2(1). 2.2

[27] DA SILVA, R. D. A.; MOGRABI, D. C.; LANDEIRA-FERNANDEZ, J. ; CHENIAUX, E.. O insight no transtorno bipolar: Uma revisão sistemática. Jornal Brasileiro de Psiquiatria, 63(3):242-254, 2014. 2.2, 3.4

[28] MURNANE, E. L.; HUfFAKER, D. ; KOSSINETS, G.. Mobile Health Apps : Adoption, Adherence, and Abandonment. UBICOMP/ISWC '15, p. 261-264, 2015. 2.3, 4.2 
[29] BOURLA, A.; FERRERI, F.; OGORZELEC, L.; GUINCHARD, C. ; MOUCHABAC, S.. Évaluation des troubles thymiques par l'étude des données passives: Le concept de phénotype digital à l'épreuve de la culture de métier de psychiatre. [Assessment of mood disorders by passive data gathering: The concept of digital phenotype versus psychiatrist's professional culture.], 2018. 2.3, 4.2

[30] BARDRAM, J. E.; FROST, M. ; MARCU, G.. The MONARCA Selfassessment System - Persuasive Personal Monitoring for Bipolar Patients. 5th International Conference on Pervasive Computing Technologies for Healthcare (PervasiveHealth) and Workshops, 2011. 2.3

[31] CARVALHO, L. D. F.; PIANOWSKI, G.. Digital phenotyping and personality disorders: A necessary relationship in the digital age. Psicologia - Teoria e Prática, 21(2):122-133, 2019. 2.4

[32] YILDIRIM, C.; CORREIA, A. P.. Exploring the dimensions of nomophobia: Development and validation of a self-reported questionnaire. Computers in Human Behavior, 49:130-137, 2015. 2.5, 5.2.1, 5.4.1, 6.1

[33] AUGUSTO HERNANDES ROCHA, T.; THUMÉ, E.; CRISTINA DA SILVA, N.; CLAUDIUS QUEIROZ BARBOSA, A.; DO CARMO, M.; MARÇAL RODRIGUES, J. ; AUGUSTO FACHINI, L.. Saúde Móvel: novas perspectivas para a oferta de serviços em saúde. Epidemiologia e Serviços de Saúde, 25(1):1-10, 2016. 2.6

[34] GRAVENHORST, F.; MUAREMI, A.; BARDRAM, J.; GRÜNERBL, A.; MAYORA, O.; WURZER, G.; FROST, M.; OSMANI, V.; ARNRICH, B.; LUKOWICZ, P. ; TRÖSTER, G. Mobile phones as medical devices in mental disorder treatment: an overview. Personal and Ubiquitous Computing, 19(2):335-353, 2015. 2.6

[35] MATTHEWS, M.; VOIDA, S.; ABDULLAH, S.; DOHERTY, G.; CHOUDHURY, T.; IM, S. ; GAY, G.. In situ design for mental illness: Considering the pathology of bipolar disorder in mHealth design. MobileHCI Proc, p. 86-97, 2015. 2.6

[36] LÚCIO PITA, G.. Design por todos: participação de deficientes visuais no codesign de interação humano-computador. 2016. 2.6, $4.3,4.3,4.4 .2$ 
[37] DEPP, C. D.; BEN-ZEEV, D.; PH, D.; PATTERSON, T. L.; PH, D. ; LEBOWITZ, B. D.. Preliminary Data from Three Approaches. 198(10):715-721, 2011. 2.6, 4.3, 4.4.1, 4.4.2

[38] SCOTT, J.; COLOM, F.; POPOVA, E.; BENABARRE, A.; CRUZ, N.; VALENTI, M.; GOIKOLEA, J. M.; SÁNCHEZ-MORENO, J.; ASENJO, M. A. ; VIETA, E.. Long-term mental health resource utilization and cost of care following group psychoeducation or unstructured group support for bipolar disorders: a cost-benefit analysis. The Journal of clinical psychiatry, 70(3):378-386, mar 2009. 2.6

[39] COLLIS, J.; HUSSEY, R.. Business Research: A Practical Guide for Undergraduate and Postgraduate Students. Palgrave Macmillan, 4th edition, 2003. 3.1

[40] BELL, J.. Doing Your Research Project: A Guide for First-Time Researchers in Education and Social Science. London, 4th edition, 2005. 3.1

[41] DENZIN, N. K.; LINCOLN, Y. S.. Introduction: The Discipline and Practice of Qualitative Research. In: THE SAGE HANDBOOK OF QUALITATIVE RESEARCH, 3RD ED., p. 1-32. Sage Publications Ltd, Thousand Oaks, CA, 2005. 3.1

[42] LANGKOS, S.. An empirical investigation to the city's imagery and the role of local DMO's. PhD thesis, University of Derby, 2014. 3.1

[43] FREEDMAN, D. A.; PISANI, R. ; PURVES, R. A.. Statistics. W. W. Norton \& Company, New York, 4th edn. $n$ edition, 2007. 3.2

[44] MONTI, M.. Projeto de Lei da Câmara $n^{\circ}$ 53, de 2018, 2018. 3.4

[45] FAURHOLT-JEPSEN, M.; VINBERG, M.; FROST, M.; CHRISTENSEN, E. M.; BARDRAM, J. E. ; KESSING, L. V.. Smartphone data as an electronic biomarker of illness activity in bipolar disorder. Bipolar Disorders, 17(7):715-728, 2015. 4.1

[46] DA COSTA, R.; ZOÉGA SOARES, M. R. ; GROSSI, R.. Estrutura das sessões de uma intervenção analítico-comportamental em grupo para pessoas diagnosticadas com transtorno bipolar. Acta Comportamentalia, 25(1):57-72, 2017. 4.1, 4.2, 5.4 
[47] MATTHEWS, M.; ABDULLAH, S.; MURNANE, E.; VOIDA, S.; CHOUDHURY, T.; GAY, G. ; FRANK, E.. Development and Evaluation of a Smartphone-Based Measure of Social Rhythms for Bipolar Disorder. Assessment, 23(4):472-483, 2016. (document), 4.1

[48] LOPEZ, M. A.. Remote work culture in IT companies. 2016. 4.2

[49] EYBEN, F.; HUBER, B.; MARCHI, E.; SCHULLER, D. ; SCHULLER, B.. Real-time robust recognition of speakers' emotions and characteristics on mobile platforms. 2015 International Conference on Affective Computing and Intelligent Interaction, ACII 2015, p. 778-780, 2015. 4.2

[50] CARNEY, M.. AnyPresence partners with Heroku to beef up its enterprise mBaaS offering, 2013. 4.4.1

[51] MOHAMMED, M. A.; BRIGHT, A. S. K.; APOSTOLIC, C.; ASHIGBE, F. D. ; SOMUAH, C.. Mobile-Based Medical Health Application -MediChat App. International Journal of Scientific \& Technology Research, 6(05):70-76, 2017. 4.4.1

[52] J. RANA AND A. BAJPAYEE. HealthCare Monitoring and Alerting System Using Cloud Computing. International Journal on Recent and Innovation Trends in Computing and Communication, 3(2):102-105. 4.4.1

[53] SHAIKH, Z.. E-Healthcare Android Application based On Cloud Computing. International Journal on Recent and Innovation Trends in Computing and Communication, p. 307-310, 2018. (document), 4.4.1, 4.7

[54] STONE, D.; JARRETT, C.; WOODROFFE, M. ; MINOCHA, S.. User Interface Design and Evaluation. San Francisco, 2005. 5.1

[55] NOGUEIRA, J.. Reflexões sobre métodos de avaliação de interface. $\mathrm{PhD}$ thesis, Universidade Federal Fluminense, 2003. 5.4

[56] NIELSEN, J.; BLATT, L. A.; BRADFORD, J. ; BROOKS, P.. Usability Inspection Method. p. 413-414, 1994. 5.4 
9

Anexos

9.1

Anexo A Termo de consentimento livre e esclarecido - Paciente

Termo de consentimento livre e esclarecido - Versão Paciente

Nome:

RG:

Titulo do projeto: "BraPolar: um aplicativo m-health para monitoramento remoto de pessoas com transtorno bipolar"

Pesquisadores responsáveis pelo projeto: Eng. Abel González Mondéjar* / Prof. Dr. Alberto Raposo* / Dr. Greys Francy Mireya Calpa* / Prof. Dr. Daniel Mograbi** / Prof. Dr. Elie Cheniaux***

*Departamento de Informática da Pontifícia Universidade Católica do Rio de Janeiro (PUC-Rio) / **Departamento de Psicologia da Pontifícia Universidade Católica do Rio de Janeiro (PUC-Rio) / ** Instituto de Psiquiatria da Universidade Federal do Rio de Janeiro (IPUB/UFRJ)

Contato:

- Eng Abel G Mondéjar amondejar@inf.puc-rio.br (21) 3527-1500/4338

- Dr Alberto Raposo: abraposo@inf.puc-rio.br (21) 3527-1500/4338

- Dr Greys Francy M. Calpa: gcalpa@inf.puc-rio.br (21) 3527-1500/4338

- Dr Daniel Mograbi: danielmograbi@puc-rio.br (21) 3527-2086/2075

- Dr. Elie Cheniaux echeniaux@gmail.com (21) 3938-5510

Comitê de ética em pesquisa do IPUB/UFRJ: Endereço Av. Venceslau Brás 71, fds - Prédio da Direção - $2^{\circ}$ andar - sala do CEP. 22.290-140 - Campus Praia Vermelha - Botafogo - Rio de Janeiro. Telefone/Fax: 55 (21) 3938-5510 
Termo de consentimento livre e esclarecido - Versão do Paciente

Você está convidado a participar de uma pesquisa científica realizada pela Pontifícia Universidade Católica do Rio de Janeiro (PUC-Rio) e pelo Instituto de Psiquiatria da UFRJ (IPUB). Este projeto de pesquisa foi aprovado pelo comitê de ética em pesquisa (CEP) do IPUB.

Primeiro, gostaríamos de esclarecer que a sua participação é inteiramente voluntária, isto é, você pode optar por não participar ou se retirar a qualquer momento do estudo. Embora não haja garantia de qualquer benefício pessoal, a sua participação na pesquisa certamente ajudará para o avanço do conhecimento científico na área. A base legal de este TCLE vasa-se no Art 7, Secção IV da Lei no. 13.709 de 14 de agosto de 2018 sobre a proteção de dados pessoais.

A sua identidade estará protegida o tempo todo. Não haverá qualquer despesa para você por participar desse projeto. Sinta-se à vontade para discutir qualquer dúvida ou preocupação de ordem médica ou pessoal com a equipe médica, científica ou de apoio, antes do fornecer seu consentimento. Mesmo após, a qualquer momento, você poderá retirar seu consentimento e retirar-se do estudo.

\section{Objetivo do estudo}

O principal objetivo do projeto é adaptar para o Brasil uma solução para a monitoração do transtorno afetivo bipolar usando dispositivos móveis como marcador de estado e traço de intervenção terapêutica não invasiva para os pacientes e especialistas. Com este estudo, pretendemos detectar precocemente e observar alterações do insight nos pacientes. Atualmente não é oferecido na rede pública nenhum acompanhamento usando os dispositivos móveis para pessoas com TAB no Brasil, e com esse estudo pretendemos dar um passo na direção de aumentar o número de tratamentos para transtorno afetivo bipolar em nosso país. Para isso, trabalharemos com um grupo de pessoas com TAB enquanto seguem seu tratamento rotineiro.

\section{A sua participação envolverá:}

(1) Leitura e assinatura deste documento com consentimento;

(2) Manuseio do prontuário do paciente por parte do pesquisador responsável;

(3) Entrevista com o pesquisador responsável;

(4) Preenchimento de um questionário online pelo paciente;

(5) Instalação e capacitação do aplicativo para o monitoramento das atividades. 


\section{Instalação do aplicativo}

Você será notificado por um pesquisador participante do projeto o dia que deverá comparecer para a instalação no seu dispositivo móvel. Após a instalação, você responderá o questionário Teste de Nomofobia disponivel online. Esse questionário é geralmente aplicado para conhecer seu estado no início da avaliação e os padrões de uso e interação com seu dispositivo móvel, não existem respostas certas ou erradas, e sua honestidade é fundamental para o sucesso do nosso estudo. Depois, de instalado e respondido o formulário anteriormente mencionado, será instalado no seu smartphone o aplicativo e o pesquisador responsável the ensinará como trabalhar com ele.

\section{Monitoramento das atividades}

Uma vez que você tenha instalado o aplicativo, o mesmo vai monitorar a sua atividade com o objetivo de detectar uma possível mudança de estado. Verificaremos padrões de uso que possam ajudar-nos a detectar precocemente mudanças em seu estado, tendo em conta a sua privacidade, só levaremos o controle quantitativo de alguns indicadores e não o conteúdo em si deles.

\section{Benefícios:}

A sua participação poderá trazer benefícios leves e passageiros no seu estado e qualidade de vida, mas não há nenhuma garantia disso. O estudo proporcionará um melhor conhecimento a respeito de formas de tratamento para a bipolaridade, o que poderá traduzir-se em benefícios futuros à comunidade como um todo.

\section{Eventos adversos}

A participação no estudo não constitui uma inconveniência na sua vida diária, pois não há necessidade de deslocamento ao centro de pesquisa, nem tempo em entrevistas além do encontro e configurações iniciais. $O$ benefício clínico ao participar do estudo não está estabelecido, entretanto, como trata-se de uma intervenção não farmacológica, não são esperados eventos adversos decorrentes da mesma. As informações que obtivermos a partir deste estudo podem nos ajudar a validar no nosso meio uma estratégia de tratamento não farmacológica para pacientes portadores de transtorno afetivo bipolar. $\mathrm{O}$ único possivel evento adverso é desconforto com perguntas que podem ser vistas como pessoais pelos participantes. A negativa em respondê-las está garantida pelos pesquisadores e consignada no TCLE. Entretanto, no caso de ocorrerem crises de ansiedade, as perguntas serão suspensas e você será encaminhado ao seu médico assistente no CDA imediatamente. 


\section{Diretos do Sujeito Pesquisado:}

Você é livre para parar sua participação a qualquer momento sem nenhuma penalização ou prejuízo. Caso esteja em tratamento, a interrupção de sua participação no estudo não implicará em qualquer prejuízo ao mesmo. Em qualquer etapa do estudo, você terá acesso a representantes da equipe de pesquisa do Instituto de Psiquiatria da UFRJ (IPUB). A equipe pode ser contatada a qualquer momento para tirar qualquer dúvida ou para obter atualização sobre os resultados parciais da pesquisa. Se você tiver alguma consideração ou dúvida sobre a ética da pesquisa, entre em contato com o CEP do IPUB (tel. 22953449/9549/5549).

As informações coletadas durante a sua participação serão analisadas em conjunto com as informações dos outros voluntários. O seu consentimento permite o uso dos dados coletados apenas para pesquisa científica e educação. Todos os dados relativos à sua participação serão mantidos em local reservado e seguro. Os dados poderão ser discutidos com pesquisadores de outras instituições e publicados em revistas científicas, ou fazerem parte de material educacional. Nenhuma informação privada, ou que possa levar à identificação dos participantes será fornecida a terceiros.

\section{Despesas decorrentes da participação na pesquisa}

Você não terá nenhum custo financeiro decorrente da participação neste estudo, e também não receberá recompensa de qualquer espécie pela participação. Entretanto, se necessário, você terá direito ao ressarcimento relativo às despesas decorrentes exclusivamente do seu transporte para a participação nesta pesquisa.

\section{Acesso aos resultados, dúvidas e esclarecimentos}

O conhecimento dos resultados será opção sua. Na opção de tomar conhecimento sobre os resultados da pesquisa, você poderá solicitar informações referentes a todos os dados resultantes das avaliações, sabendo-se que, na grande maioria dos casos, este conhecimento não trará qualquer benefício individual direto a você; e à divulgação científica destes resultados (sabendo-se que os seus dados individuais não serão divulgados). Você deve guardar uma cópia deste termo de consentimento e toda vez que tiver dúvidas sobre o protocolo do estudo, ou quiser saber os seus resultados, poderá consultar ao pesquisador Daniel Mograbi, pelo telefone (21) 3527-2086/2075 ou Abel González através do e-mail amondejar@inf.puc-rio.br ou pelo telefone (21) 3527-1500/4338. 
Acredito ter sido informado a respeito do estudo acima citado. As etapas do estudo ficaram claras para mim. Concordo voluntariamente em participar deste estudo. Recebi uma cópia assinada deste consentimento livre e esclarecido. Estou ciente que a minha assinatura neste consentimento, como participante, não significa que estou renunciando aos meus direitos legais, de acordo com as leis vigentes no Brasil.

Este termo de consentimento é feito em duas vias, sendo que uma permanecerá em meu poder e outra com o pesquisador responsável.

Eu li e compreendi as explicações sobre este estudo e me foi dada a chance de discutir e fazer perguntas. Forneço aqui o meu consentimento para participação no protocolo de estudo.

Rio de Janeiro, de 2019.

Nome:

Assinatura:

Pesquisador:

Assinatura:

Pesquisadores Responsáveis:

- Eng Abel G Mondéjar amondejar@inf.puc-rio.br (21) 3527-1500/4338

- Dr Alberto Raposo: abraposo@inf.puc-rio.br (21) 3527-1500/4338

- Dr Greys Francy M. Calpa: gcalpa@inf.puc-rio.br (21) 3527-1500/4338

- Dr Daniel Mograbi: danielmograbi@puc-rio.br (21) 3527-2086/2075

- Dr. Elie Cheniaux echeniaux@gmail.com (21) 3938-5510

Comitê de ética em pesquisa do IPUB/UFRJ: Endereço Av. Venceslau Brás 71, fds - Prédio da Direção - $2^{\circ}$ andar - sala do CEP. 22.290-140 - Campus Praia Vermelha - Botafogo - Rio de Janeiro. Telefone/Fax: 55 (21) 3938-5510 
9.2

Anexo B Teste de dependência ao celular

\section{Teste de dependência ao celular}

A avaliação foi retirada do artigo "Computadores em Comportamento Humano", criado por Caglar Yildirim, da Universidade Estadual de lowa, e Ana-Paula Correia, professora associada da ISU's School of Education, os quais identificaram quatro dimensões dessa fobia moderna.

O formulário encontra-se disponível em: https://goo.gl/forms/pAANoV35mqRseuEX2

\section{Seção I: Dados demográficos}

1. Sua idade:

2. Seu sexo: a. Masculino b. Feminino

3. Grau de escolaridade (ex, ensino fundamental): $(4 \text { e } 5)^{1}$

Seção II: Uso do smartphone

6. Há quanto tempo você usa um smartphone?
a. Menos de um ano
b. Mais de 1 ano e menos de 2 anos
c. Mais de 2 anos e menos de 3 anos
d. Mais de 3 anos e menos de 4 anos
e. Mais de 4 anos e menos de 5 anos
f. 5 anos ou mais

7. Você tem um plano de dados móveis que permite acessar a Internet através do smartphone?
a) $\mathrm{Sim}$
b) Não

8. Aproximadamente quanto tempo por dia você acha que gasta usando seu smartphone? horas.

\footnotetext{
${ }^{1}$ Perguntas 4 e 5 não são de nosso interesse para este estudo.
} 
9. Em média, quantas vezes por dia você acha que checa seu smartphone? vezes

10. Com que frequência você costuma checar seu smartphone?
a. A cada 5 minutos
e) a cada hora
b. A cada 10 minutos
f) A cada 2 horas
c. A cada 20 minutos
g) A cada 3 horas
d. A cada 30 minutos
h) Outro (por favor especifique):

11. Por favor, indique o número aproximado de vezes por dia que você faz o seguinte em seu smartphone.

a) Número de chamadas telefônicas feitas por dia:

b) Número de chamadas telefônicas que você recebe por dia:

c) Número de mensagens de texto enviadas por dia:

d) Número de mensagens de texto recebidas por dia:

e) Número de e-mails que você envia por dia:

f) Número de e-mails que você recebe por dia:

12. Aproximadamente, quantos aplicativos você tem em seu smartphone? aplicativos

13. Para quais dos seguintes fins você costuma usar seu smartphone? (Por favor selecione tudo que se aplica.)
$\square$ Verificar e-mail
$\square$ Fazer anotações
$\square$ Verificar mídias sociais
$\square$ Jogar
$\square$ Receber notícias
$\square$ Passar o tempo

$\square$ Procurar informações na Internet

$\square$ Ouvir música

$\square$ Agendar reuniões e eventos

$\square$ Falar com a família ou amigos

$\square$ Trocar mensagens com família ou amigos

$\square$ Outro (por favor, especifique): 
14. Em qual dos seguintes contextos você usaria seu smartphone? (Por favor selecione tudo que se aplica.)

$\square$ Em uma mesa de jantar

$\square$ Quando eu estou chateado

$\square$ Entre classes

$\square$ Durante uma aula

$\square$ Enquanto saio com amigos

$\square$ No banheiro

$\square$ Enquanto converso com alguém

$\square$ No transporte público

$\square$ Enquanto espero por alguém ou algo

$\square$ Enquanto dirijo

$\square$ Enquanto ando

$\square$ Quando estou sozinho

$\square$ Enquanto assisto TV ou um filme

$\square$ Outro (por favor, especifique):

\begin{tabular}{|c|c|c|c|c|c|c|c|}
\hline \multirow{2}{*}{$\begin{array}{l}\text { Por favor, indique o quanto você concorda ou } \\
\text { discorda de cada declaração em relação ao uso do } \\
\text { smartphone. }\end{array}$} & \multicolumn{3}{|c|}{$\begin{array}{l}\text { Discordo } \\
\text { Totalmente }\end{array}$} & \multicolumn{4}{|c|}{$\begin{array}{l}\text { Concordo } \\
\text { Totalmente }\end{array}$} \\
\hline & 1 & 2 & 3 & 4 & 5 & 6 & 7 \\
\hline $\begin{array}{l}\text { 15. Muitas vezes penso no meu smartphone } \\
\text { quando não o estou usando. }\end{array}$ & O & O & $\mathrm{O}$ & $\mathrm{O}$ & O & O & O \\
\hline $\begin{array}{l}\text { 16. Costumo usar } m \\
\text { motivo específico. }\end{array}$ & O & O & O & O & 0 & 0 & O \\
\hline $\begin{array}{l}\text { 17. Outras pessoas já discutiram comigo por causa } \\
\text { do uso do smartphone. }\end{array}$ & 0 & O & O & $\mathrm{O}$ & O & O & $\mathrm{O}$ \\
\hline $\begin{array}{l}\text { 18. Eu interrompo o que eu estou fazendo quando } \\
\text { eu sou contatado no meu smartphone. }\end{array}$ & O & O & O & O & 0 & 0 & O \\
\hline $\begin{array}{l}\text { 19. Eu me sinto con } \\
\text { meu smartphone. }\end{array}$ & O & O & $\mathrm{O}$ & $\mathrm{O}$ & O & O & $\mathrm{O}$ \\
\hline $\begin{array}{l}\text { 20. Eu perco a noção do quanto estou } \\
\text { smartphone. }\end{array}$ & O & 0 & 0 & O & 0 & O & O \\
\hline 21. O pensamento de estar ser & O & O & $\mathrm{O}$ & O & O & O & O \\
\hline 22. Não consigo reduzir o & 0 & 0 & 0 & 0 & O & $\mathrm{O}$ & $\mathrm{O}$ \\
\hline
\end{tabular}


Seção III: Questionário de Nomofobia (Nomophobia Questionnaire (NMP-Q) em inglês)

\begin{tabular}{|c|c|c|c|c|c|c|c|}
\hline \multirow{2}{*}{$\begin{array}{l}\text { Por favor, indique o quanto você concorda ou } \\
\text { discorda de cada declaração em relação ao uso do } \\
\text { smartphone. }\end{array}$} & \multicolumn{3}{|c|}{$\begin{array}{l}\text { Discordo } \\
\text { Totalmente }\end{array}$} & \multicolumn{4}{|c|}{$\begin{array}{l}\text { Concordo } \\
\text { Totalmente }\end{array}$} \\
\hline & 1 & 2 & 3 & 4 & 5 & 6 & 7 \\
\hline $\begin{array}{l}\text { 1. Eu me sentiria desconfortável sem acesso } \\
\text { constante a informações através do meu } \\
\text { smartphone. }\end{array}$ & O & O & O & O & O & O & 0 \\
\hline $\begin{array}{l}\text { 2. Eu fica } \\
\text { informaç } \\
\text { quisesse }\end{array}$ & O & O & O & O & O & 0 & O \\
\hline $\begin{array}{l}\text { 3. Ser inc } \\
\text { acontecim } \\
\text { deixaria } n\end{array}$ & O & 0 & O & O & O & O & O \\
\hline $\begin{array}{l}\text { 4. Eu } \\
\text { smart } \\
\text { quise }\end{array}$ & O & O & $\mathrm{O}$ & O & O & O & O \\
\hline ateria no meu smartphone me & O & O & O & O & O & O & O \\
\hline $\begin{array}{l}\text { 6. Se e } \\
\text { limite }\end{array}$ & O & O & O & O & 0 & O & O \\
\hline $\begin{array}{l}\text { 7. Se eu não tivesse um sinal de dados ou não } \\
\text { conseguisse me conectar ao Wi-Fi, verificaria } \\
\text { constantemente se eu tinha um sinal ou se poderia } \\
\text { encontrar uma rede Wi-Fi. }\end{array}$ & O & O & $\mathrm{O}$ & O & O & 0 & 0 \\
\hline $\begin{array}{l}\text { 8. Se eu não pudesse usar meu smartphone, teria } \\
\text { medo de ficar preso em algum lugar. }\end{array}$ & O & O & O & O & $\mathrm{O}$ & O & 0 \\
\hline $\begin{array}{l}\text { 9. Se eu não conseguisse ch } \\
\text { por um tempo, eu sentiria o c }\end{array}$ & 0 & 0 & $\mathrm{O}$ & 0 & 0 & 0 & 0 \\
\hline
\end{tabular}




\begin{tabular}{|c|c|c|c|c|c|c|c|}
\hline \multirow[t]{2}{*}{ Se eu não tivesse meu smartphone comigo: } & \multicolumn{3}{|c|}{$\begin{array}{l}\text { Discordo } \\
\text { Totalmente }\end{array}$} & \multicolumn{4}{|c|}{$\begin{array}{l}\text { Concordo } \\
\text { Totalmente }\end{array}$} \\
\hline & 1 & 2 & 3 & 4 & 5 & 6 & 7 \\
\hline $\begin{array}{l}\text { 10. Eu me sentiria ansioso porque não conseguiria } \\
\text { me comunicar instantaneamente com minha família } \\
\text { e / ou amigos. }\end{array}$ & O & O & O & 0 & O & O & 0 \\
\hline $\begin{array}{l}\text { 11. Eu ficaria preocupado porque minha família e } / \\
\text { ou amigos não poderiam me contatar. }\end{array}$ & O & O & O & O & O & O & O \\
\hline $\begin{array}{l}\text { 12. Eu me sentiria nervoso porque não conseguiria } \\
\text { receber mensagens de texto e chamadas. }\end{array}$ & O & O & 0 & O & O & O & 0 \\
\hline $\begin{array}{l}\text { 13. Eu ficaria } \\
\text { manter contat }\end{array}$ & O & O & O & O & O & O & O \\
\hline $\begin{array}{l}\text { 14. Eu ficaria ne } \\
\text { alguém tentou } \mathrm{r}\end{array}$ & O & 0 & O & 0 & 0 & $\mathrm{O}$ & 0 \\
\hline $\begin{array}{l}\text { 15. Eu me sen } \\
\text { constante com } \\
\text { quebrada. }\end{array}$ & O & 0 & 0 & O & O & 0 & 0 \\
\hline $\begin{array}{l}\text { 16. Eu ficaria nervoso porque estaria desconectado } \\
\text { da minha identidade online. }\end{array}$ & 0 & 0 & 0 & 0 & 0 & 0 & 0 \\
\hline $\begin{array}{l}\text { 17. Eu ficaria desconfortável porque não } \\
\text { conseguiria ficar em dia com redes sociais e redes } \\
\text { online. }\end{array}$ & O & 0 & O & 0 & 0 & 0 & 0 \\
\hline $\begin{array}{l}\text { 18. Eu me sentiria desconfortável porque não } \\
\text { podia checar minhas notificações de atualizações } \\
\text { de minhas conexões e redes online. }\end{array}$ & 0 & 0 & 0 & 0 & 0 & 0 & 0 \\
\hline $\begin{array}{l}\text { 19. Eu me sentiria ansioso porque não podia } \\
\text { checar minhas mensagens de e-mail. }\end{array}$ & 0 & 0 & 0 & 0 & 0 & 0 & 0 \\
\hline $\begin{array}{l}\text { 20. Eu me sentiria estranho porque não saber } \\
\text { que fazer. }\end{array}$ & 0 & 0 & 0 & 0 & 0 & 0 & 0 \\
\hline
\end{tabular}


9.3

\section{Anexo C Orientações gerais - participantes}

\section{3- Roteiro do teste}

Olá e muito obrigado por aceitar participar do Teste de Usabilidade do aplicativo BraPolar. Suas contribuições serão muito importantes para o aperfeiçoamento do produto, para assim entendermos melhor o que funciona e o que não serve, aperfeiçoando a solução.

\section{POR FAVOR, LEIA ESTE ROTEIRO COM CUIDADO E ATENÇÃO}

Após a leitura você pode sanar todas as suas dúvidas com o moderador. Porém, após o início da atividade, nenhuma pergunta será respondida, pois as dificuldades com que você compreende as tarefas e as interfaces é parte do que estamos avaliando no produto e no procedimento de teste.

Importante frisar que o sistema que está em teste, NÃO você. Não hesite em executar as tarefas da maneira que entendeu no enunciado e na interface.

Caso ocorra algum problema técnico no funcionamento do aplicativo, não se preocupe. A equipe de apoio lidará com a situação, suspendendo a atividade até o restabelecimento da condição de teste. Se necessário, o teste será remarcado conforme a sua disponibilidade.

Muito importante!

Durante a atividade:

Execute uma tarefa por vez, na ordem apresentada;

Pedimos que fale em voz alta o que está pensando ou o motivo de estar executando cada ação. Caso o resultado não seja o esperado, fale o que esperava que acontecesse;

Não espere respostas do moderador para suas indagações durante as tarefas;

Quando finalizar uma tarefa, avise o moderador que considera a tarefa concluída;

Se estiver com dificuldade na realização da tarefa pedida, você pode desistir a qualquer momento. Avise o moderador, informando o motivo, e prossiga para a próxima tarefa;

Ao final de cada tarefa, finalizada ou não, o moderador e os observadores poderão fazer algumas perguntas sobre o processo, ações tomadas e escolhas que você fez durante a execução. 
9.4

Anexo D Lista de atividades - participantes

\section{4- Atividades}

Você é um paciente e precisa deixar gravada toda a informação possivel das suas atividades no dia-dia. A continuação você irá receber um conjunto de cenários e realizará um conjunto de tarefas. Muito importante: fale em voz alta o que estiver pensando durante toda a avaliação.

\section{T1: Instalar o aplicativo BraPolar}

O moderador Ihe enviou um link onde você precisa descarregar o aplicativo BraPolar para prosseguir com o monitoramento das suas atividades. Faça o download do aplicativo e forneça as permissões necessárias conforme vão aparecer na tela do seu celular. Ao finalizar, reinicie seu dispositivo móvel.

\section{T2: Indicar no BraPolar qual o seu estado de humor a qualquer momento}

Como você acordou animicamente hoje? No BraPolar você consegue definir seu estado de ânimo o qual é enviado automaticamente aos especialistas os quais poderão Ihe auxiliar se for necessário! Abra o BraPolar e clique na secção Estado de Ânimo, após, movimente o slider e salve seu estado atual.

\section{T3: Estabelecer que o BraPolar capture suas interações com o celular durante o teste \\ Considerando a velocidade que você digita, o BraPolar poderá capturar essa informação e ajudar aos especialistas a detectar as flutuações na rapidez da escrita. Para configurar isto, você vai fazer o seguinte: \\ 1- No seu celular, vai à Configuração > Gerenciamento Geral > Idioma de entrada \\ 2- $\quad$ Clique em Teclado Padrão \\ 3- Selecione: Português (Brasil) BraPolarKeyboard.}


T4: Configurar o teclado BraPolar e envie um e-mail usando outro aplicativo fora do BraPolar

Agora precisamos configurar o teclado BraPolar e enviar um e-mail. Para isto, abra o BraPolar, acesse a Configurações / Calibrar teclado e siga as instruções da tela.

Ao finalizar, abra seu e-mail e envie o seguinte:

Para: amondejar@inf.puc-rio.br,

Assunto: Teste BraPolar

Corpo da mensagem: Estou experimentando o BraPolar e o teclado personalizado deste.

T5: Fazer uma ligação e envie um SMS para verificar se o BraPolar interrompe a interação com outros aplicativos instalados em seu telefone.

Opa! Você esqueceu de ligar para alguém próximo de você! Ligue agora mesmo ao número 21-965XXXXXX. Se a pessoa não te responder, envie um SMS a esse mesmo número com o texto 'Testando BraPolar'.

T6: Estabelecer o número de horas que o usuário dormiu na última noite.

Você conseguiu dormir a noite toda desde as 23:00 de ontem até 07:00 hoje e acordou cheio de energia.

Abra BraPolar e defina na funcionalidade Sono, esta informação.

\section{T7: Visualizar os dados coletados.}

Você está curioso por saber o que aconteceu durante toda a avaliação? Abra o BraPolar e navegue pelas funcionalidades apresentadas na tela inicial. Ao concluir, avise ao moderador. 
9.5

Anexo E Questionário de usabilidade - participante

\section{BraPolar v1.0 - Teste de usabilidade}

\begin{tabular}{|c|c|c|c|c|c|c|c|c|}
\hline \multicolumn{9}{|c|}{ PARTE A - REAÇÃO DO APLICATIVO } \\
\hline & & 1 & 2 & 3 & 4 & 5 & & $\mathrm{~N} / \mathrm{A}$ \\
\hline Usar o aplicativo foi & Difícil & & & & & & Fácil & \\
\hline A informação apresentada no aplicativo foi & Inadequado & & & & & & Adequado & \\
\hline Interagir com o aplicativo foi & Frustrante & & & & & & Satisfatório & \\
\hline \multicolumn{9}{|c|}{ PARTE B - TELA DO APLICATIVO } \\
\hline & & 1 & 2 & 3 & 4 & 5 & & $\mathrm{~N} / \mathrm{A}$ \\
\hline As formas e tamanho das letras é & Difícil de ler & & & & & & Satisfatório & \\
\hline As cores usadas na tela são & Inadequadas & & & & & & Adequadas & \\
\hline A organização dos elementos na tela é & Confusa & & & & & & Clara & \\
\hline $\begin{array}{l}\text { A quantidade de informação } \\
\text { apresentada na tela é }\end{array}$ & Inadequada & & & & & & Adequada & \\
\hline A sequência de telas é & Confuso & & & & & & Claro & \\
\hline O retorno à tela anterior é & Confuso & & & & & & Claro & \\
\hline $\begin{array}{l}\text { Os itens da tela são fáceis para } \\
\text { encontrar }\end{array}$ & Nunca & & & & & & Sempre & \\
\hline \multicolumn{9}{|c|}{ PARTE C - TERMINOLOGIA E INFORMAÇÕES DO APLICATIVO } \\
\hline & & 1 & 2 & 3 & 4 & 5 & & $\mathrm{~N} / \mathrm{A}$ \\
\hline Os termos usados no aplicativo são & Confusos & & & & & & Claros & \\
\hline As mensagens apresentadas tela são & Confusas & & & & & & Claras & \\
\hline A localização de mensagens na tela é & Inadequada & & & & & & Adequada & \\
\hline As instruções para o usuário são & Confusas & & & & & & Claras & \\
\hline $\begin{array}{l}\text { O aplicativo mantém você informado } \\
\text { sobre o que está fazendo }\end{array}$ & Nunca & & & & & & Sempre & \\
\hline As mensagens de erro são & Inúteis & & & & & & Úteis & \\
\hline $\begin{array}{l}\text { Os ícones no aplicativo representam o } \\
\text { que será encontrado ao entrar neles }\end{array}$ & Confuso & & & & & & Claro & \\
\hline \multicolumn{9}{|c|}{ PARTE D - APRENDIZADO E UTILIZAÇÃO } \\
\hline & & 1 & 2 & 3 & 4 & 5 & & $\mathrm{~N} / \mathrm{A}$ \\
\hline Aprender a operar o aplicativo é & Difícil & & & & & & Fácil & \\
\hline O tempo de aprendizado do aplicativo é & Inadequado & & & & & & Adequado & \\
\hline $\begin{array}{l}\text { Explorar as tarefas do aplicativo por } \\
\text { tentativa e erro são }\end{array}$ & Difíceis & & & & & & Fáceis & \\
\hline Concluir uma tarefa na app é & Confuso & & & & & & Claro & \\
\hline Realizar configurações na app é & Difícil & & & & & & Fácil & \\
\hline $\begin{array}{l}\text { Ativar/desativar a coleta de dados em } \\
\text { Configurações no aplicativo é }\end{array}$ & Difícil & & & & & & Fácil & \\
\hline Estabelecer o estado de ânimo é & Difícil & & & & & & Fácil & \\
\hline $\begin{array}{l}\text { Definir a quantidade de horas e a } \\
\text { qualidade do sonho é }\end{array}$ & Difícil & & & & & & Fácil & \\
\hline Utilizar o teclado do aplicativo é & Difícil & & & & & & Fácil & \\
\hline
\end{tabular}




\begin{tabular}{|c|c|c|c|c|c|c|c|c|}
\hline $\begin{array}{l}\text { O teclado da app interfere na velocidade } \\
\text { da escrita }\end{array}$ & Nunca & & & & & & Sempre & \\
\hline $\begin{array}{l}\text { A app e seus componentes atrapalham } \\
\text { a interação com outras apps no celular }\end{array}$ & Nunca & & & & & & Sempre & \\
\hline Gostaria de manter a app no seu celular & Nunca & & & & & & Sempre & \\
\hline \multicolumn{9}{|c|}{ PARTE E - DADOS COLETADOS } \\
\hline & & & & & & & & N/A \\
\hline $\begin{array}{l}\text { As notificações recebidas pelo aplicativo } \\
\text { para coletar informação, atrapalhou }\end{array}$ & Muito & & & & & & Pouco & \\
\hline $\begin{array}{l}\text { Eu me senti confiante ao usar o } \\
\text { aplicativo quando enviei SMS e fiz } \\
\text { ligações }\end{array}$ & Pouco & & & & & & Muito & \\
\hline $\begin{array}{l}\text { A opção ativar/desativar a coleta de } \\
\text { dados é }\end{array}$ & Innecesario & & & & & & Necessário & \\
\hline $\begin{array}{l}\text { Ao visualizar os meus dados coletados } \\
\text { pelo aplicativo móvel, me senti }\end{array}$ & Incômodo & & & & & & Tranquilo & \\
\hline $\begin{array}{l}\text { Os dados coletados se apresentam de } \\
\text { forma }\end{array}$ & Confusa & & & & & & Clara & \\
\hline \multicolumn{9}{|c|}{ PARTE F - CAPACIDADE DO SISTEMA } \\
\hline & & 1 & 2 & 3 & 4 & 5 & & $\mathrm{~N} / \mathrm{A}$ \\
\hline A velocidade do aplicativo é & Lenta & & & & & & Rápida & \\
\hline $\begin{array}{l}\text { O tempo de resposta para a maioria das } \\
\text { funcionalidades é }\end{array}$ & Lento & & & & & & Rápido & \\
\hline O aplicativo apresentou falhas & Sempre & & & & & & Nunca & \\
\hline Corrigir erros ao usar o aplicativo é & Difícil & & & & & & Fácil & \\
\hline $\begin{array}{l}\text { O aplicativo é projetado para todos os } \\
\text { níveis de usuários (iniciantes e } \\
\text { experientes) }\end{array}$ & $\begin{array}{r}\text { Com } \\
\text { dificuldade }\end{array}$ & & & & & & Facilmente & \\
\hline
\end{tabular}

PARTE G - SUGESTÕES E COMENTÁRIOS

Novamente agradecemos sua participação.

Equipe do BraPolar 


\section{6}

Anexo F Resultados teste de dependência ao celular

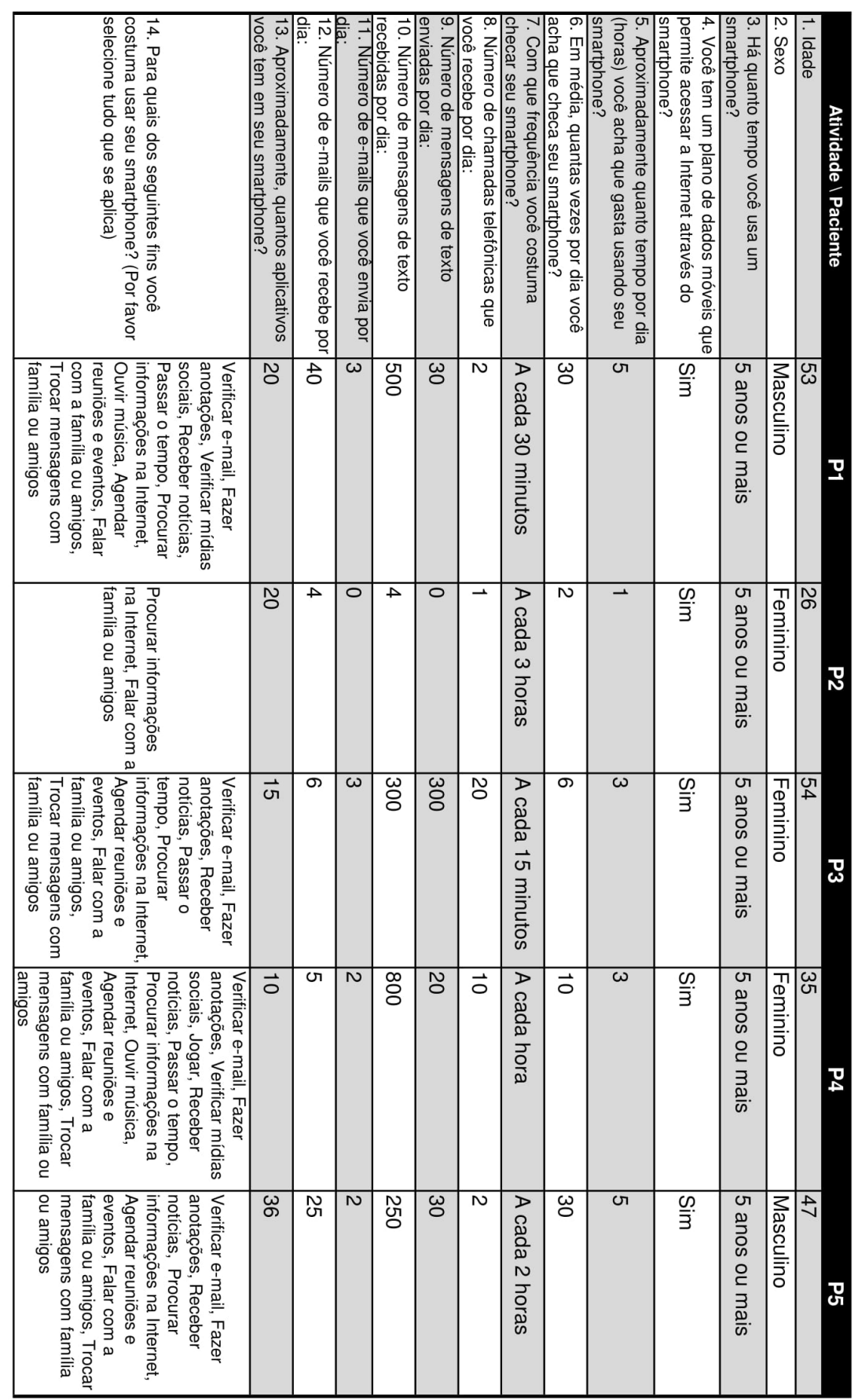

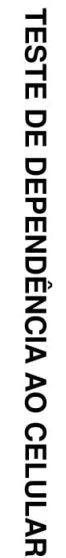


Ữ

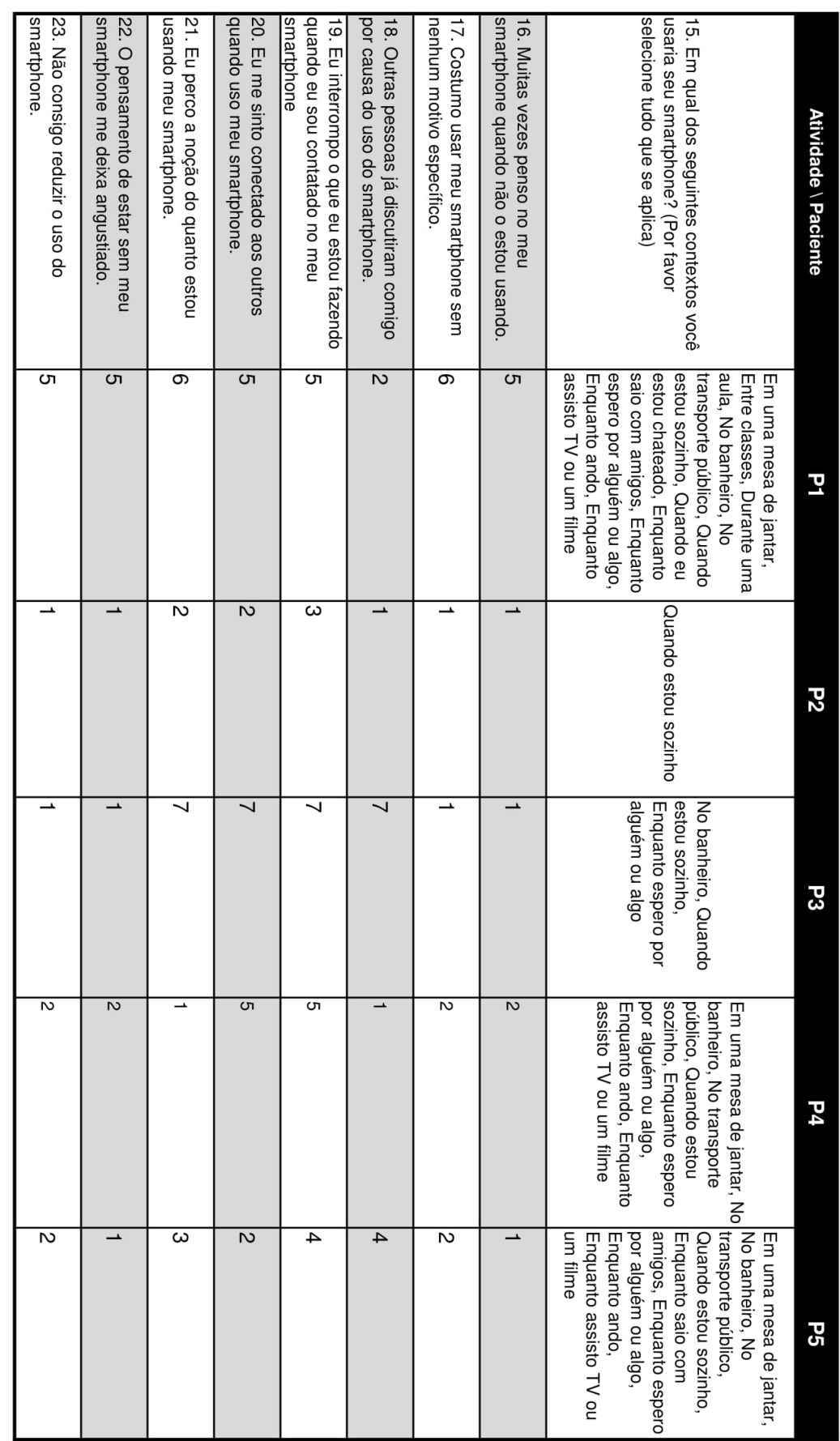

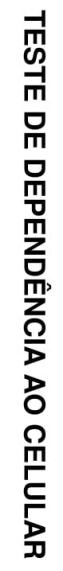




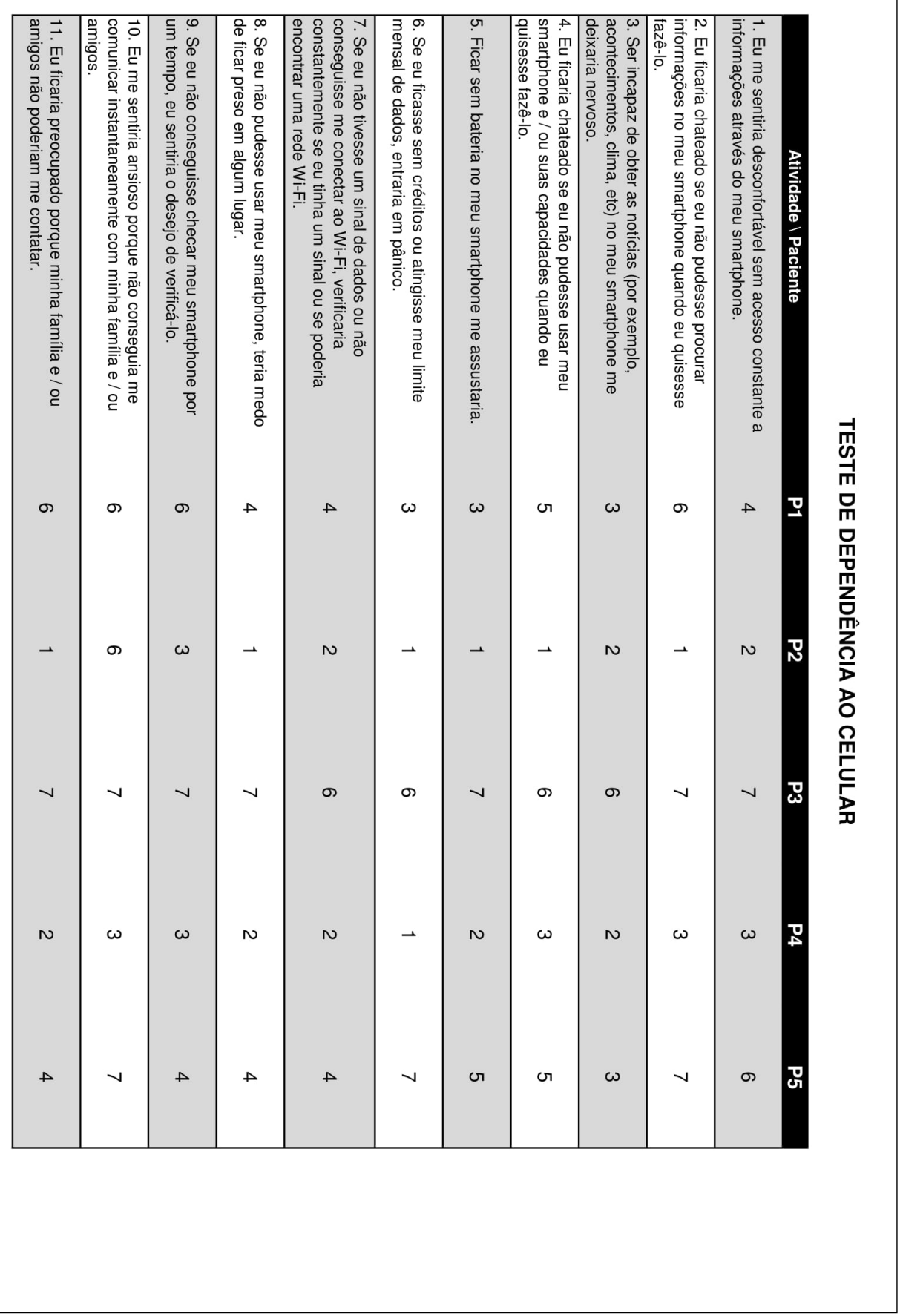




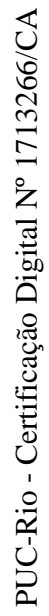

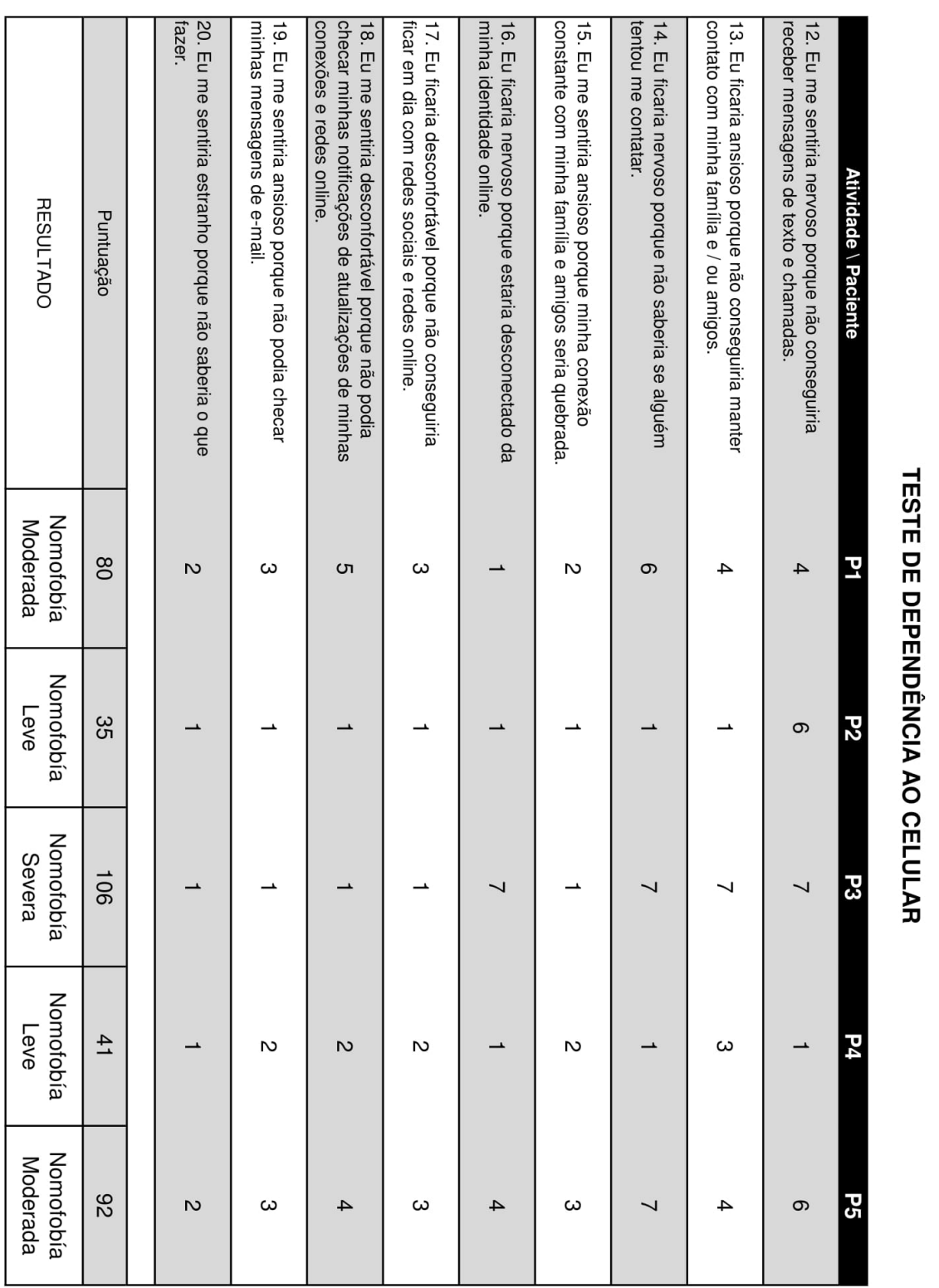


9.7

\section{Anexo G Termo de consentimento livre e esclarecido - Especialista}

\section{Termo de consentimento livre e esclarecido - Versão especialista}

Nome

RG:

Título do projeto: "BraPolar: um aplicativo m-health para monitoramento remoto de pessoas com transtorno bipolar"

Pesquisadores responsáveis pelo projeto: Eng. Abel González Mondéjar* / Prof. Dr. Alberto Raposo* / Dr. Greys Francy Mireya Calpa* / Prof. Dr. Daniel Mograbi** / Prof. Dr. Elie Cheniaux ${ }^{* * *}$

*Departamento de Informática da Pontifícia Universidade Católica do Rio de Janeiro (PUC-Rio) / **Departamento de Psicologia da Pontifícia Universidade Católica do Rio de Janeiro (PUC-Rio) / ** Instituto de Psiquiatria da Universidade Federal do Rio de Janeiro (IPUB/UFRJ)

Contato:

- Eng Abel G Mondéjar amondejar@inf.puc-rio.br (21) 3527-1500/4338

- Dr Alberto Raposo: abraposo@inf.puc-rio.br (21) 3527-1500/4338

- Dr Greys Francy M. Calpa: gcalpa@inf.puc-rio.br (21) 3527-1500/4338

- Dr Daniel Mograbi: danielmograbi@puc-rio.br (21) 3527-2086/2075

- Dr. Elie Cheniaux echeniaux@gmail.com (21) 3938-5510

Comitê de ética em pesquisa do IPUB/UFRJ: Endereço Av. Venceslau Brás 71, fds - Prédio da Direção - $2^{\circ}$ andar - sala do CEP. 22.290-140 - Campus Praia Vermelha - Botafogo - Rio de Janeiro. Telefone/Fax: 55 (21) 3938-5510 


\section{Termo de consentimento livre e esclarecido - Versão do Paciente}

Você está convidado a participar de uma pesquisa científica realizada pela Pontifícia Universidade Católica do Rio de Janeiro (PUC-Rio) e pelo Instituto de Psiquiatria da UFRJ (IPUB). Este projeto de pesquisa foi aprovado pelo comitê de ética em pesquisa (CEP) do IPUB.

Primeiro, gostaríamos de esclarecer que a sua participação é inteiramente voluntária, isto é, você pode optar por não participar ou se retirar a qualquer momento do estudo. Embora não haja garantia de qualquer benefício pessoal, a sua participação na pesquisa certamente ajudará para o avanço do conhecimento científico na área. A base legal de este TCLE vasa-se no Art 7 , Secção IV da Lei no. 13.709 de 14 de agosto de 2018 sobre a proteção de dados pessoais.

A sua identidade estará protegida o tempo todo. Não haverá qualquer despesa para você por participar desse projeto. Sinta-se à vontade para discutir qualquer dúvida ou preocupação de ordem médica ou pessoal com a equipe médica, científica ou de apoio, antes do fornecer seu consentimento. Mesmo após, a qualquer momento, você poderá retirar seu consentimento e retirar-se do estudo.

\section{Objetivo do estudo}

O principal objetivo do projeto é adaptar para o Brasil uma solução para a monitoração do transtorno afetivo bipolar usando dispositivos móveis como marcador de estado e traço de intervenção terapêutica não invasiva para os pacientes e especialistas. Com este estudo, pretendemos detectar precocemente e observar alterações do insight nos pacientes. Atualmente não é oferecido na rede pública nenhum acompanhamento usando os dispositivos móveis para pessoas com TAB no Brasil, e com esse estudo pretendemos dar um passo na direção de aumentar o número de tratamentos para transtorno afetivo bipolar em nosso país. Para isso, trabalharemos com um grupo de pessoas com TAB enquanto seguem seu tratamento rotineiro.

\section{A sua participação envolverá:}

(1) Leitura e assinatura deste documento com consentimento;

(2) Manuseio dos resultados de dependência ao celular dos participantes do estudo anterior;

(3) Capacitação do aplicativo;

(4) Avaliação com o BraPolar dos participantes do estudo anterior;

(5) Preenchimento de um questionário. 


\section{Capacitação e avaliação dos participantes no estudo anterior}

Você será notificado por um pesquisador participante do projeto o dia que deverá comparecer para a avaliação do aplicativo BraPolar. Uma vez lido inteiramente este documento, você irá receber por parte do pesquisador responsável um celular com a versão BraPolar para avaliar um conjunto de 5 voluntários de um estudo prévio com um conjunto de atividades que irá fazer. Ao finalizar, você responderá dois questionários com o intuito de conhecer sua percepção sobre o BraPolar, não existem respostas certas ou erradas, e sua honestidade é fundamental para o sucesso do nosso estudo.

\section{Benefícios:}

O estudo proporcionará um melhor conhecimento a respeito de formas de tratamento para a bipolaridade, o que poderá traduzir-se em benefícios futuros à comunidade como um todo.

\section{Eventos adversos}

A participação no estudo não constitui uma inconveniência na sua vida diária, pois não há necessidade de deslocamento ao centro de pesquisa, nem tempo em entrevistas além do encontro e configurações inicial. As informações que obtivermos a partir deste estudo podem nos ajudar a validar no nosso meio uma estratégia de tratamento não farmacológica para pacientes portadores de transtorno afetivo bipolar. O único possivel evento adverso é desconforto com perguntas que podem ser vistas como pessoais pelos participantes. A negativa em respondê-las está garantida pelos pesquisadores e consignada no TCLE.

\section{Diretos do Sujeito Pesquisado:}

Você é livre para parar sua participação a qualquer momento sem nenhuma penalização ou prejuízo. Em qualquer etapa da avaliação, você terá acesso a representantes da equipe de pesquisa do Instituto de Psiquiatria da UFRJ (IPUB). A equipe pode ser contatada a qualquer momento para tirar qualquer dúvida ou para obter atualização sobre os resultados parciais da pesquisa. Se você tiver alguma consideração ou dúvida sobre a ética da pesquisa, entre em contato com o CEP do IPUB (tel. 2295-3449/9549/5549).

As informações coletadas durante a sua participação serão analisadas em conjunto com as informações dos outros especialistas. O seu consentimento permite o uso dos dados coletados apenas para pesquisa científica e educação. Todos os dados relativos à sua participação serão mantidos em local reservado e seguro. Os dados poderão ser discutidos com pesquisadores de outras instituições e publicados em revistas cientificas, ou fazerem parte de material educacional. Nenhuma informação privada, ou que possa levar à identificação dos 
especialistas será fornecida a terceiros. Nenhuma informação privada, ou que possa levar à identificação dos participantes será fornecida a terceiros.

\section{Despesas decorrentes da participação na pesquisa}

Você não terá nenhum custo financeiro decorrente da participação neste estudo, e também não receberá recompensa de qualquer espécie pela participação. Entretanto, se necessário, você terá direito ao ressarcimento relativo às despesas decorrentes exclusivamente do seu transporte para a participação nesta pesquisa.

\section{Acesso aos resultados, dúvidas e esclarecimentos}

O conhecimento dos resultados será opção sua. Na opção de tomar conhecimento sobre os resultados da pesquisa, você poderá solicitar informações referentes a todos os dados resultantes das avaliações, sabendo-se que, na grande maioria dos casos, este conhecimento não trará qualquer benefício individual direto a você; e à divulgação científica destes resultados (sabendo-se que os seus dados individuais não serão divulgados). Você deve guardar uma cópia deste termo de consentimento e toda vez que tiver dúvidas sobre o protocolo do estudo, ou quiser saber os seus resultados, poderá consultar ao pesquisador Daniel Mograbi, pelo telefone (21) 3527-2086/2075 ou Abel González através do e-mail amondejar@inf.puc-rio.br ou pelo telefone (21) 3527-1500/4338. 
Acredito ter sido informado a respeito do estudo acima citado. As etapas do estudo ficaram claras para mim. Concordo voluntariamente em participar deste estudo. Recebi uma cópia assinada deste consentimento livre e esclarecido. Estou ciente que a minha assinatura neste consentimento, como participante, não significa que estou renunciando aos meus direitos legais, de acordo com as leis vigentes no Brasil.

Este termo de consentimento é feito em duas vias, sendo que uma permanecerá em meu poder e outra com o pesquisador responsável.

Eu li e compreendi as explicações sobre este estudo e me foi dada a chance de discutir e fazer perguntas. Forneço aqui o meu consentimento para participação no protocolo de estudo.

Rio de Janeiro, de 2019.

Nome:

Assinatura:

Pesquisador:

Assinatura:

Pesquisadores Responsáveis:

- Eng Abel G Mondéjar amondejar@inf.puc-rio.br (21) 3527-1500/4338

- Dr Alberto Raposo: abraposo@inf.puc-rio.br (21) 3527-1500/4338

- Dr Greys Francy M. Calpa: gcalpa@inf.puc-rio.br (21) 3527-1500/4338

- Dr Daniel Mograbi: danielmograbi@puc-rio.br (21) 3527-2086/2075

- Dr. Elie Cheniaux echeniaux@gmail.com (21) 3938-5510

Comitê de ética em pesquisa do IPUB/UFRJ: Endereço Av. Venceslau Brás 71, fds - Prédio da Direção - $2^{\circ}$ andar - sala do CEP. 22.290-140 - Campus Praia Vermelha - Botafogo - Rio de Janeiro. Telefone/Fax: 55 (21) 3938-5510 
9.8

\section{Anexo H Orientações gerais - especialistas}

\section{2- Apresentação}

Olá e muito obrigado por aceitar participar do Teste de Usabilidade do aplicativo BraPolar v1.0. Suas contribuições serão muito importantes para o aperfeiçoamento do produto, para assim entendermos melhor o que funciona e o que não serve, aperfeiçoando a solução.

Em primer lugar, a fenotipagem digital é uma nova abordagem para tratar a interação das pessoas com seus dispositivos móveis. Em BraPolar o usamos para armazenar a interação dos participantes com seus dispositivos móveis tais como quantidade de ligações realizadas/recebidas, SMS e vezes que bloqueia/desbloqueia o dispositivo, por exemplo. Por outra parte, um estudo desenvolvido Yildirim et al. ${ }^{1}$ da ISU's School of Education, avalia, através de um conjunto de perguntas o grau de dependência das pessoas com seus dispositivos móveis e coloca numa escala de nomofobía (leve, moderada ou severa) dos examinandos.

A continuação será apresentada um cenário onde você irá simular uma avaliação dos dados apresentados e a dependência ao celular dos participantes para detectar possíveis mudanças no comportamento. É válido ressaltar que os participantes não possuem doenças mentais.

\section{POR FAVOR, LEIA ESTE ROTEIRO COM CUIDADO E ATENÇÃO}

Após a leitura você pode sanar todas as suas dúvidas com o moderador. Porém, após o início da atividade, nenhuma pergunta será respondida, pois as dificuldades com que você compreende as tarefas e as interfaces é parte do que estamos avaliando no produto e no procedimento de teste.

Importante frisar que o sistema que está em teste, NÃO você. Não hesite em executar as tarefas da maneira que entendeu no enunciado e na interface.

Caso ocorra algum problema técnico no funcionamento do aplicativo, não se preocupe. $O$ moderador lidará com a situação, suspendendo a atividade até o restabelecimento da condição de teste. Se necessário, o teste será remarcado conforme a sua disponibilidade.

Muito importante!

Durante a atividade

Execute uma atividade por vez, na ordem apresentada;

Pedimos que fale em voz alta o que está pensando ou o motivo de estar executando cada ação. Caso o resultado não seja o esperado, fale o que esperava que acontecesse;

Não espere respostas do moderador para suas indagações durante as tarefas;

Quando finalizar uma atividade, avise o moderador que considera a atividade concluída;

Se estiver com dificuldade na realização da atividade pedida, você pode desistir a qualquer momento. Avise o moderador, informando o motivo, e prossiga para a próxima atividade;

Ao final de cada atividade, finalizada ou não, o moderador e os observadores poderão fazer algumas perguntas sobre o processo, ações tomadas e escolhas que você fez durante a execução.

LEMBRE-SE: Quem está sendo testado é a aplicação, não você.

${ }^{1}$ Yildirim, C. \& Correia, A. (2015). Exploring the dimensions of nomophobia: Development and validation of a self-reported questionnaire. Computers in Human Behavior, 49, 130-137. 
9.9

\section{Anexo I Lista de atividades - especialistas}

\section{3- Cenário e Atividades a ser realizadas}

Você é o especialista responsável por atender a 5 pacientes através do BraPolar e tem interesse em fazer uma revisão para avaliar o estado deles. Para ajudar você, o moderador the entregou os resultados do teste de dependência ao celular. Por outra parte, foi coletado por um mês a fenotipagem digital dos participantes entretanto, BraPolar coleta em tempo real toda a interação dos avaliados e em algum momento você poderá perceber alguma alteração em algum indicador.

Convidamos você a fazer as seguintes atividades na ordem apresentada, considerando que cada paciente tem distinto grau de nomofobía conforme os resultados do teste previamente realizado.

\section{A1- Fazer login.}

Pré-requisito: Ter BraPolar instalado.

Descrição: Com o usuário e senha fornecido pelo moderador, inicie sessão no BraPolar

\section{A2- Atividades a ser realizadas no BraPolar.}

Pré-requisito: Ter iniciado sessão no aplicativo.

Descrição: Auxiliado do resultado do teste de nomofobía, você irá avaliar os pacientes listados no aplicativo.

Para realizar esta atividade, solicitamos que clique num paciente e acesse a cada uma das categorias apresentadas na tabela a continuação na ordem que quiser. Você irá a avaliar a informação apresentada alternando entre os tipos de gráficos mostrados e intervalos de datas

Na medida que você conclua, coloque a ordem em que acessou a cada uma das funcionalidades na seguinte tabela.

\begin{tabular}{|l|l|l|l|l|l|}
\hline \multirow{2}{*}{ Aspectos a serem avaliados } & \multicolumn{5}{|c|}{ Ordem em que foi realizada por participante } \\
\cline { 2 - 6 } & P1 & P2 & P3 & P4 & P5 \\
\hline T1- Estado de ânimo & & & & & \\
\hline T2 - Interação social & & & & & \\
\hline T3 - Atividade Física & & & & & \\
\hline T4 - Qualidade de sono & & & & & \\
\hline T5 - Medicação & & & & & \\
\hline
\end{tabular}

Sinta-se livre de navegar pelo aplicativo como quiser e avaliar o paciente que achar necessário. 
9.10

Anexo J Questionário pós teste - Especialistas

Questionários pos-test

\section{1- Questionário de relevância}

Considerando as funcionalidades e a importância que você atribui ao estudo das funcionalidades apresentadas no BraPolar, responda as seguintes questões.

1- Considerando a ordem que você definiu na tabela anterior, que informação apresentada levou você a avaliar nessa sequência? Preencha a continuação o porquê da sua seleção para cada participante?

P1-

P2-

P3-

P4-

P5-

2- Como BraPolar poderia auxiliar você na detecção de flutuações em tempo real no comportamento / estado de humor dos pacientes com TAB? Como detectaria quando intervir?

3- Você considera importante conhecer o grau de dependência ao celular dos pacientes? Por quê?, É útil fazer o seguimento dos pacientes através da fenotipagem digital? 
5- Como o uso do BraPolar poderia complementar os testes de avaliação clínica convencionais ou outros padrões a avaliação psiquiátrica?

6- Você acha que os aspectos apresentados pelo BraPolar são suficientes para fazer um seguimento no tratamento? O que você incluiria ou retiraria da versão atual do BraPolar?

7- Gostaria de deixar algum comentário ou sugestão adicional para futuras versões do projeto? Sua opinião é muito importante. 
9.11

Anexo K Questionário usabilidade - Especialistas

\section{2- Questionário de usabilidade}

Por gentileza, marque a opção mais indicada em cada uma das seções do formulário. Ao finalizar, na parte $\mathrm{G}$ responda à pergunta requisitada. Solicitamos que seja honesto(a) nas respostas.

\begin{tabular}{|c|c|c|c|c|c|c|c|c|}
\hline \multicolumn{9}{|c|}{ PARTE A - REAÇÃO DO APLICATIVO } \\
\hline & & 1 & 2 & 3 & 4 & 5 & & $\mathrm{~N} / \mathrm{A}$ \\
\hline Usar o aplicativo foi & Difícil & & & & & & Fácil & \\
\hline $\begin{array}{r}\text { A informação apresentada no } \\
\text { aplicativo foi }\end{array}$ & Inadequado & & & & & & Adequado & \\
\hline Interagir com o aplicativo foi & Frustrante & & & & & & Satisfatório & \\
\hline \multicolumn{9}{|c|}{ PARTE B - TELA DO APLICATIVO } \\
\hline & & 1 & 2 & 3 & 4 & 5 & & $\mathrm{~N} / \mathrm{A}$ \\
\hline As formas e tamanho das letras é & Difícil de ler & & & & & & Fácil de ler & \\
\hline As cores usadas na tela são & $\begin{array}{l}\text { Inadequada } \\
\mathrm{s}\end{array}$ & & & & & & Adequadas & \\
\hline $\begin{array}{r}\text { A organização dos elementos na } \\
\text { tela é }\end{array}$ & Confusa & & & & & & Clara & \\
\hline $\begin{array}{r}\text { A quantidade de informação } \\
\text { apresentada na tela é }\end{array}$ & Inadequada & & & & & & Adequada & \\
\hline A sequência de telas é & Confuso & & & & & & Claro & \\
\hline O retorno à tela anterior é & Confuso & & & & & & Claro & \\
\hline $\begin{array}{r}\text { Os itens da tela são fáceis para } \\
\text { encontrar }\end{array}$ & Nunca & & & & & & Sempre & \\
\hline \multicolumn{9}{|c|}{ PARTE C - TERMINOLOGIA E INFORMAÇÕES DO APLICATIVO } \\
\hline & & 1 & 2 & 3 & 4 & 5 & & $\mathrm{~N} / \mathrm{A}$ \\
\hline Os termos usados no aplicativo são & Confusos & & & & & & Claros & \\
\hline $\begin{array}{r}\text { As mensagens apresentadas na tela } \\
\text { são }\end{array}$ & Confusas & & & & & & Claras & \\
\hline A localização de mensagens na tela & Inadequada & & & & & & Adequada & \\
\hline As instruções para o usuário são & Confusas & & & & & & Claras & \\
\hline $\begin{array}{r}\text { O aplicativo mantém você informado } \\
\text { sobre o que está fazendo }\end{array}$ & Nunca & & & & & & Sempre & \\
\hline $\begin{array}{r}\text { Os ícones no aplicativo representam } \\
\text { o que será encontrado ao entrar } \\
\text { neles }\end{array}$ & Confuso & & & & & & Claro & \\
\hline \multicolumn{9}{|c|}{ PARTE D - APRENDIZADO E UTILIZAÇÃO } \\
\hline & & 1 & 2 & 3 & 4 & 5 & & $\mathrm{~N} / \mathrm{A}$ \\
\hline Aprender a operar o aplicativo é & Difícil & & & & & & Fácil & \\
\hline
\end{tabular}




\begin{tabular}{|c|c|c|c|c|c|c|c|c|}
\hline $\begin{array}{r}\text { O tempo de aprendizado do } \\
\text { aplicativo é }\end{array}$ & Inadequado & & & & & & Adequado & \\
\hline $\begin{array}{r}\text { Explorar as funcionalidades do } \\
\text { aplicativo por tentativa e erro são }\end{array}$ & Dificeis & & & & & & Fáceis & \\
\hline $\begin{array}{l}\text { As atividades podem ser executadas } \\
\text { de uma maneira rápida e/ou direta }\end{array}$ & Nunca & & & & & & Sempre & \\
\hline Concluir uma atividade é & Confuso & & & & & & Claro & \\
\hline \multicolumn{9}{|c|}{ PARTE F - DADOS COLETADOS E FUNCIONALIDADES } \\
\hline $\begin{array}{r}\text { Os dados coletados se apresentam } \\
\text { de forma }\end{array}$ & Confusa & & & & & & Clara & N/A \\
\hline $\begin{array}{l}\text { A funcionalidade Estado de ânimo } \\
\text { para o controle do TAB é relevante }\end{array}$ & Pouco & & & & & & Muito & \\
\hline $\begin{array}{l}\text { A funcionalidade Interação Social / } \\
\text { Ligações para o controle do TAB é } \\
\text { relevante }\end{array}$ & Pouco & & & & & & Muito & \\
\hline $\begin{array}{r}\text { A funcionalidade Interação Social / } \\
\text { SMS para o controle do TAB é } \\
\text { relevante }\end{array}$ & Pouco & & & & & & Muito & \\
\hline $\begin{array}{r}\text { A funcionalidade Interação Social / } \\
\text { Velocidade de escritura para o } \\
\text { controle do TAB é relevante }\end{array}$ & Pouco & & & & & & Muito & \\
\hline $\begin{array}{r}\text { A funcionalidade Atividade Física / } \\
\text { Torre celular para o controle do TAB } \\
\text { é relevante }\end{array}$ & Pouco & & & & & & Muito & \\
\hline $\begin{array}{r}\text { A funcionalidade Atividade Física / } \\
\text { Tela celular para o controle do TAB } \\
\text { é relevante }\end{array}$ & Pouco & & & & & & Muito & \\
\hline $\begin{array}{l}\text { A funcionalidade Qualidade de sono } \\
\text { para o controle do TAB é relevante }\end{array}$ & Pouco & & & & & & Muito & \\
\hline $\begin{array}{r}\text { A funcionalidade Medicação para o } \\
\text { controle do TAB é relevante }\end{array}$ & Pouco & & & & & & Muito & \\
\hline \multicolumn{9}{|c|}{ PARTE G - CAPACIDADE DO SISTEMA } \\
\hline & & 1 & 2 & 3 & 4 & 5 & & N/A \\
\hline A velocidade do aplicativo é & Lenta & & & & & & Rápida & \\
\hline $\begin{array}{r}\text { O tempo de resposta para a maioria } \\
\text { das funcionalidades é }\end{array}$ & Lento & & & & & & Rápido & \\
\hline O aplicativo é confiável & Nunca & & & & & & Sempre & \\
\hline Corrigir erros ao usar o aplicativo é & Difícil & & & & & & Fácil & \\
\hline $\begin{array}{r}\text { O aplicativo é projetado para todos } \\
\text { os níveis de usuários (iniciantes e } \\
\text { experientes) }\end{array}$ & $\begin{array}{l}\text { Com } \\
\text { dificuldade }\end{array}$ & & & & & & Facilmente & \\
\hline
\end{tabular}

Novamente agradecemos pela sua participação.

Equipe BraPolar 
9.12

Anexo L Certificado de apresentação na conferência SeGAH

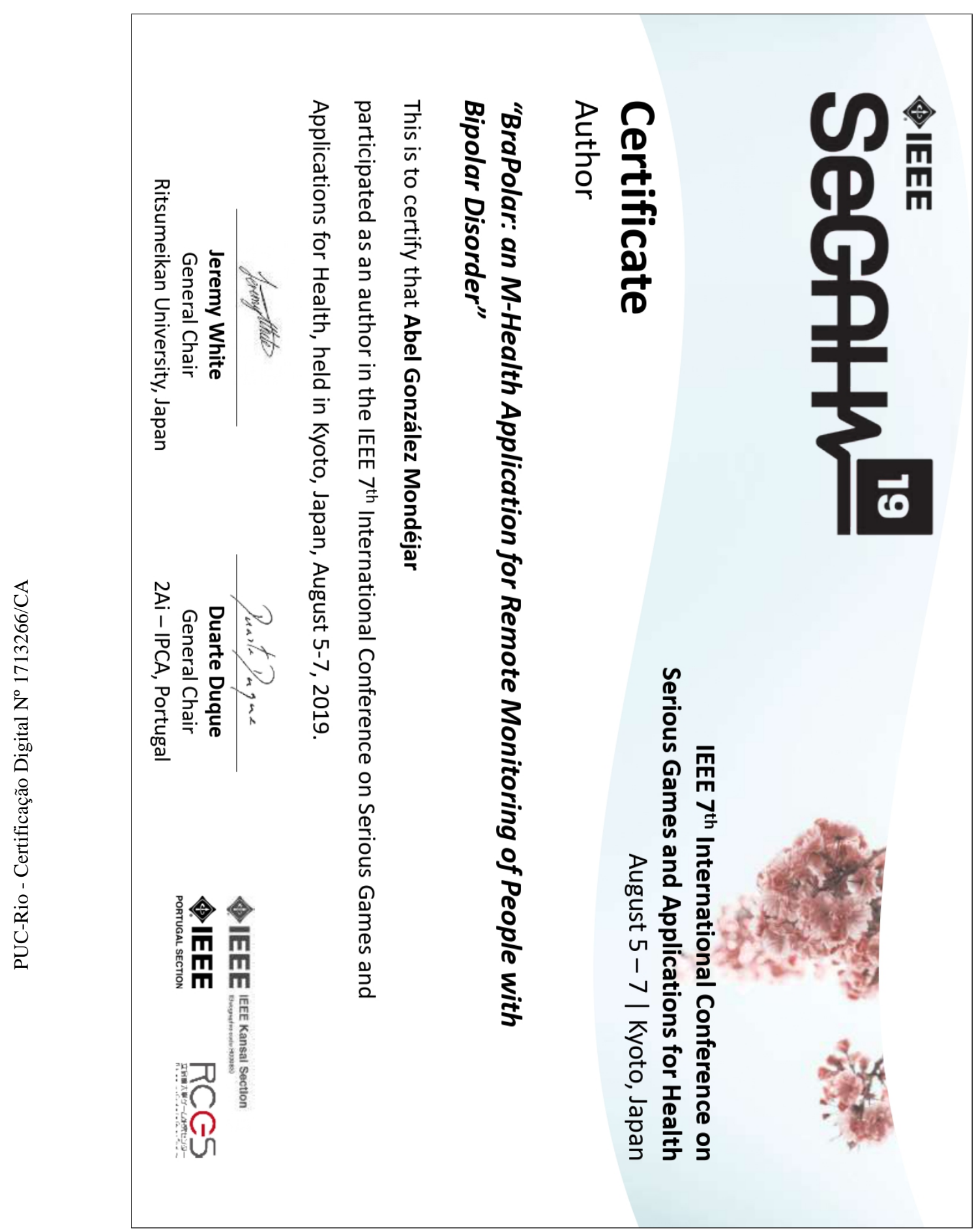

